Göttingen Centre for Biodiversity and Ecology

Biodiversity and Ecology Series B Volume 8

Kerstin Heidemann

The nematode-based food-chain of a temperate deciduous forest

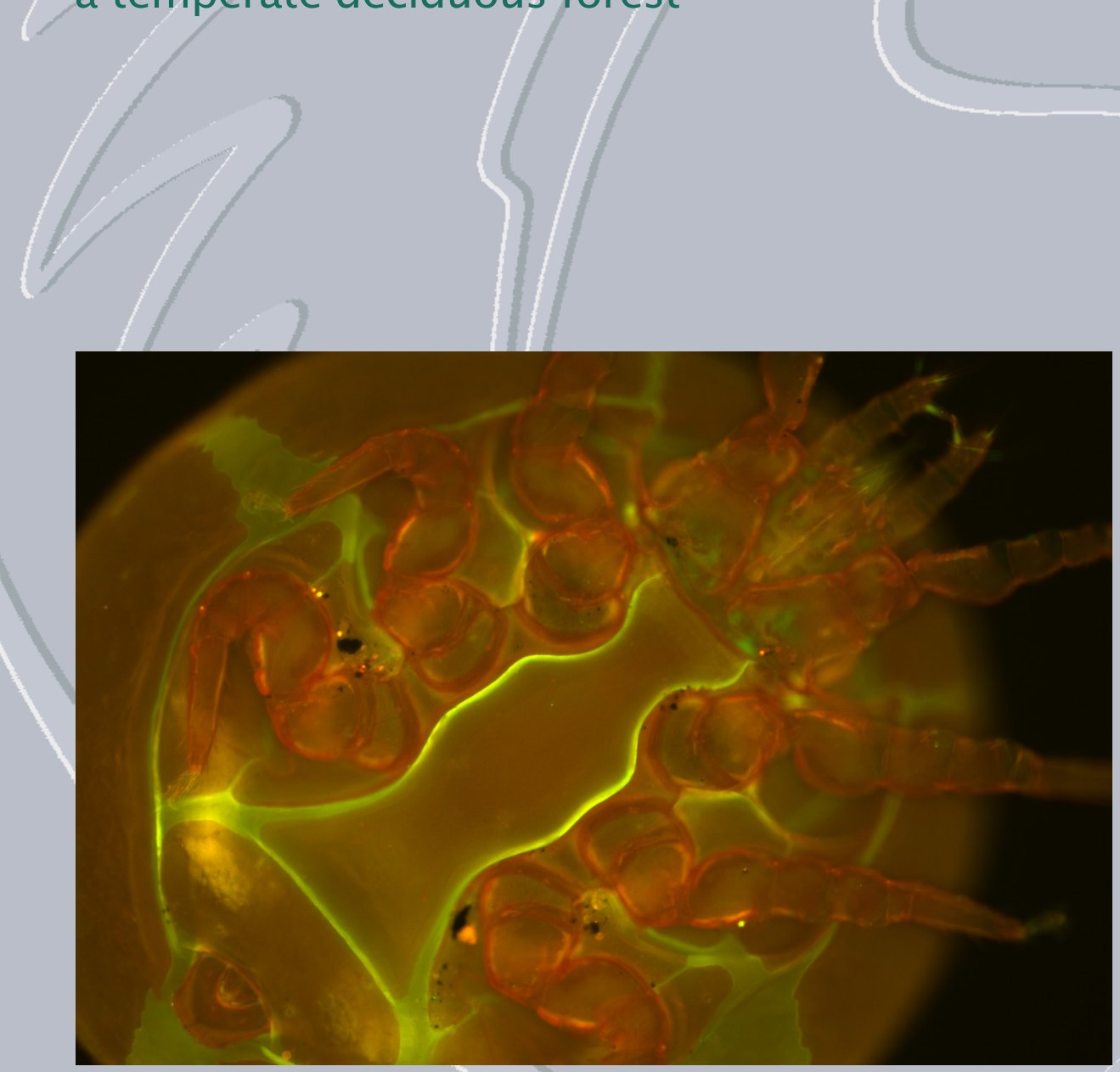

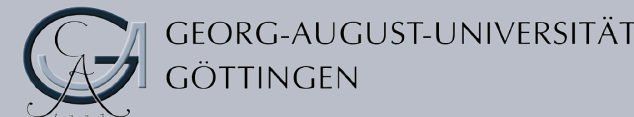
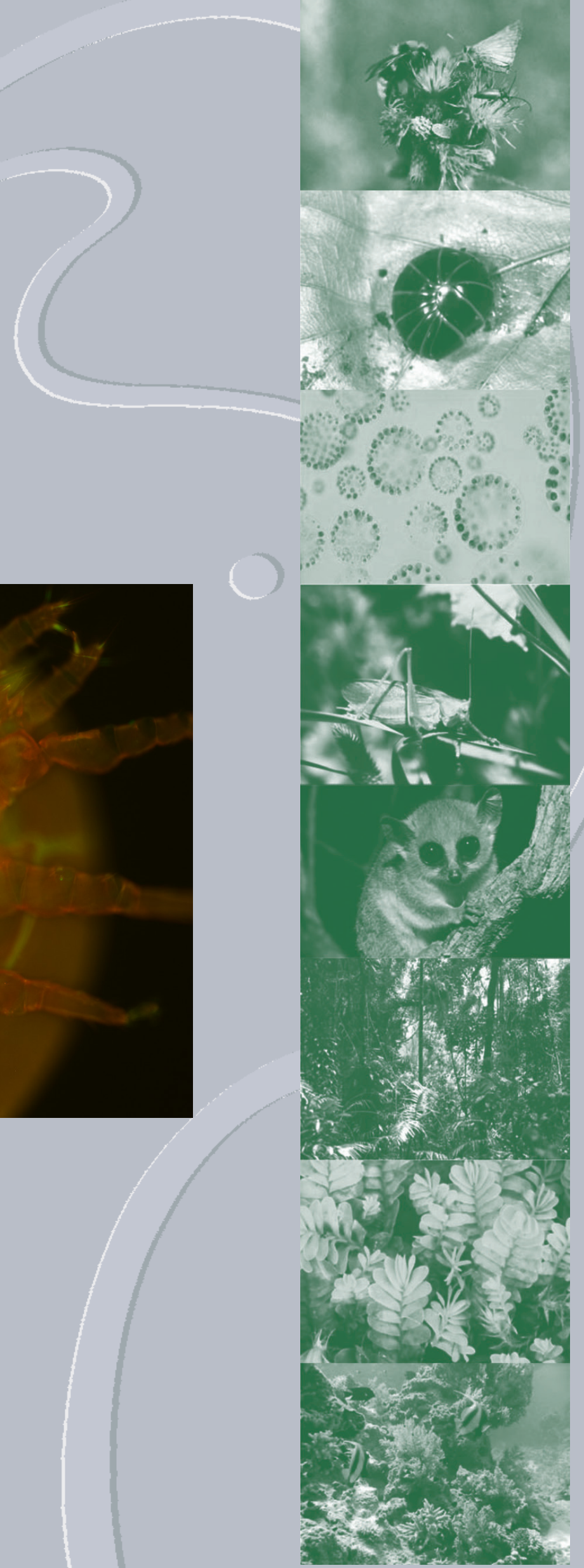

Published as volume 8 in the Series B as part of the „Biodiversity and Ecology Series“

Kerstin Heidemann

The nematode-based food-chain of a temperate deciduous forest

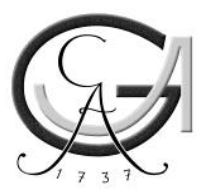

Georg-August-Universität Göttingen 2013

This work is licensed under the

Creative Commons License 3.0 "BY-ND", allowing you to download, distribute and print the document in a few copies for private or educational use, given that the document stays unchanged and the creator is mentioned.

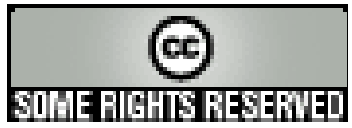


Bibliographische Information der Deutschen Nationalbibliothek

Die Deutsche Nationalbibliothek verzeichnet diese Publikation in der Deutschen Nationalbibliographie; detaillierte bibliographische Daten sind im Internet über $<$ http://dnb.ddb.de> abrufbar.

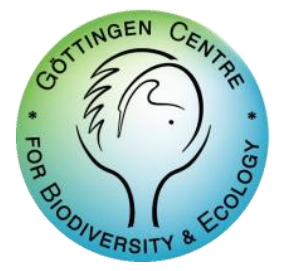

Editor Dr. Dirk Gansert

Göttingen Centre for Biodiversity and Ecology,

Georg-August-Universität Göttingen, www.biodiversitaet.gwdg.de

Dissertation zur Erlangung des Doktorgrades der

Naturwissenschaftlichen Fakultäten der

Georg-August-Universität Göttingen

vorgelegt von Kerstin Heidemann

Referent: PD Dr. Mark Maraun

Koreferent: Prof. Dr. Stefan Scheu

Anschrift des Autors

Kerstin Heidemann

e-mail: kerstin.heidemann@biologie.uni-goettingen.de

Typesetting and layout: Kerstin Heidemann

Cover image: Kerstin Heidemann and Ellen Latz

DOI: http://dx.doi.org/10.3249/webdoc-3897 


\author{
ZENTRUM \\ FÜR BIODIVERSITÄT UND NACHHALTIGE LANDNUTZUNG \\ SEKTION \\ BIODIVERSITÄT, ÖKOLOGIE UND NATURSCHUTZ \\ - Centre of Biodiversity and Sustainable LAND USE - \\ SECTION: BIOdIVERsity, Ecology and Nature Conservation
}

\title{
The nematode-based food-chain of a temperate deciduous forest
}

\author{
Dissertation zur Erlangung des Doktorgrades der \\ Mathematisch-Naturwissenschaftlichen Fakultäten der \\ Georg-August-Universität Göttingen
}

\author{
vorgelegt von \\ Diplom-Biologin \\ Kerstin Heidemann \\ aus \\ Groß-Gerau
}

Göttingen, Februar, 2013 
Referentin/Referent:

PD. Dr. Mark Maraun

Korreferentin/Korreferent: Prof. Dr. Stefan Scheu

Tag der mündlichen Prüfung: 


\section{Contents}

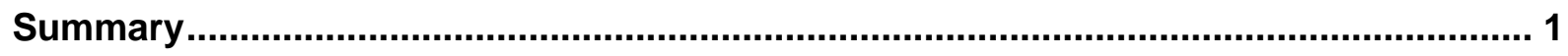

Chapter 1: General Introduction................................................................................ 4

1. Soil food webs and their main energy channels ............................................... 5

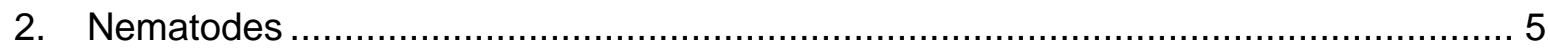

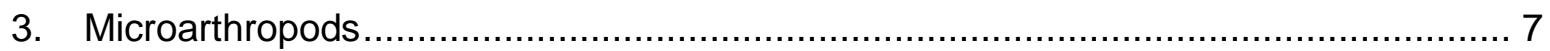

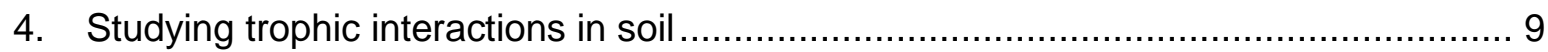

5. Molecular gut content analysis ................................................................. 10

6. Objectives and chapter outline ...................................................................... 11

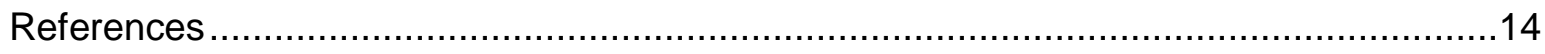

Chapter 2: Molecular detection of nematode predation and scavenging in oribatid mites:

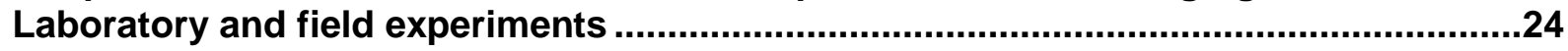

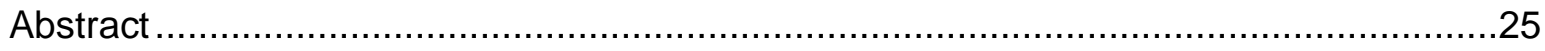

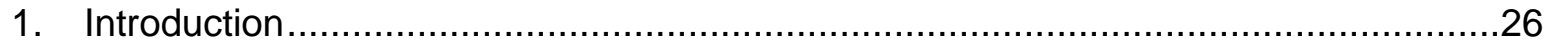

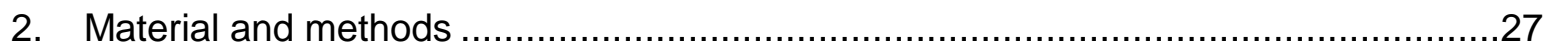

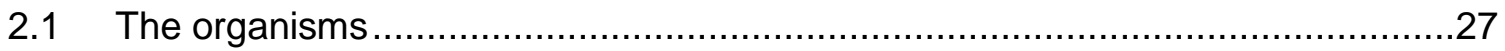

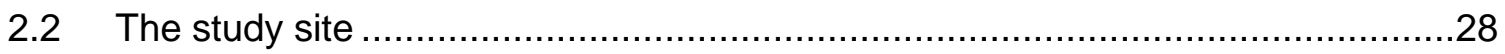

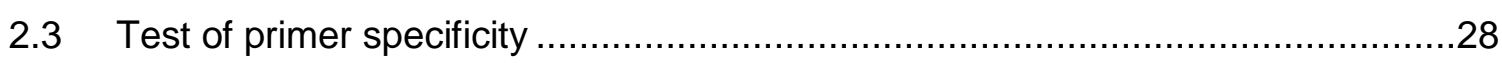

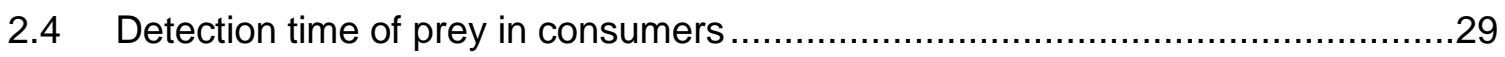

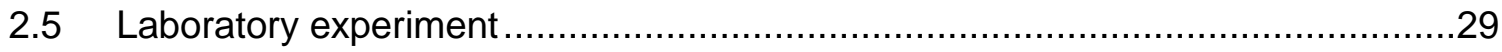

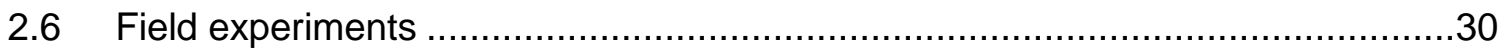

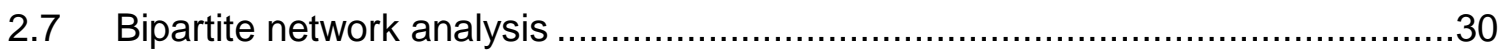

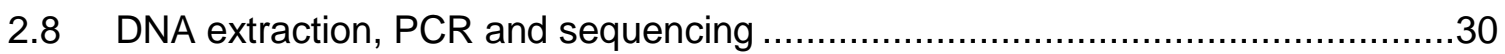

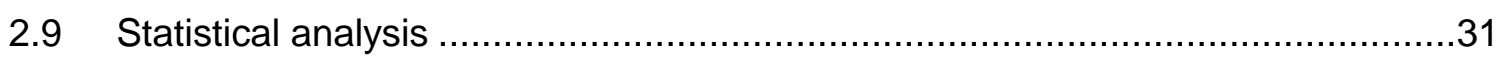

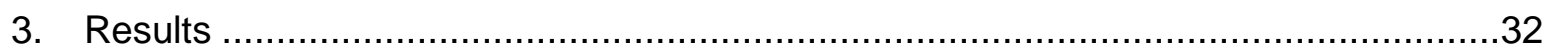

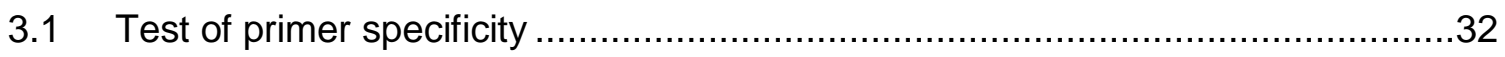

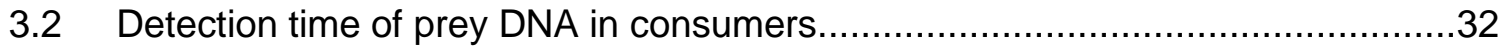

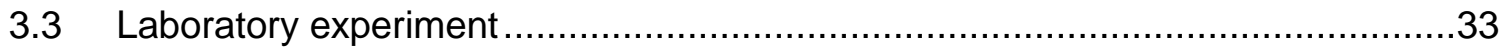

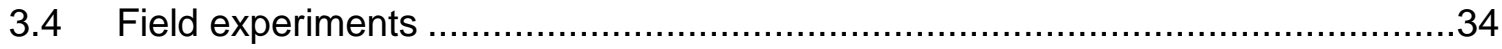

3.4.1 Experiment with living P. hermaphrodita and dead S. feltiae.......................34

3.4.2 Experiment with dead $P$. hermaphrodita and living $S$. feltiae......................35

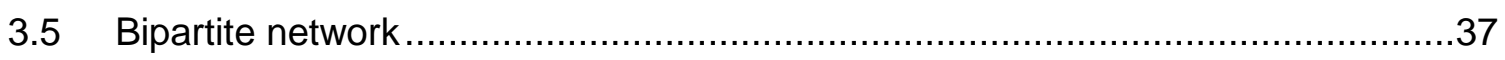

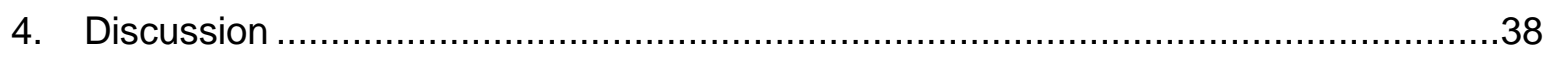

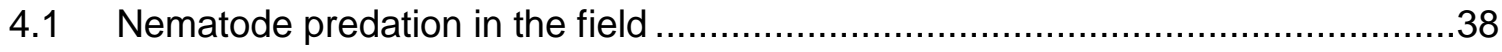




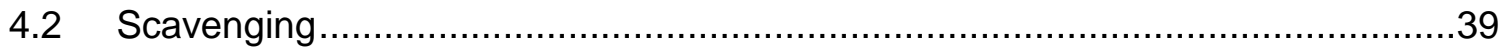

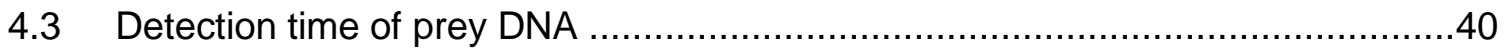

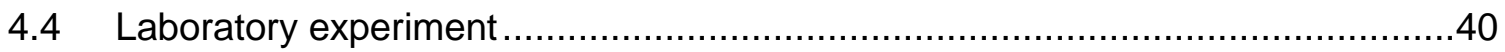

4.5 Suitability of the method............................................................................ 41

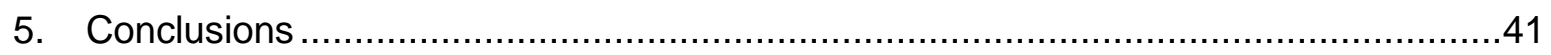

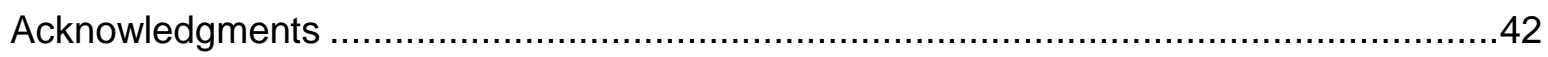

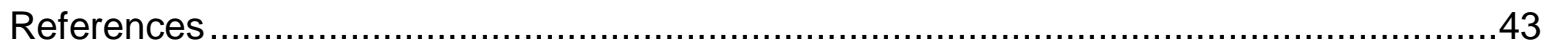

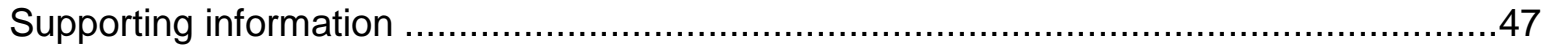

Chapter 3: The role of free-living nematodes as prey for higher trophic levels of forest soil food webs .50

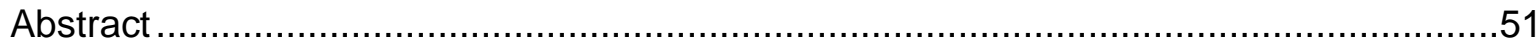

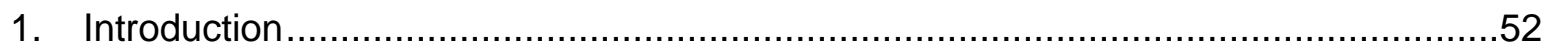

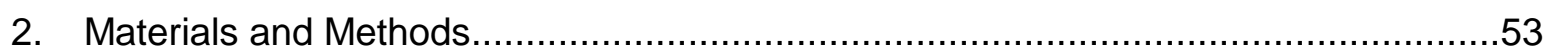

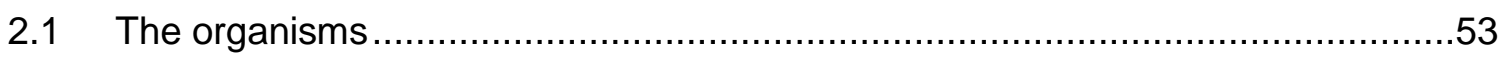

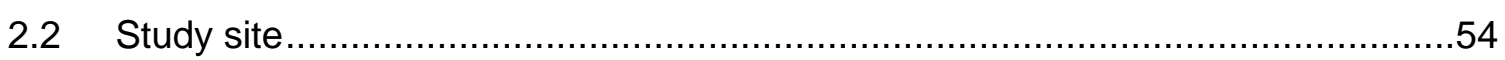

2.3 Alignment, primer design and primer sensitivity …......................................55

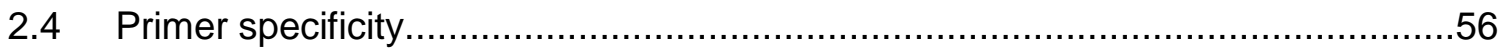

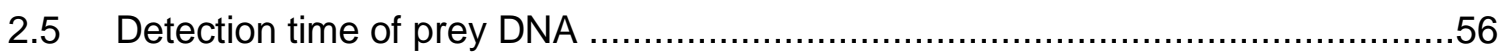

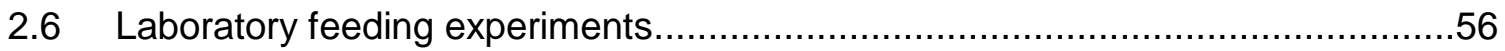

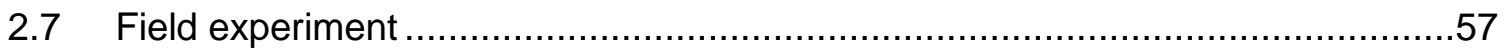

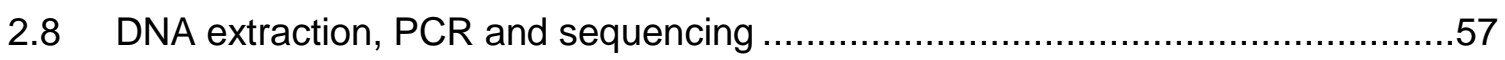

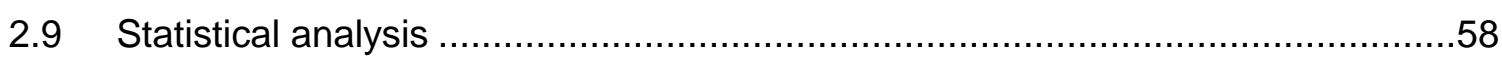

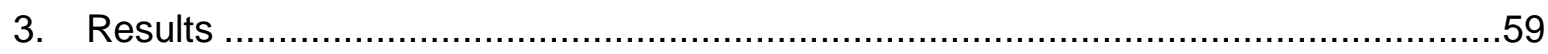

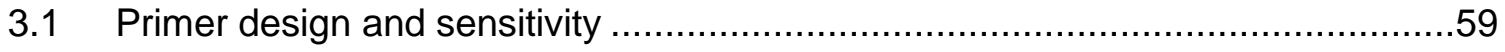

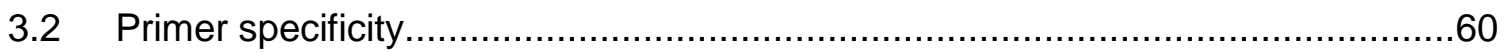

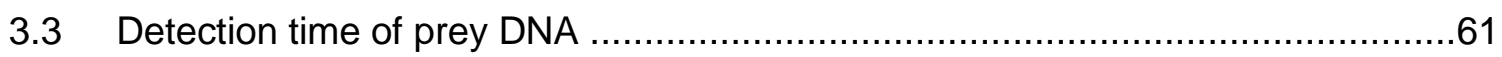

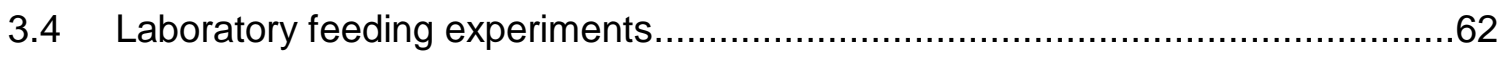

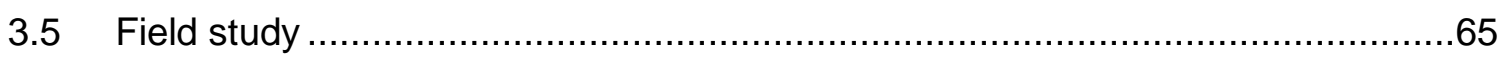

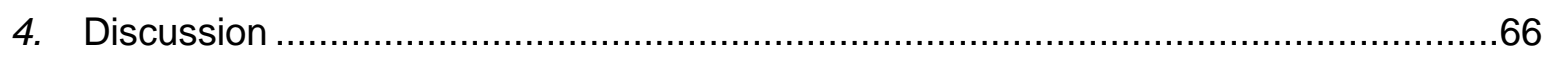

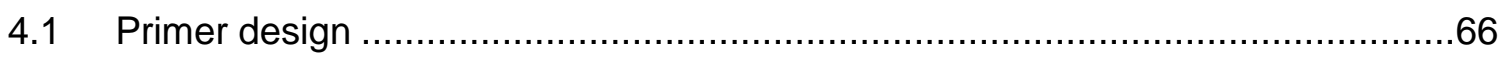

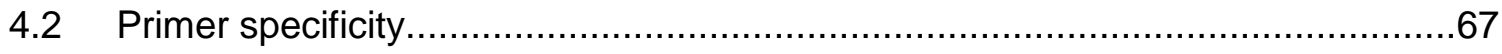

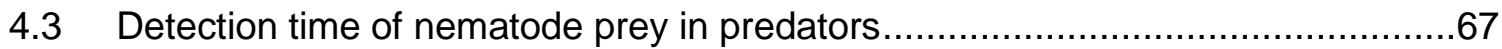

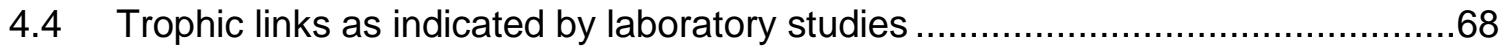

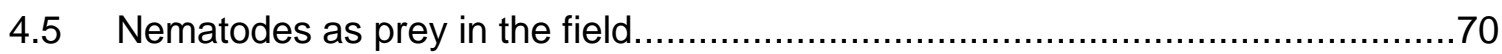

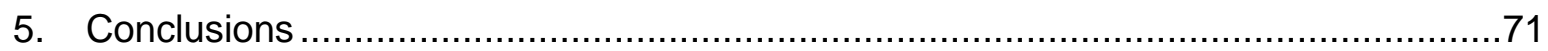




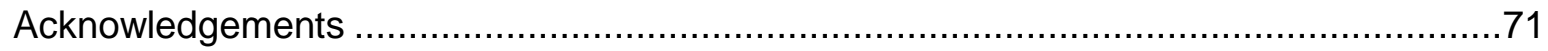

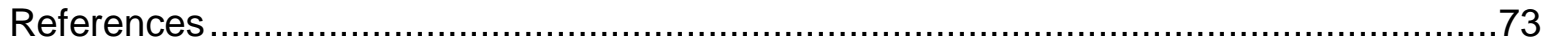

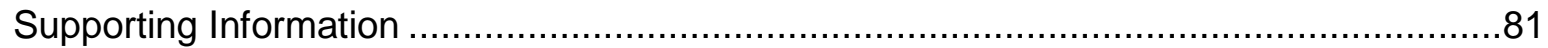

Chapter 4: Consumption of nematodes by soil microarthropods varies between microhabitats of deciduous forests as indicated by molecular gut content analyses ..86

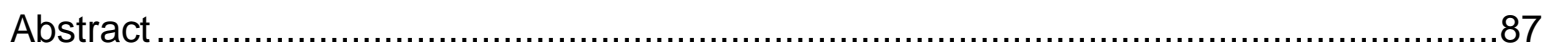

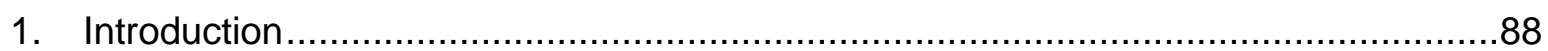

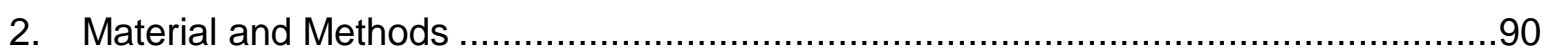

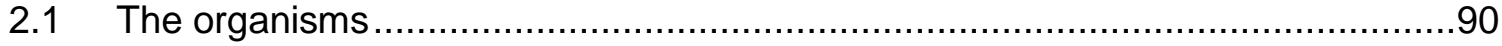

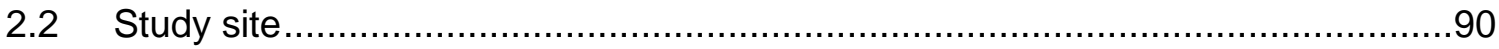

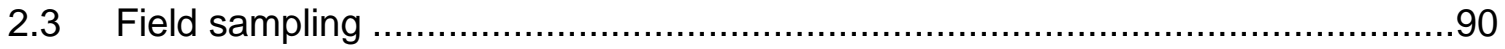

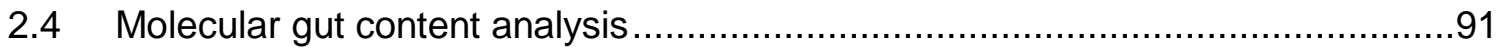

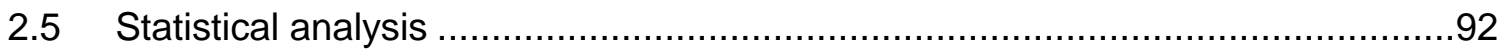

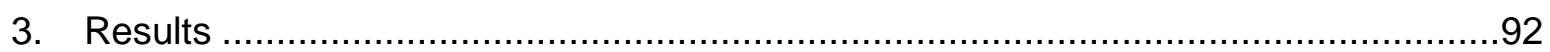

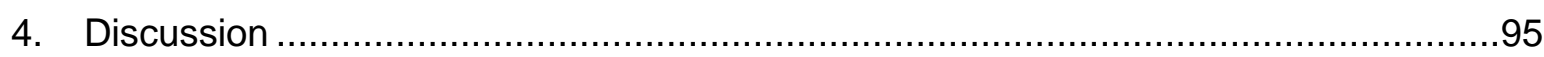

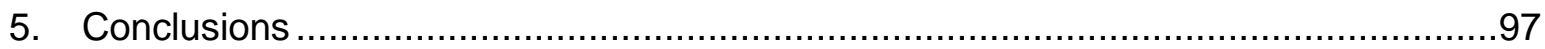

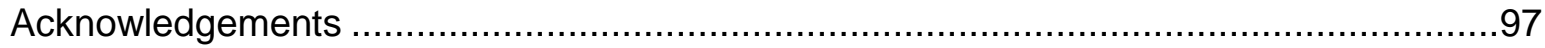

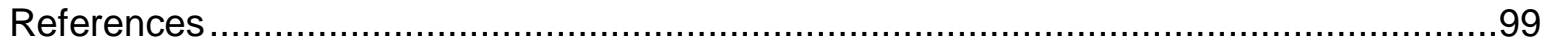

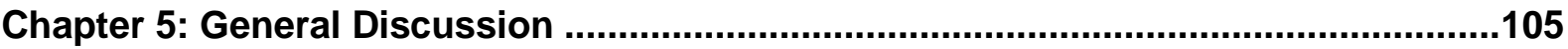

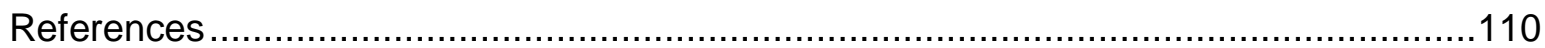

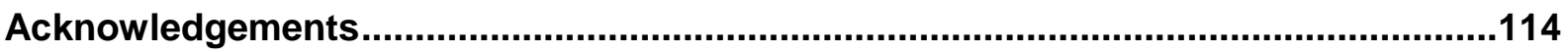

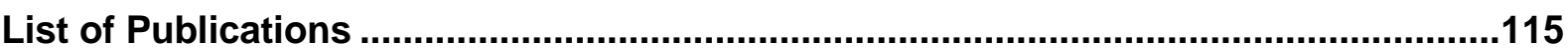

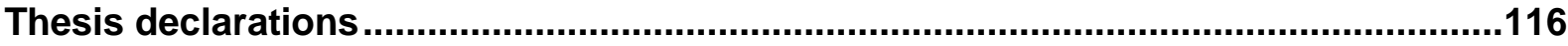




\section{Summary}

Soils are complex and heterogeneous habitats for soil animals. Trophic interactions between soil animals are depicted in soil food webs which form an essential component of terrestrial ecosystems. Soil food webs are based on predator-prey interactions and reflect the flux of matter and energy through ecological systems. The soil food web is compartmentalized in distinct energy channels that process energy in different ways. The main energy channels in forest systems are the bacterial, fungal and plant litter energy channel with the bacterial channel probably being the fastest. However, the importance of predator-prey interactions in these channels remains little understood. Especially nematodes are an understudied group in soil food webs since they are small, difficult to determine and also difficult to detect as prey organism.

I investigated the role of nematodes as prey for microarthropods using molecular gut content analysis. Therefore, specific primers for certain prey taxa were used to screen potential predators for presence of the respective prey. With this approach the consumption and distribution of certain prey among many potential predators can be investigated (bottom-up view). By screening many individuals the importance of predator species as antagonists of nematode prey species can be evaluated (top-down view). Thereby, molecular gut content analysis provides the opportunity to investigate predator-prey interactions allowing to trace trophic links between certain prey taxa and higher consumers of the soil food web.

In the first study (Chapter 2) I investigated if nematodes serve as prey for microarthropods. Therefore, the entomopathogenic nematodes Phasmarhabditis hermaphrodita and Steinernema feltiae were used as model organisms to investigate if soil mites, especially species that have been assumed to live as decomposers, include nematodes in their diet. Established molecular markers for the two nematode species were used in these studies. To confirm detection of predation events, I investigated how long nematode DNA can be traced in the gut of the oribatid mite species Steganacarus magnus. In the field I investigated if soil mites preferentially consume dead or living nematode prey and if active predation for nematode prey occurred. The results indicate that nematode DNA can be traced for up to 128 $\mathrm{h}$ in the gut of $S$. magnus confirming good detection of nematode prey during the experiments. However, the detection time of prey DNA varied between nematode species and depended on the exposure time of the nematodes to the mites. Soil mite species consumed the two model nematode species in the laboratory and in the field suggesting that nematodes form part of their regular diet. In the field experiment many 'classical decomposer' soil mite species fed on the nematodes $P$. hermaphrodita and $S$. feltiae. Living and dead nematodes were consumed indicating that both feeding modes, predation and scavenging, occur. The mites differentially 
consumed the two nematode species depending on whether they were dead or alive pointing to nematode defence mechanisms that influence this predator-prey interaction.

It is very likely that microarthropods also feed on indigenous nematode species and may significantly impact nematode communities; however, no molecular markers exist to test this assumption. Therefore, I designed specific primers for four free-living bacterial feeding soil nematode species (Acrobeloides buetschlii, Panagrellus redivivus, Plectus minimus and Plectus velox) and established them for molecular gut content analyses of potential microarthropod predators (Chapter 3). The specificity of the molecular markers was confirmed by a non-target test to check for cross-reactions, and the sensitivity was confirmed by a twofold serial dilution of prey DNA. The newly designed molecular markers amplify sensitively taxon-specific $18 \mathrm{~S}$ rDNA up to $128 \mathrm{~h}$ after ingestion in the gut of a microarthropod predator. The detection time for the respective nematode species varied between nematode species, mite species and time of exposure indicating that these prey detection times differ for every predator-prey interaction. Abundant soil mite and collembolan species were shown to feed on these nematode species in the laboratory and on $A$. buetschlii and Plectus spp. in the field indicating that indigenous nematodes indeed form part of the diet of soil microarthropods including those previously assumed to live as detritivores. Nematode-predator interactions presumably contribute significantly to the flux of energy from root exudates via bacteria to higher trophic levels.

Forest soils are patchy habitats comprising different microhabitats, such as litter, moss and grass. These microhabitats significantly affect the density and distribution of nematode and microarthropod species, but also contribute to variations in interactions between soil animal species. I investigated if $A$. buetschlii and Plectus spp. were differentially consumed by fourteen abundant soil mite species including Mesostigmata and Oribatida from litter, moss and grass using molecular gut content analysis (Chapter 4). The mites differentially consumed the two nematode taxa related to their density and the consumption of nematodes differed between the habitats. Our results indicate shifts in trophic niches with changing habitat characteristics which likely contribute to the high diversity of microarthropods in deciduous forests.

By designing and establishing specific nematode markers for molecular gut content analysis to investigate the role of indigenous bacterial feeding nematodes as prey for microarthropods this thesis provides promising tools to investigate how carbon is channelled from roots over bacteria to higher trophic levels. Although the few analyzed nematode taxa only represent a small fraction of the nematode community of temperate forest soils, they were frequently detected as prey of microarthropods - including those previously thought to live as 
decomposers - suggesting that the impact of microarthropods on nematodes is high. Overall, the results represent a major step forward for the understanding of soil animal food webs and highlight that the decomposer food web is more complex and trophically diverse than previously assumed. 
Chapter 1

General Introduction 


\section{Soil food webs and their main energy channels}

Searching for food is essential for most terrestrial animals. It is one of the driving forces for niche differentiation, i.e. species numbers, in above- and below-ground systems. Predatorprey interactions are the base for channelling energy from lower to higher trophic levels and are depicted as links in food webs (Pimm 1991; Terborgh \& Estes 2010). A major component of terrestrial ecosystems is the soil food web (Scheu \& Setälä 2002; Bardgett \& Wardle 2010). The density and distribution of species is affected by the patchiness of the soil which comprises different microhabitats such as litter, fine and coarse woody debris and patches of mosses and grass (Sulkava \& Huhta 1998; Hohberg \& Traunspurger 2005). The patchiness of soil habitats also contributes to variations in predator-prey interactions and allows coexistence of the high number of soil animal species (Anderson 1975; Mikola \& Sulkava 2001; Proctor et al. 2002; Scheu \& Setälä 2002; Maraun et al. 2003). Since soil systems are species-rich, the organisms typically are small and difficult to observe; due to these difficulties soil food webs are often viewed as 'black box' and trophic relationships are little understood (Wardle \& Yeates 1993; Symondson 2002; Scheu et al. 2005).

The soil food web is compartmentalized in the bacterial, fungal and plant litter energy channel, and carbon and nutrients are transferred to higher trophic levels via these pathways (Moore \& Hunt 1988; Scheu et al. 2005). The relative contribution of the different energy channels to carbon and nutrient cycling varies depending on forest type and microhabitat (Ruess 2003). Recent studies indicate that a wide range of predators rely on carbon from the bacterial channel (Pollierer et al. 2012) which is assumed to be the fastest as it has a high turnover rate and needs only $\sim 72$ hours to transfer carbon from microbial biomass to higher trophic levels, i.e. to predatory microarthropods (van Hees et al. 2005; Strickland et al. 2012). One of the most important links in the bacterial energy channel presumably are bacterialfeeding nematodes transferring carbon from bacteria to higher trophic levels (Freckman 1988; Crotty et al. 2011; Ferlian et al. 2012) since bacteria have a higher nutrient content (Griffiths \& Caul 1993) than fungi and less defence mechanisms against grazing by nematodes (Wardle \& Yeates 1993). However, this predator-prey interaction is still little understood.

\section{Nematodes}

Nematodes are the most diverse and abundant soil Metazoa on earth (Baxter 2003). They live freely in aquatic and terrestrial systems but also parasitic in animals and plants. Free-living nematodes are key players in soil systems (Moore et al. 2003; Ferris 2010; Yeates 2010) due to their nutrition, diversity, density and role as prey, thereby having an important function for 
transferring carbon to higher trophic levels. Nematodes feed on bacteria, fungi, algae, plants, dead organic material, invertebrates or are omnivorous (Yeates 1993). They can be identified and determined to family level by their mouthparts which are often typical for their nutrition. Free-living soil nematodes usually reach a size of $0.3-3 \mathrm{~mm}$, and forest soils can inhabit up to 100 species and up to several million individuals per square meter (Yeates et al. 2000). Especially bacterial feeding nematodes form one of the most important bacterial grazers in soil since they account for $>50 \%$ and at hotspots of microbial activity sum up to about $90 \%$ of total free-living nematodes (Griffiths 1990; Zunke \& Perry 1997; Scheu et al. 2005; Mulder \& Vonk 2011). Therefore, they are an important food source for other soil animals including tardigrades (Hohberg \& Traunspurger 2005), predatory nematodes (Small \& Grootaert 1983), testate amoebae (Yeates \& Foissner 1995), mites and collembolans (Rockett \& Woodring 1966; Muraoka \& Ishibashi 1976; Walter 1988a,b; Read et al. 2006).

Although some taxa of nematode predators are known, the involved species and their impact on the nematode community are still unclear. Therefore, it is still unknown if the nematode density is controlled by their resource ("bottom-up") or by predators ("top-down"; Ferris et al. 2001; Read et al. 2006).

Terrestrial nematodes are worldwide distributed, even occurring in Antarctica and colonize nearly every habitat of the world (Powers et al. 1998; Wu et al. 2011). In forest ecosystems free-living nematodes form part of the main energy channels and due the high densities and diversity of grazers especially of the fungal and bacterial energy channel. In agrosystems plant parasitic and entomopathogenic nematodes play a major role. Plant parasitic nematodes are host-specific and cause extensive crop losses as pests in monocultures, e.g. Oliveira et al. (2007) stated global crop loss in the order of US $\$ 78$ billion per year relatable to the nematodes Meloidogyne spp., Heterodera spp., Globodera spp. and Pratylenchus spp., therefore, appropriate agents for biological control of these nematodes are in demand. Entomopathogenic nematodes are host specific and are used for biological control of larger pests, e.g. Heterorhabditis bacteriophora is specific to insect larvae and has been used against the western corn root worm (the beetle lavae Diabrotica virgifera virgifera; Toepfer et al. 2005). However, since they are spread out with water to the soil surface numerous nematode individuals are lost either by stress or by predation of soil animals, most importantly microarthropods (Dunphy \& Webster 1986; Hyvönen \& Persson 1996; Read et al. 2006).

Plant resources form the basis of soil food webs thereby governing plant-, bacterial- and fungal-feeding nematodes in soil. Structure, texture, soil mineralogy, and nutrient and water availability influence capturing these resources (Eisenhauer et al. 2011). In addition to resources nematode communities depend on habitat characteristics. Temperature, soil type 
and moisture are the most important factors affecting nematode distribution (Yeates 1979; Verschoor et al. 2001). For plant-parasitic nematodes the presence of the host-plant is also important (Yeates \& Boag 2004). If the temperature is low nematodes become inactive and are unable to develop (Yeates \& Boag 2004), if the temperature is too high, nematodes also reduce their activity (Boag 1980; Burman \& Pye 1980), paralyse or die (Wallace 1963). Nematodes need to pass through soil pores that have a diameter equal or greater than their body width to migrate through soils (Yeates \& Boag 2004), whereas too small or too large soil pores avoid nematode concealment or allow predators access of their hiding place (Hohberg \& Traunspurger 2005). Soil moisture is also an important factor since nematodes move in waterfilms and therefore water is essential for nematode migration (Wallace 1959). All these factors likely also influence the accessibility of nematodes as prey, since paralyzed, slow or immobile nematodes are easier to subdue for predators.

\section{Microarthropods}

Microarthropods (collembolans and mites) are abundant and species rich in soil systems. Stable isotope analyses indicate that collembolans and mites are very diverse in their nutrition and that their trophic level spans from primary and secondary decomposers (feeding predominantly on litter or fungi) to predators (feeding predominantly on nematodes and microarthropods; Schneider et al. 2004a Chahartaghi et al. 2005; Klarner et al. 2013). The degree of food specialization in microarthropods has been discussed intensively (Giller 1996; Schneider et al. 2004b) as it forms a major determinant of the diversity of microarthropods in the terrestrial systems (described as 'enigma of soil animal species diversity'; Anderson 1975; Scheu \& Setälä 2002; Maraun et al. 2003a). Trophic niches are key to explain species richness since even small differences in food preferences may reduce competition (Maraun et al. 1998). Unfortunately, food resources and trophic niches of many soil microarthropod species still are little known (Scheu \& Setälä 2002; Maraun et al. 2003a).

Collembolans are worldwide distributed and reach high densities of up to million individuals per square metre in forest soils (Petersen \& Luxton, 1982) and first occurred in the early Devonian 400 million years ago (Grimaldi 2010). They are a species-rich group of small wingless hexapods and about 7000 species are described (Rusek 1998). Collembolans typically are equipped with a furca which increases mobility and allows escape from predators. Collembolans without furca avoid predation by excretion of a glue from pseudocells on the body surface. Collembolans are assumed to be mainly fungivorous (Chen et al. 1996; Hopkin 1997) but their nutrition is as diverse as that of mites (Rusek 1998; Chahartaghi et al. 2005) also including predators of nematodes (Read et al. 2006). 
Soil mites (Acari) are spider-like arthropods possessing a sclerotized chitinous exoskeleton and four pairs of legs. Mites have a worldwide distribution and can be found in virtually all habitats (Walter \& Proctor 1999; Köhler 1997). The Acari contain mainly predatory groups such as gamasid and uropodid mites (both Parasitiformes: Mesostigmata) and predominantly primary and secondary decomposers such as oribatid mites (Acariformes: Oribatida).

Most gamasid mites are exclusively predatory and only Macrocheles vagabundus and few genera from the superfamily Phytoseioidea are known to additionally include plant diets (Karg 1993). Gamasid mites contain large, aggressive and very mobile predators such as species of the genera Pergamasus and Veigaia that even subdue larger collembolans, whereas smaller species predominantly include small collembolans without furca and nematodes in their diet (Karg 1993; Koehler 1997, 1999; Klarner et al. 2013). Gamasid mites have an extra-intestinal digestion, an overall sensitivity to light but no optical orientation and detect prey by chemical or tactile stimuli (Karg 1993; Köhler 1997). Their prey choice seems to be limited by size, e.g. too large prey gets attacked but not killed whereas too small prey is ignored (Karg 1993).

Many uropodid mite species are known to feed on nematodes and therefore prefer organic matter with many nematodes as habitat which influences its distribution (Karg 1989; Köhler 1997). Rich uropodine communities in the range of 10,000 individuals per square meter can be found in organic materials such as deciduous forest litter and reflect the increase of pore volume and soil organic matter (Karg 1986; Karg 1989). Overall, gamasid and uropodid mites are top-predators in the mesofaunal food web and often form part of the highest trophic level in soil systems.

Oribatid mites are species-rich with about 10,000 described species worldwide (Schatz 2002) and reach high densities of up to 400,000 individuals per square meter in forest ecosystems (Maraun \& Scheu 2000). Recently, the origin of oribatid mites has been dated back to the Precambrian some 570 million years ago by molecular clock analyses (Schaefer et al. 2010) and the oldest fossils are from Devonian sediments 380 million years ago (Shear et al. 1984; Norton et al. 1988). Oribatid mites convergently evolved defence mechanisms against predators such as ptychoid body form, hologastry and cuticular mineralization (Pachl et al. 2012). Today, adult oribatid mites are assumed to live in enemy-free space and avoid predation by other mesofauna taxa due to strongly sclerotized cuticle and chemical defence by secretions of opisthonotal glands (Peschel et al. 2006; Heethoff et al. 2011). Occasionally, however, they are consumed by large animals such as salamanders (Norton \& McNamara 1978), frogs (Saporito et al. 2007), centipedes (Lebrun 1970), scydmaenid beetles (Mollemann \& Walter 2001) and ants (Masuko 1994; Wilson 2005). Oribatid mites have been assumed to feed mainly on litter and fungi (Maraun \& Scheu 2000), and hold a key position in 
decomposition and mineralization processes of soils (Seastedt 1984). Therefore, they are classified as 'classical' decomposers and are often pooled as one functional group in food web analyses. However, recent studies indicate that the nutrition of oribatid mites is more diverse than presumably assumed and that they span over four trophic levels from primary decomposers up to predators that most likely feed on nematodes (Schneider et al. 2004a; Rockett \& Woodring 1966; Muraoka \& Ishibashi 1976; Oliveira et al. 2007; Norton \& BehanPelletier 2009).

\section{Studying trophic interactions in soil}

Trophic interactions in soil are often difficult to observe and to evaluate which is due to a number of factors. First, soil animals are small; second, they live in opaque and inaccessible habitats; and third, direct observations are difficult without disturbing the system (Symondson 2002; Scheu et al. 2005). Therefore, analysis of predator's gut content (Symondson 2002; King et al. 2008), faeces (Seeber et al. 2010) or regurgitates (Waldner \& Traugott 2012) are necessary to determine the ingested prey. Microscopic analyses allow to identify and quantify prey remnants (Symondson 2002), however, the technique relies on hard prey fragments and is unsuitable for soft bodied prey, such as earthworms but also nematodes which only provide sclerotized mouthparts for detection (Walter 1988a; Sunderland 1988). Moreover, numerous predatory soil organisms including microarthropods either digest their prey extra-intestinally or are liquid feeders consuming only fluid prey components. Therefore, analyses based on indigestible remains provide biased results, missing many predator-prey interactions (Dennison \& Hodkinson 1983; Walter 1988a; Sunderland 1988; Symondson 2002; Sheppard \& Harwood 2005).

Several indirect methods for studying predator-prey interactions in soil have been established in the last years, e.g. fatty acid analysis (Ruess et al. 2004) and the analysis of stable isotope ratios $\left({ }^{15} \mathrm{~N} /{ }^{14} \mathrm{~N},{ }^{13} \mathrm{C} /{ }^{12} \mathrm{C}\right.$; Maraun et al. 2011). These techniques allow insight into the trophic position of soil animal species and ascribing species to energy channels such as the bacterial and fungal decomposition pathway (Pollierer et al. 2012). However, determination of predator-prey interactions at the level of species or individuals are not possible. Other indirect methods have been used recently, e.g. gas chromatography-mass spectrometry analysis of prey alkaloid markers (Sloggett et al. 2009), protein electrophoresis (Traugott 2003), immunoassays using polyclonal or monoclonal antibodies (Sunderland 1988; Harwood et al. 2004), but the use of molecular markers for a certain prey was the most promising and best evaluated approach to detect neglected trophic links of the soil food web (Symondson 2002). 


\section{Molecular gut content analysis}

Molecular gut content analysis is a novel and promising tool to detect predator-prey interactions in soil food webs. Molecular markers, i.e. primers for a certain prey taxon, are used to detect its DNA in the gut of predators to determine consumption and can also be used to identify parasite-host interactions (Traugott et al. 2008).

General or specific primers can be used as molecular markers. General primers amplify prey groups or families pointing to the prey spectrum of a predator but are prone to PCR bias (Vestheim \& Jarman 2008). Specific primers amplify prey DNA on genus or species level and point to the distribution of a certain prey taxon within the food web, thereby identifying many potential predators in short time.

Primers for molecular gut content analyses need to be sensitive in detecting small amounts of prey DNA after ingestion, since the prey individual typically is smaller than the predator and only consumed partially (Eitzinger \& Traugott 2011; King et al. 2008). They need to amplify their target specifically and not the DNA of the predator or alternative food. Therefore, they have to be tested against a wide range of non-target species for possible cross-reactions to exclude false positive results (Harwood et al. 2007; King et al. 2008). Prey DNA detection decreases with time since prey in the gut is digested by the predator (Sheppard et al. 2005; Read et al. 2006; von Berg et al. 2008; Gagnon et al. 2011). Therefore, the primers need to detect prey DNA long enough to allow identifying feeding events that occurred before sampling of soil animals in the field.

Mitochondrial or ribosomal multi-copy genes are preferred to single-copy genes for designing primers as this increases the probability of detecting prey DNA (King et al. 2008). Moreover, primers need to amplify short fragments (typically 300 bp; Zaidi et al. 1999; Sint et al. 2011) to allow detection of degraded prey DNA by gut enzymes and to prolong detection time. However, since DNA can be detected between some hours and several days after feeding in the gut of a predator the method provides more than a short term 'snapshot' of feeding events (Pollierer et al. 2012).

Molecular gut content analysis also has limitations. The amplification of prey bands and its visualization shows only the presence or absence of prey DNA but neither the amount of prey consumed nor if the prey was dead or alive, i.e. does not allow to differentiate between predation and scavenging (Juen \& Traugott 2005; Foltan et al. 2005; von Berg et al. 2012) nor to identify secondary predation (hyperpredation; Sheppard et al. 2005). Further, detection of cannibalism is impossible. A quantification of the prey/predator DNA ratio is possible by quantitative real-time PCR (qPCR; Weber \& Lundgren 2009) but gives only hints which of the 
predator individuals has consumed more than the other. Future work is necessary for allowing to relate the amount of prey DNA detected to the number (biomass) of prey individuals consumed. However, by screening a large number of predator individuals the method allows to determine trophic links and their strength in the food web if specific primers exist. Since the soil system is exceptionally rich in species the method needs primarily to be applied to abundant prey species that hold key positions in soil food webs such as nematodes.

Molecular markers have been designed and evaluated for three entomopathogenic nematodes Phasmarhabditis hermaphrodita, Steinernema feltiae and Heterorhabditis megidis and were used to investigate the gut content of collembolans (Read et al. 2006). The results suggest that these microarthropods indeed feed on nematodes in the laboratory and the field when available. If other soil microarthropods, such as mesostigmatid and oribatid mites, also include nematodes in their diet remains a goal for future work.

\section{Objectives and chapter outline}

This thesis focuses on the role of nematodes as prey for microarthropods. Therefore, molecular markers for entomopathogenic model nematodes (Phasmarhabditis hermaphrodita and Steinernema feltiae) were used to identify potential predators and to distinguish in a field experiment the importance of scavenging or predation as feeding mode (Chapter 2). Moreover, new molecular markers for free-living bacterial feeding nematodes (Acrobeloides buetschlii, Plectus minimus, Plectus velox and Panagrellus redivivus) were designed and optimized for molecular gut content analyses to investigate if microarthropods consume these nematode species in the field (Chapter 3). Further, using these primers we investigated if nematode consumption differs between microhabitats (litter, grass and moss) indicating trophic niche differentiation and contributing to the coexistence of the many soil animal species (Chapter 4).

We examined the following main hypothesis:

(1) Nematodes form important prey of many microarthropod taxa including those that have been assumed to live as decomposers. Therefore, established and new designed molecular markers were used (Chapter 2 and 3).

(2) Microarthropods prefer dead over living prey (scavenging vs. predation; Chapter 2).

(3) Nematode species are differentially consumed by mites pointing to differences in predator-prey interactions on species level (Chapter 2, 3, 4). 
(4) Consumption of nematodes by microarthropods differs between microhabitats, i.e. their trophic niches vary in space (Chapter 4).

In the following, the content of the chapters is summarized:

In Chapter 2 we used two entomopathogenic nematode species (Phasmarhabditis hermaphrodita and Steinernema feltiae) as model organisms to investigate if abundant soil mites feed on nematodes, how long nematode DNA is detectable in predator guts, and if they prefer dead or living nematode prey. Established molecular markers were used in these analyses (Read et al. 2006). In the laboratory potential mite predators of nematode species were identified including those previously assumed to live as decomposers. Prey DNA was detectable in predators for up to $128 \mathrm{~h}$ but detection depended on the time the nematodes were exposed to the predator. Since these two nematode species are large predators needed long (up to $48 \mathrm{~h}$ ) to subdue and consume them. Dead and living $P$. hermaphrodita and $S$. feltiae were added to the forest floor food web for $48 \mathrm{~h}$. Then, soil mites were extracted and screened for nematode prey. Soil mites including species that were previously assumed to live as decomposers frequently consumed the nematodes. Soil mites consumed dead and living nematodes indicating that they function as both scavengers and predators. The two nematode species were differentially consumed depending on whether they were dead or alive, indicating that defence mechanisms alter predator-prey interactions. The results suggests that the mite species studied also feed on free living nematode species in the field thereby controlling nematode populations.

In Chapter $\mathbf{3}$ we investigated the role of field-living nematodes as prey for soil microarthropods. Therefore, we designed new primers for free-living bacterial feeding nematode species including Acrobeloides buetschlii, Plectus minimus, Plectus velox and Panagrellus redivivus and used them for molecular gut content analyses of soil mite and collembolan species in the laboratory and the field. The molecular markers amplify short parts of the respective nematode $18 \mathrm{~S}$ rDNA and allowed detecting even small amounts of DNA in the gut of predators. DNA of these four nematode species was detectable for up to $128 \mathrm{~h}$ in the gut of mite predators. Detection time varied between nematode species, mite species and time of exposure indicating that detection times are specific for every predator-prey interaction. Abundant mite and collembolan species proved to feed on the studied nematode species in the laboratory and on $A$. buetschlii and Plectus spp. in the field. We could not detect $P$. redivivus in mites from the study site since it does not occur there, however, $P$. redivivus is easy to culture in large numbers and can be used as model organism for experimental studies. The results suggest that in the field nematodes form an important component of the diet of soil 
microarthropods and that this presumably contributes to the flux of energy from root exudates via bacteria to higher trophic levels.

In Chapter 4 we used the newly designed molecular markers for A. buetschlii and Plectus spp. to investigate if the consumption of these nematode species differs between habitats. Therefore, we investigated the consumption of nematode prey in fourteen abundant soil mite species from three different habitats (litter, grass and moss). The mite species differentially consumed the two nematode taxa and consumption differed between the three habitats. The results suggest that feeding of mites on nematodes is more common than previously assumed and that their diet varies between microhabitats. Trophic niche differentiation and spatial variation of trophic niches is likely to contribute to the coexistence of the many mite species in the seemingly homogeneous soil habitat. 


\section{References}

Anderson JM (1975) The enigma of soil animal species diversity. In: Vanek, J., (Ed.), Progress in Soil Ecology. Proceedings of the Fifth International Colloquium of Soil Zoology, 1973, pp. 51-58. Academica, Prague.

Bardgett RD, Wardle DA, (2010) Above-Belowground Linkages: Biotic Interactions, Ecosystem Processes, and Global Change (Oxford Series in Ecology and Evolution). Oxford University Press, New York.

Baxter M (2003) Counting angels with DNA. Nature, 421, 122-124.

Boag B (1980) Effect of temperature on rate of feeding of the plant parasitic nematodes Rotylenchus robustus, Xiphinema diversicaudatum and Hemicycliophora conida. Journal of Nematology, 12, 193-195.

Burman M, Pye AE (1980) Neoaplectana carpocapsae: Movements of nematode populations on a thermal gradient. Experimental Parasitology, 49, 258-265.

Chahartaghi M, Langel R, Scheu S, Ruess L (2005) Feeding guilds in Collembola based on nitrogen stable isotope ratios. Soil Biology and Biochemistry, 37, 1718-1725.

Chen B, Snider RJ, Snider RM (1995) Food preference and effects of food type on the life history of some soil Collembola. Pedobiologia, 39, 496-505.

Crotty FV, Blackshaw RP, Murray PJ (2011) Tracking the flow of bacterially derived ${ }^{13} \mathrm{C}$ and ${ }^{15} \mathrm{~N}$ through soil fauna feeding channels. Rapid Communication of Mass Spectromony, 25, 1503-1513.

Dunphy GB, Webster JM (1986) Temperature effects on the growth and virulence of Steinernema feltiae strains and Heterorhabditis heliothidis. Journal of Nematology, 18, 270 272.

Eisenhauer N, Migunova VD, Ackermann M, Ruess L, Scheu S, (2011) Changes in plant species richness induce functional shifts in soil nematode communities in experimental grassland. PloS one, 6, e24087.

Eitzinger B, Traugott M (2011) Which prey sustains cold-adapted invertebrate generalist predators in arable land? Examining prey choices by molecular gut-content analysis. Journal of Applied Ecology, 48, 591-599. 
Ferlian O, Scheu S, Pollierer MM (2012) Trophic interactions in centipedes (Chilopoda, Myriapoda) as indicated by fatty acid patterns: Variations with life stage, forest age and season. Soil Biology and Biochemistry, 52, 33-42.

Ferris H, Bongers T, de Goede RGM (2001) A framework for soil food web diagnostics: extension of the nematode faunal analysis concept. Applied Soil Ecology, 18, 13-29.

Ferris $\mathrm{H}$ (2010) Contribution of nematodes to the structure and function of the soil food web. Journal of Nematology, 42, 63-67.

Freckman DW (1988) Bacterivorous nematodes and organic-matter decomposition. Agriculture, Ecosystems and Environment, 24, 195-217.

Foltan P, Sheppard SK, Konvicka M, Symondson WOC (2005) The significance of facultative scavenging in generalist predator nutrition: detecting decayed prey in the guts of predators using PCR. Molecular Ecology, 14, 4147-4158.

Gagnon A-È, Doyon J, Heimpel GE, Brodeur J (2011) Prey DNA detection success following digestion by intraguild predators: influence of prey and predator species. Molecular Ecology Resources, 11, 1022-1032.

Giller PS (1996) The diversity of soil communities, the 'poor man's tropical rainforest'. Biodiversity and Conservation, 5, 135-168.

Griffiths BS (1990) A comparison of microbial-feeding nematodes and protozoa in the rhizosphere of different plants. Biology and Fertility of Soils, 9, 83-88.

Griffiths BS, Caul S (1993) Migration of bacterial-feeding nematodes, but not protozoa, to decomposing grass residues. Biology and Fertility of Soil, 15, 201-207.

Grimaldi DA (2010) 400 million years on six legs: on the origin and early evolution of Hexapoda. Arthropod Structure and Development, 39, 191-203.

Harwood JD, Sunderland KD, Symondson WOC (2004) Prey selection by linyphiid spiders: molecular tracking of the effects of alternative prey on rates of aphid consumption in the field. Molecular Ecology, 13, 3549-3560.

Harwood JD, Desneux N, Yoo HJS, Rowley DL, Greenstone MH, Obrycki JJ, O'Neil RJ (2007) Tracking the role of alternative prey in soybean aphid predation by Orius insidiosus: a molecular approach. Molecular Ecology, 16, 4390-4400. 
Heethoff M, Koerner L, Norton RA, Raspotnig G (2011) Tasty but protected - first evidence of chemical defense in oribatid mites. Journal of Chemical Ecology, 37, 1037-1043.

Hohberg K, Traunspurger W (2005) Predator-prey interaction in soil food web: functional response, size-dependent foraging efficiency, and the influence of soil texture. Biology and Fertility of Soils, 41, 419-427.

Hopkin SP (1997) Biology of the Springtails (Insecta: Collembola). Oxford University Press, Oxford/New York/Tokyo.

Hyvönen R, Persson T (1996) Effects of fungivorous and predatory arthropods on nematodes and tardigrades in microcosms with coniferous forest soil. Biology and Fertility of Soils, 21, 121-127.

Juen A, Traugott M (2005) Detecting predation and scavenging by DNA gut-content analysis: a case study using a soil insect predator-prey system. Oecologia, 142, 344-352.

Karg W (1986) Vorkommen und Ernährung der Milbencohors Uropodina Kramer (Schildkrötenmilben) sowie ihre Eignung als Indikatoren in Agroökosystemen. Pedobiologia, 29, 285- 295.

Karg W (1989) Acari (Acarina), Milben. Unterordnung Parasitiformes (Anactinochaeta). Cohors Uropodina Kramer. Schildkrötenmilben. Die Tierwelt Deutschlands 67. Teil; 2. überarbeitete Auflage. Gustav Fischer, Jena, Germany.

Karg W (1993) Acari (Acarina), Milben. Unterordnung Parasitiformes (Anactinochaeta). Cohors Gamasina Leach. Raubmilben. Die Tierwelt Deutschlands 59. Teil; 2. überarbeitete Auflage. Gustav Fischer, Jena, Germany.

King RA, Read DS, Traugott M, Symondson WOC (2008) Molecular analysis of predation: a review of best practice for DNA-based approaches. Molecular Ecology, 17, 947-963.

Klarner B, Maraun M, Scheu S (2013) Trophic diversity and niche partitioning in a species rich predator guild - natural variations in stable isotope ratios $\left({ }^{13} \mathrm{C} /{ }^{12} \mathrm{C},{ }^{15} \mathrm{~N} /{ }^{14} \mathrm{~N}\right)$ of mesostigmatid mites (Acari, Mesostigmata) from Central European beech forest. Soil Biology and Biochemistry, 57, 323-333.

Koehler HH (1997) Mesostigmata (Gamasina, Uropodina), efficient predators in agroecosystems. Agriculture, Ecosystems \& Environment, 62, 105-117.

Koehler HH (1999) Predatory mites (Gamasina, Mesostigmata). Agriculture, Ecosystem and Environment, 74, 395-410. 
Lebrun P (1970) E' cologie et biologie de Nothrus palustris (C.L. Koch, 1839) 3eme note: cycle de la vie. Acarologia, 12, 193-207.

Maraun M, Migge S, Schaefer M, Scheu S (1998) Selection of microfungal food by six oribatid mite species (Oribatida, Acari) from two different beech forests. Pedobiologia, 42, 232-240.

Maraun M, Scheu S (2000) The structure of oribatid mite communities (Acari, Oribatida): patterns, mechanisms and implications for future research. Ecography, 23, 374-382.

Maraun M, Martens H, Migge S, Theenhaus A, Scheu S (2003) Adding to "the enigma of soil animal diversity": fungal feeders and saprophagous soil invertebrates prefer similar food substrates. European Journal of Soil Biology, 39, 85-95.

Maraun M, Erdmann G, Fischer BM, Pollierer MM, Norton RA, Schneider K, Scheu S (2011) Stable isotopes revisited: Their use and limits for oribatid mite trophic ecology. Soil Biology and Biochemistry, 43, 877-882.

Masuko K (1994) Specialized predation on oribatid mites by two species of the ant genus Myrmecina (Hymenoptera: Formicidae). Psyche, 101, 159-173.

Mikola J, Sulkava P (2001) Responses of microbial-feeding nematodes to organic matter distribution and predation in experimental soil habitat. Soil Biology and Biochemistry, 33, 811-817.

Molleman F, Walter DE (2001) Niche segregation and can-openers: scydmaenid beetles as predators of armoured mites in Australia. In: Halliday RB, Walter DE, Proctor HC, Norton RA, Colloff MJ (Eds.), Acarology. Proceeding of the 10th International Congress. CSIRO Publishing, Melbourne.

Moore JC, Hunt HW (1988) Resource compartmentation and the stability of real ecosystems. Nature, 333, 261-263.

Moore JC, McCann K, Setälä H, De Ruiter PC (2003) Top-down is bottom-up: does predation in the rhizosphere regulate aboveground dynamics? Ecology, 84, 846-857.

Mulder C, Vonk JA (2011) Nematode traits and environmental constraints in 200 soil systems: scaling within the 60-6000 $\mu \mathrm{m}$ body size range. Ecology, 92, 2004.

Muraoka M, Ishibashi N (1976) Nematode-feeding mites and their feeding behaviour. Applied Entomology and Zoology, 11, 1-7. 
Norton RA, MacNamara MC (1976) The common newt (Notophthalmus viridescens) as a predator of soil mites in New York. Journal of the Georgia Entomological Society, 11, 8388.

Norton RA, Bonamo PM, Grierson JD, Shear WA (1988) Oribatid mite fossils from a terrestrial Devonian deposit near Gilboa, New York. Journal of Paleontology, 62, 259- 269.

Norton RA, Behan-Pelletier VM (2009) Suborder Oribatida. In: Krantz GW, Walter DE (Editors), A manual of Acarology, third ed. Texas Tech University Press.

Oliveira AR, de Moraes GJ, Ferraz LCCB (2007) Consumption rate of phytonematodes by Pergalumna sp. (Acari: Oribatida: Galumnidae) under laboratory conditions determined by a new method. Experimental and Applied Acarology, 41, 183-189.

Pachl P, Domes K, Schulz G, Norton RA, Scheu S, Schaefer I, Maraun M (2012) Convergent evolution of defense mechanisms in oribatid mites (Acari, Oribatida) shows no "ghosts of predation past". Molecular Phylogenetics and Evolution, 65, 412-420.

Peschel K, Norton RA, Scheu S, Maraun M (2006) Do oribatid mites live in enemy-free space? Evidence from feeding experiments with the predatory mite Pergamasus septentrionalis. Soil Biology and Biochemistry, 38, 2985-2989.

Petersen H, Luxton M (1982) A comparative analysis of soil fauna populations and their role in decomposition processes. Oikos, 39, 288-309.

Pimm SL, Lawton JH, Cohen JE (1991) Food web patterns and their consequences. Nature, $350,669-674$.

Pollierer MM, Dyckmans J, Scheu S, Haubert D (2012) Carbon flux through fungi and bacteria into the forest soil animal food web as indicated by compound-specific ${ }^{13} \mathrm{C}$ fatty acid analysis. Functional Ecology, 26, 978-990.

Powers LE, Ho M, Freckman DW, Virginia RA (1998) Distribution, community structure and microhabitats of soil invertebrates along an elevational gradient in Taylor Valley, Antarctica. Arctic and Alpine Research, 30, 133-141.

Proctor HC, Montgomery KM, Rosen KE, Kitching RL (2002) Are tree trunks habitats or highways? A comparison of oribatid mite assemblages from hoop-pine bark and litter. Australian Journal of Entomology, 41, 294-299.

Read DS, Sheppard SK, Bruford MW, Glen DM, Symondson WOC (2006). Molecular detection of predation by soil micro-arthropods on nematodes. Molecular Ecology, 15, 1963-1972. 
Rockett CL, Woodring JP (1966) Oribatid mites as predators of soil nematodes. Annual Entomological Society of America, 59, 669-671.

Ruess L (1995) Studies on the nematode fauna of an acid forest soil: spatial distribution and extraction. Nematologica, 41, 229-239.

Ruess L, Häggblom MM, Langel R, Scheu S (2004) Nitrogen isotope ratios and fatty acid composition as indicators of animal diets in belowground systems. Oecologia, 139, 336346.

Rusek J (1998) Biodiversity of Collembola and their functional role in the ecosystem. Biodiversity and Conservation, 7, 1207-1219.

Saporito RA, Donnelly MA, Norton RA, Garraffo HM, Spande TF, Daly JW (2007) Oribatid mites as a major dietary source for alkaloids in poison frogs. Proceedings of the National Academy of Sciences of the USA, 104, 8885-8890.

Schaefer I, Norton RA, Scheu S, Maraun M (2010) Arthropod colonization of land - linking molecules and fossils in oribatid mites (Acari, Oribatida). Molecular Phylogenetics and Evolution, 57, 113-121.

Schatz H (2002) Die Oribatidenliteratur und die beschriebenen Oribatidenarten (1758-2001) Eine Analyse. Abhandlungen und Berichte des Naturkundemuseums Görlitz, 74, 37-45.

Scheu S, Setälä H (2002) Multitrophic interactions in decomposer food webs. In: Multitrophic Level Interactions (eds. Tscharntke T, Hawkins BA), pp. 223-264. Cambridge University Press, Cambridge.

Scheu S, Ruess L, Bonkowski, M (2005) Interactions between microorganisms and soil microand mesofauna. Soil Biology, 3, 253-275.

Schneider K, Migge S, Norton RA, Scheu S, Langel R, Reineking A, Maraun M (2004a) Trophic niche differentiation in oribatid mites (Oribatida, Acari): evidence from stable isotope ratios $\left({ }^{15} \mathrm{~N} /{ }^{14} \mathrm{~N}\right)$. Soil Biology and Biochemistry, 36, 1769-1774.

Schneider K, Renker C, Scheu S, Maraun M (2004b) Feeding biology of oribatid mites: a minireview. Phytophaga, 14, 247-256.

Seastedt TR (1984) The role of microarthropods in decomposition and mineralization processes. Annual Review of Entomology, 29, 25-46. 
Seeber J, Rief A, Seeber GUH, Meyer E, Traugott M (2010) Molecular identification of detritivorous soil invertebrates from their faecal pellets. Soil Biology and Biochemistry, $\mathbf{4 2}$, 1263-1267.

Shear WA, Bonamo PA, Grierson JD, Rolfe WDI, Smith EL, Norton RA (1984) Early land animals in North America: evidence from Devonian age arthropods from Gilboa, New York. Science, 224, 492-494.

Sheppard SK, Harwood JD (2005) Advances in molecular ecology: tracking trophic links through predator-prey food-webs. Functional Ecology, 19, 751-762.

Sheppard SK, Bell J, Sunderland KD, Fenlon J, Skervin D, Symondson WOC (2005) Detection of secondary predation by PCR analyses of the gut contents of invertebrate generalist predators. Molecular Ecology, 14, 4461-4468.

Sint D, Raso L, Kaufmann R, Traugott M (2011) Optimizing methods for PCR-based analysis of predation. Molecular Ecology Resources, 11, 795-801.

Sloggett JJ, Obrycki JJ, Haynes KF (2009) Identification and quantification of predation: novel use of gas chromatography-mass spectrometric analysis of prey alkaloid markers. Functional Ecology, 23, 416-426.

Small RW, Grootaert P (1983) Observations on the predation abilities of some soil dwelling predatory nematodes. Nematologica, 29, 109-118.

Strickland MS, Wickings K, Bradford MA (2012) The fate of glucose, a low molecular weight compound of root exudates, in the belowground foodweb of forests and pastures. Soil Biology and Biochemistry, 49, 23-29.

Sulkava P, Huhta V (1998) Habitat patchiness affects decomposition and faunal diversity: a microcosm experiment on forest floor. Oecologia, 116, 390-396.

Sunderland KD (1988) Quantitative methods for detecting invertebrate predation occurring in the field. Annals of Applied Biology, 112, 201-224.

Symondson WOC (2002) Molecular identification of prey in predator diets. Molecular Ecology, 11, 627-641.

Terborgh J, Estes JA (2010) Trophic Cascades and the Changing Dynamics of Nature. Island Press, Washington. 
Toepfer S, Gueldenzoph C, Ehlers R-U, Kuhlmann U (2005) Screening of entomopathogenic nematodes for virulence against the invasive western corn rootworm, Diabrotica virgifera virgifera (Coleoptera: Chrysomelidae) in Europe. Bulletin of Entomological Research, 95, 473-482.

Traugott M (2003) The prey spectrum of larval and adult Cantharis species in arable land: An electrophoretic approach. Pedobiologia, 47, 161-169.

Traugott M, Bell JR, Broad GR, Powell W, van Veen FJF, Vollhardt IMG, Symondson WOC (2008) Endoparasitism in cereal aphids: molecular analysis of a whole parasitoid community. Molecular Ecology, 17, 3928-3938.

van Hees PAW, Jones DL, Finlay R, Godbold DL, Lundström US (2005) The carbon we do not see - the impact of low molecular weight compounds on carbon dynamics and respiration in forest soils: a review. Soil Biology and Biochemistry, 37, 1-13.

Verschoor BC, de Goede RGM, de Hoop J-W, de Vries FW (2001) Seasonal dynamics and vertical distribution of plant-feeding nematode communities in grasslands. Pedobiologia, 45, 213-233.

Vestheim H, Jarman SN (2008) Blocking primers to enhance PCR amplification of rare sequences in mixed samples - a case study on prey DNA in Antarctic krill stomachs. Frontiers in Zoology, 5, e12.

von Berg K, Traugott M, Symondson WOC, Scheu S (2008) The effects of temperature on detection of prey DNA in two species of carabid beetle. Bulletin of Entomological Research, 98, 263-269.

von Berg K, Traugott M, Scheu S (2012) Scavenging and active predation in generalist predators: A mesocosm study employing DNA-based gut content analysis. Pedobiologia, 55, 1-5.

Waldner T, Traugott M (2012) DNA-based analysis of regurgitates: a noninvasive approach to examine the diet of invertebrate consumers. Molecular Ecology Resources, 12, 669-675.

Wallace HR (1959) The movement of eelworms in water films. Annals of Applied Biology, 47, 366-370.

Wallace HR (1963) The biology of plant parasitic nematodes. London: Edward Arnold.

Walter DE (1988a) Predation and mycophagy by endostigmatid mites (Acariformes: Prostigmata). Experimental and Applied Acarology, 4, 159-166. 
Walter DE (1988b) Nematophagy by soil arthropods from the Shortgrass Steppe, Chihuahuan Desert and Rocky Mountains of the Central United States. Agriculture, Ecosystems and Environment, 24, 307-316.

Walter DE, Proctor HC (1998) Feeding behaviour and phylogeny: observations on early derivative Acari. Experimental \& Applied Acarology, 22, 39-50.

Wardle DA, Yeates GW (1993) The dual system of competition and predation as regulatory forces in terrestrial ecosystems: evidence from decomposer food-webs. Oecologia, 93, 303306.

Weber DC, Lundgren JG (2009) Detection of predation using qPCR: Effect of prey quantity, elapsed time, chaser diet, and sample preservation on detectable quantity of prey DNA. Journal of Insect Science, 9, 12pp. Available online: insectscience.org/9.41

Wilson EO (2005) Oribatid mite predation by small ants of the genus Pheidole. Insect Sociaux, 52, 263-265.

Wu T, Ayres E, Bardgett RD, Wall DH, Garey JR (2011) Molecular study of worldwide distribution and diversity of soil animals. Proceedings of the National Academy of Sciences of the United States of America, 108, 17720-17725.

Yeates, GW (1979) Soil nematodes in terrestrial ecosystems. Journal of Nematology, 11, 213229.

Yeates GW, Bongers T, DeGoede RGM, Freckman DW, Georgieva SS (1993) Feeding-habits in soil nematode families and genera - an outline for soil ecologists. Journal of Nematology, 25, 315-331.

Yeates GW, Foissner W (1995) Testate amoebae as predators of nematodes. Biology and Fertility of Soils, 20, 1-7.

Yeates GW, Hawke MF, Rijkse WC (2000) Changes in soil fauna and soil conditions under Pinus radiata agroforestry regimes during a 25-year tree rotation. Biology and Fertility of Soils, 31, 391-406.

Yeates GW, Boag B (2004) Background for nematode ecology in the $21^{\text {st }}$ century. In: Chen ZX, Chen SY, Dickson DW, editors. Nematology, advances and perspectives. Vol. 1: Nematode morphology, physiology and ecology. Cambridge, MA. Tsinghua University Press and $\mathrm{CABI}$ Publishing. 
Yeates GW (2010) Nematodes in ecological webs. In: Encyclopedia of Life Sciences, pp. 111. Wiley \& Sons, Chichester.

Zaidi RH, Jaal Z, Hawkes NJ, Hemingway J, Symondson WOC (1999) Can multiple-copy sequences of prey DNA be detected amongst the gut contents of invertebrate predators? Molecular Ecology, 8, 2081-2087.

Zunke U, Perry RN (1997) Nematodes: harmful and beneficial organisms. In: Fauna in soil ecosystems (ed. Benckiser G), pp. 85-133. Marcel Dekker, New York. 


\section{Chapter 2}

\section{Molecular detection of nematode predation and scavenging in oribatid mites: Laboratory and field experiments}

Kerstin Heidemann, Stefan Scheu, Liliane Ruess, Mark Maraun

\section{Published in:}

Heidemann, K., Scheu, S., Ruess, L., Maraun M. (2011) Molecular detection of nematode predation and scavenging in oribatid mites: Laboratory and field experiments. Soil Biology \& Biochemistry 43, 2229-2236. 


\begin{abstract}
Recent stable isotope analyses indicate that a number of putative detritivorous soil microarthropods is not typical detritivores but rather live as predators or scavengers. Using molecular gut content analyses the present study investigates if nematodes indeed form part of the diet of oribatid mites. First, in a no-choice laboratory feeding experiment two nematode species (Phasmarhabditis hermaphrodita and Steinernema feltiae) were offered to eight species of oribatid mites and one gamasid mite. Second, after feeding for 4 and $48 \mathrm{~h}$ on each nematode species the detection time of prey DNA in the oribatid mite species Steganacarus magnus was investigated. Third, in a field experiment nematode prey ( $P$. hermaphrodita and $S$. feltiae) in the diet of microarthropods was investigated distinguishing between scavenging and predation. In the no-choice laboratory experiment not only the gamasid mite but also several of the studied oribatid mite species consumed nematodes. After feeding on nematodes for $4 \mathrm{~h}$ prey DNA was detectable in $S$. magnus for only $4 \mathrm{~h}$, but after feeding for $48 \mathrm{~h}$ prey DNA was detectable for $128 \mathrm{~h}$, indicating that the duration of feeding on prey is an important determinant for prey DNA detection. The field experiment confirmed that oribatid mite species including Liacarus subterraneus, Platynothrus peltifer and $S$. magnus intensively prey on nematodes. Interestingly, DNA of dead $P$. hermaphrodita was detectable to a similar degree as that of living individuals indicating that scavenging is of significant importance in decomposer food webs. Results of our study indicate that predation and scavenging on nematodes by "detritivorous" microarthropods in soil food webs need to be reconsidered.
\end{abstract}




\section{Introduction}

Predator-prey interactions are an important component of terrestrial food webs influencing population densities and energy fluxes through the system (Terborgh \& Estes 2010). Knowledge on predator-prey interactions is of prime importance for understanding aboveground as well as belowground food webs and for evaluating the relative importance of top-down forces in decomposer systems (Milton \& Kaspari 2007; Tylianakis et al. 2008). In contrast to aboveground systems, predator-prey interactions in belowground food webs are difficult to study since (1) trophic links are difficult to observe without disturbing the system, (2) most soil animals are small $(<1 \mathrm{~mm})$ and therefore direct observation is difficult, and (3) liquidfeeding hampers tracing the food in the gut (Symondson 2002; Read et al. 2006; Juen \& Traugott 2007).

Molecular methods may help to overcome these limitations (King et al. 2008). First, extraorally digested prey can be detected in the predator gut (Kuusk et al. 2008). Second, the investigation of the gut content of soil-living predators using specific primers allows distinguishing the prey at the level of species (Read et al. 2006; Juen \& Traugott 2007). Specific primers amplifying short DNA fragments allow detection of prey DNA in the gut of predators even days after prey consumption (Agusti et al. 1999; Zaidi et al. 1999; Hoogendorn \& Heimpel 2001). Using specific primers allows identifying the spectrum of predators of single species and thereby investigating the level of specialism vs. generalism in soil food webs. Molecular gut content analyses, however, also have limitations. One particular weakness is that predation, i.e. feeding on living prey, cannot be separated from scavenging (Juen \& Traugott 2005) and from secondary predation, i.e. the feeding of a predator by another predator (Sheppard et al. 2005). One of the first important studies using molecular markers for the detection of nematode DNA in predator guts was carried out by Read et al. (2006) who developed specific primers for three nematode species (Phasmarhabditis hermaphrodita, Steinernema feltiae, Heterorhabditis megidis).

Nematodes hold a key position in soil food webs (Yeates et al. 1993; Bongers \& Ferris 1999; Moore et al. 2003), little is known on their role as prey for other soil animals and to what extent their density is controlled by predators. They are among the most diverse and abundant animals on earth (Baxter 2003). Nematodes live not only as parasites in animals and plants, but also freely in aquatic and soil systems, where they can reach densities of up to several million individuals and up to 100 species per square meter (Yeates et al. 2000). In soil they feed on bacteria, fungi, algae, invertebrates, plants or are omnivorous, and, due to their generally high density, they form an important food source for other soil animals (Yeates et al. 1993; Read et al. 2006). 
Mites (Acari) also reach high diversity and density in soil systems (Maraun \& Scheu 2000) comprising not only "classical detritivores", such as Oribatida, but also predators, such as Gamasina and Uropodina. Laboratory studies (Muraoka \& Ishibashi 1976) as well as stable isotope analyses (Schneider et al. 2004) indicate that several species of oribatid mites can live also predatory, most likely on nematodes. Gamasid mites are free-living, motile, liquid-feeding predatory mites (Koehler 1997). They are assumed to be generalist predators that feed on a variety of prey including nematodes. Uropodid mites live in soil where they mainly consume not only nematodes, but also slugs, insect larvae and dead animals (Karg 1989; Raut \& Panigrahi 1991; Scheu \& Falca 2000).

The aims of this study were to investigate (1) if soil mite species (mainly from the taxa Oribatida, but also Gamasina and Uropodina) feed on nematodes, (2) if the nematode species are consumed to a different degree, (3) the detection time of prey DNA after different time periods of feeding by Steganacarus magnus, (4) the relevance of laboratory feeding experiments for understanding trophic interrelationships in the field, and (5) the relevance of predation and scavenging in soil food webs, i.e. if microarthropod predators discriminate between dead and living prey. Therefore, laboratory no-choice feeding experiments were established using the two model nematode species $S$. feltiae and $P$. hermaphrodita. In the laboratory, nematodes were offered separately to investigate if the studied mite species differentially feed on nematode species. To determine the detection time of prey DNA $S$. magnus was fed with each nematode species for $4 \mathrm{~h}$ and $48 \mathrm{~h}$. To prove the validity of the results of the laboratory studies in the field the two nematode species were added to the soil of a beech forest. Each species was added dead and alive to separate the role of scavenging and predation for soil mite nutrition. Low natural abundance of the added model nematodes in field soil allowed separating them from the resident nematode community. We hypothesized that a large number of mite species, including putatively detritivorous taxa such as oribatid mites feed on nematodes in the field.

\section{Material and methods}

\subsection{The organisms}

Infective juveniles (dauerlarvae) of two pathogenic nematode species were used for this study. The infective non-feeding third stage of the rhabditid $P$. hermaphrodita (Schneider, 1859) has a length of $\sim 1 \mathrm{~mm}$. $P$. hermaphrodita is a parasitic bacterivore that infects the mantle of slugs where it reproduces and kills the slug before the new larvae are spread to the soil. The entomopathogenic $S$. feltiae (Filipjev, 1934) dauerlarvae has a length of w0.8mm and 
parasitizes the hemocoel of sciarid and drosophilid larvae. Juveniles of both species search in soil for new hosts. $P$. hermaphrodita and S. feltiae are cosmopolitan species; however, their density in the field is low. At the studied beech forest they could not be detected by standard soil sampling and nematode extraction making them ideal model prey species as there are no background signals in nematode consumers (K. Heidemann, unpubl. data). Both nematode species were supplied by 'prime factory' (www.schneckenprofi.de, Hennstedt, Germany). They are able to survive in soil for several weeks which is more than sufficient for the purpose of our experiment (Kaya \& Gaugler 1993).

Three mite taxa, i.e. Oribatida, Gamasina and Uropodina, were studied as potential predators for the two nematode species. In the laboratory experiment the gamasid mite Hypoaspis aculeifer (Canestrini, 1883) and eight oribatid mite species were included: Achipteria coleoptrata (Linné, 1758), Atropacarus striculus (Koch, 1835), Carabodes coriaceus Koch, 1835, Damaeus riparius Nicolet, 1855, Eupelops plicatus (Koch, 1835), Hypochthonius rufulus Koch, 1835, Steganacarus magnus (Nicolet, 1855) and Archegozetes longisetosus Aoki, 1965. In the field experiment the gamasid mite Pergamasus septentrionalis (Oudemans, 1902), the uropodid mite Uropoda cassidea (Hermann, 1804) and seven species of oribatid mites were investigated: Chamobates voigtsi (Oudemans, 1902), Liacarus subterraneus (Koch, 1844), Platynothrus peltifer (Koch, 1839), Nothrus silvestris Nicolet, 1855 and S. magnus. All species are inhabitants of European forest soils except $A$. longisetosus which is tropical and was included as it is the most frequently cultured oribatid mite species.

\subsection{The study site}

The Kranichstein forest is an oak-beech forest near Darmstadt, Hesse, Germany. The annual temperature is $9.5^{\circ} \mathrm{C}$ and the annual precipitation is about $700 \mathrm{~mm}$. Soil pH is $3.6-4.3$ and the humus form is moder. The tree layer is dominated by beech (Fagus sylvatica, L.); parent rock is Cisuralian (Rotliegendes, Early Permian; Schneider et al. 2007).

\subsection{Test of primer specificity}

Both nematode primer pairs used were tested against 16 non-target species by Read et al. (2006). Additionally, we tested them against further 74 non-target species (Table S1, Supporting information), including the 15 mite species used in this study. The animals were starved for seven days and stored separately at $-80^{\circ} \mathrm{C}$ in $180 \mathrm{~mL}$ ATL-Buffer of the extraction 
kit DNeasy ${ }^{\circledR}$ Blood \& Tissue Kit (Qiagen GmbH, Hilden, Germany). After DNA extraction the mesofauna taxa were tested with the D3 primers, and the macrofauna taxa with general COI primers (Folmer et al. 1994), to check success of the DNA extraction. The specific primers for $P$. hermaphrodita and $S$. feltiae were used in a PCR with the non-target taxa and with the respective nematode species as positive control to check for cross-reactions.

\subsection{Detection time of prey in consumers}

Detection time of prey DNA in consumers was investigated using the oribatid mite $S$. magnus which were extracted from soil of the Göttinger forest and the Hainich forest. All individuals were starved for seven days. The two nematode species ( $S$. feltiae, $P$. hermaphrodita) were offered separately to 20 individuals of $S$. magnus for 4 and $48 \mathrm{~h}$. Afterward mites were checked for attached nematodes and starved for 0, 2, 4, 8, 16, 32, 64 and $128 \mathrm{~h}$. After these time periods we checked if mites were alive to avoid false negatives, and stored individual mites separately at $-80^{\circ} \mathrm{C}$ in $180 \mathrm{~mL}$ ATL-Buffer of the extraction kit DNeasy ${ }^{\circledR}$ Blood \& Tissue Kit (Qiagen $\mathrm{GmbH}$, Hilden, Germany). During the experiment mites were kept in darkness at $13^{\circ} \mathrm{C}$.

\subsection{Laboratory experiment}

Seven oribatid mite species were extracted from soil of the Kranichstein forest whereas $A$. longisetosus (Oribatida) and $H$. aculeifer (Gamasid mites) were taken from laboratory cultures. All species were starved for four days. The nematode species were offered separately to eight oribatid mites and one gamasid mite. The latter was included to compare the feeding of a wellknown predator with putative detritivorous species. After four days of feeding, mites were checked for attached nematodes; no nematodes were found. Subsequently, the mites were placed separately in $96 \%$ ethanol and stored at $-20{ }^{\circ} \mathrm{C}$. Five replicates were run for each predator species on each nematode species, except $A$. longisetosus and $D$. riparius (only four replicates for $P$. hermaphrodita) and $H$. rufulus (only three replicates for $P$. hermaphrodita). As controls, five individuals of each species were starved and tested using the specific primers to prove that there was no contamination in the handling of the samples. 


\subsection{Field experiments}

To separate between predation and scavenging two field experiments were established. In the first experiment each of two replicates of $1 \mathrm{~m}^{2}$ received 4 million living $P$. hermaphrodita and four million dead $S$. feltiae in November 2007 (average air temperature of $7-8^{\circ} \mathrm{C}$ ); in the second experiment each of two replicates received 4 million dead $P$. hermaphrodita and 4 million living $S$. feltiae. The nematodes were applied to the natural soil animal community in a water solution ( 1 I for each species) using a watering can. Nematodes were killed by freezing at $-80^{\circ} \mathrm{C}$ for two days prior to application and were used as "dead nematodes" in the experiment.

After $48 \mathrm{~h}$ the litter of each plot was collected and soil mites were extracted by heat for $\sim 6$ h (Kempson et al. 1963). The mites were checked for attached nematodes which were never found. In the following $3 \mathrm{~h}$ the most abundant large mite species were collected, washed inwater for $1 \mathrm{~min}$ and stored separately at $-80^{\circ} \mathrm{C}$ in $180 \mathrm{~mL}$ ATL-Buffer of the extraction kit DNeasy ${ }^{\circledR}$ Blood \& Tissue Kit (Qiagen GmbH, Hilden, Germany). Overall, the time between the sampling of the species in the field and the freezing was about $10 \mathrm{~h}$.

\subsection{Bipartite network analysis}

For a visualization of the predator-prey interactions between the mites and the nematodes from the field experiment, the links were graphically presented in a network using the package 'bipartite' (Dormann et al. 2008) in the program R (R Development Core Team 2009). Negative observations, i.e. no detection of feeding on any of the two nematode species (irrespective if they were dead or alive), were pooled for this figure.

\subsection{DNA extraction, PCR and sequencing}

DNA from whole individuals of soil microarthropods was extracted following the protocol of the DNeasy ${ }^{\circledR}$ Blood \& Tissue Kit (Qiagen). To verify the success of the DNA extractions and to confirm predator species identity a PCR with D3 primers amplifying a 320 bp fragment of the $28 S$ rDNA was performed with every sample (Maraun et al. 2003). Negative samples were excluded from the study.

Detection of nematode DNA followed the modified protocol established by Read et al. (2006). In short, a PCR with the specific nematode primers developed by Read et al. (2006) 
[Sf-F-1896 (forward primer) 5'-TTT AGG CCA TCC TGG AAA GAG G-3'; Sf-R-2080 (reverse primer) 5'-GCT AAA ACC GGT AAA GAA AG-3'] amplified a 203 bp fragment of the cytochrome oxidase I (COI) region. The PCR for the detection of $P$. hermaphrodita [Ph-F-1754 (forward primer) 5'-TGG GCG CCC CTG ATA TAA GAT-3'; Ph-R-1887 (reverse primer) 5'CGG ATG ACC AAG GGT ACT TAA T-3'] amplified a 203 bp and a 154 bp fragment (primer sequences are given in detail since the orientation of the two reverse primers is wrong in Read et al. 2006).

PCRs with D3 primers and specific nematode primers were carried out as follows: PCR contained $1 \mathrm{~mL}$ (concentration $100 \mathrm{pmol} \mathrm{mL}^{-1}$ ) of each primer (Operon/Eurofins, Ebersberg, Germany), $1 \mathrm{~mL}$ of BSA (3\%), $1 \mathrm{~mL}$ of $25 \mathrm{mMMgCl} 2$ (Fermentas, St. Leon-Rot, Germany), 12.5 $\mathrm{mL}$ of HotStarTaq ${ }^{\circledR}$ Master Mix Kit (Qiagen) including polymerase, $2.5 \mathrm{~mL}$ template DNA and were filled up to $25 \mathrm{~mL}$ with RNase free water. Thermal cycle parameters included an initial denaturation step of $10 \mathrm{~min}$ at $95^{\circ} \mathrm{C}$ followed by 35 cycles of $95^{\circ} \mathrm{C}$ for $30 \mathrm{~s}$, the respective annealing temperature $\left(56^{\circ} \mathrm{C}\right.$ for $S$. feltiae and $58^{\circ} \mathrm{C}$ for $P$. hermaphrodita) for $45 \mathrm{~s}$ and $72^{\circ} \mathrm{C}$ for $30 \mathrm{~s}$, and a final extension stage of $72^{\circ} \mathrm{C}$ for $10 \mathrm{~min}$. The PCR products were visualized on a $1 \%$ agarose gel. Positive samples were sequenced by Macrogen Inc. (Seoul, South Korea).

\subsection{Statistical analysis}

For the laboratory experiment a logistic regression (Hosmer \& Lemeshow 1989; Sokal \& Rohlf 1995) was used to test (i) if the mite species differently consumed the nematode prey offered, and (ii) if one of the two nematode species offered was generally preferred over the other. In the field experiment a logistic regression was used to analyze (i) if the mites selectively consumed one of the two nematode species, (ii) if dead nematodes were preferred over living ones (or vice versa), and (iii) if the mite species differentially fed on the two nematode species. The analyses were carried out for each treatment separately using SAS 9.13 (SAS Institute Inc., Cary, USA). Subsequently, mean and standard derivations of nematode detection rates were calculated by using the package 'simpleboot' in R (Simple Bootstrap Routines. Rpackage version 1.1e3; Roger D. Peng, 2008; R Development Core Team 2009). Additionally, $95 \%$ confidence limits were calculated by 9999 bootstrap resamples for each predator feeding on a certain prey. 


\section{Results}

\subsection{Test of primer specificity}

The non-target test of 74 species with the primers for $P$. hermaphrodita showed no crossreactions (Table 1; Supporting material) indicating that this primer pair is very specific. In contrast to Read et al. (2006), the non-target test with the primers for $S$. feltiae showed crossreactions for the following 12 species: Uroseius cylindricus (Berlese, 1916), Lithobius aulacopus Latzel, 1880, Lithobius lapidicola Meinert, 1872, Lithobius muticus (Koch, 1847), Lithobius crassipes Koch, 1862, Neanura muscorum (Templeton, 1835), Philonthus carbonarius (Gravenhorst, 1802), Polydesmus complanatus (Linnaeus, 1761), Glomeris sp., Porcellio sp., Trichoniscus pusillus Brandt, 1833 and Aporrectodea caliginosa (Savigny, 1826). However, the primers showed no cross-reaction with the mite predators used in our study. It can therefore be assumed that the positive cross-reactions are not relevant for our study. We sequenced about $50 \%$ of all positive prey bands and never found any of the above species in the gut of the mite species.

\subsection{Detection time of prey DNA in consumers}

Immediately after the end of the $48 \mathrm{~h}$ feeding trial $100 \%$ of the individuals of $S$. magnus that were offered $P$. hermaphrodita were tested positive for the nematode DNA. This high percentage declined during the post-feeding phase to about $20 \%$ after $128 \mathrm{~h}$ (Fig. 1a). In contrast, immediately after the end of the $4 \mathrm{~h}$ feeding trial only $55 \%$ of the individuals of $S$. magnus that were offered $P$. hermaphrodita were tested positive for nematode DNA. This number declined during the post-feeding phase to $5 \%$ after $4 \mathrm{~h}$; later no prey DNA was detectable anymore (Fig. 1b).

Prey DNA detection of $S$. feltiae was generally less frequent than that of $P$. hermaphrodita. Immediately after the end of the $48 \mathrm{~h}$ feeding trial $100 \%$ of the individuals of $S$. magnus that were offered $S$. feltiae were tested positive for the nematode DNA. This number declined quickly during the early post-feeding phase to about $20 \%$ after $4 \mathrm{~h}$, however, prey DNA could still be detected $128 \mathrm{~h}$ post feeding (Fig.1c). Immediately after the end of the $4 \mathrm{~h}$ feeding trial no individuals of $S$. magnus were tested positive for nematode DNA (Fig. 1d). 
a)

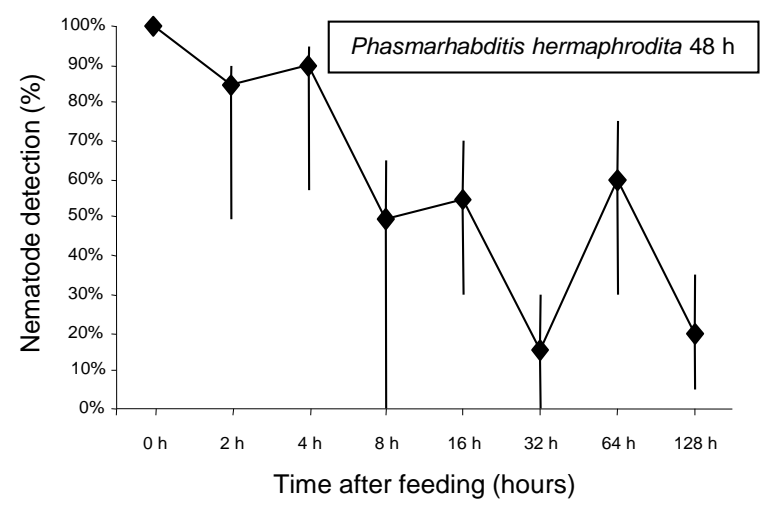

c)

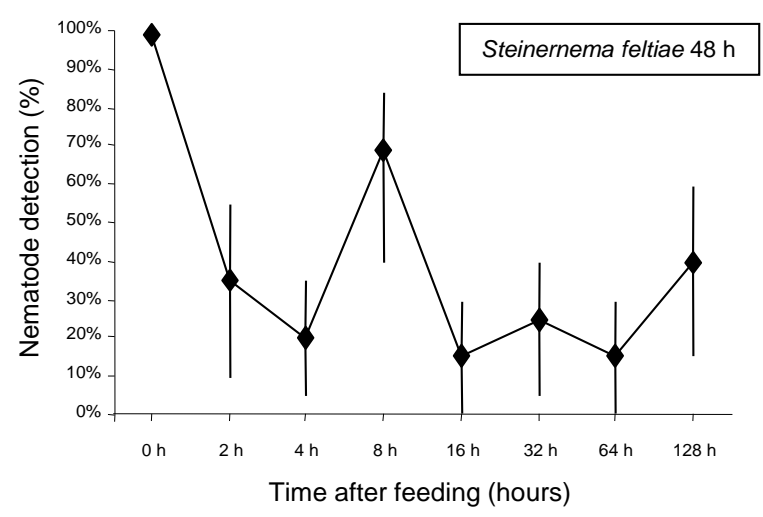

b)

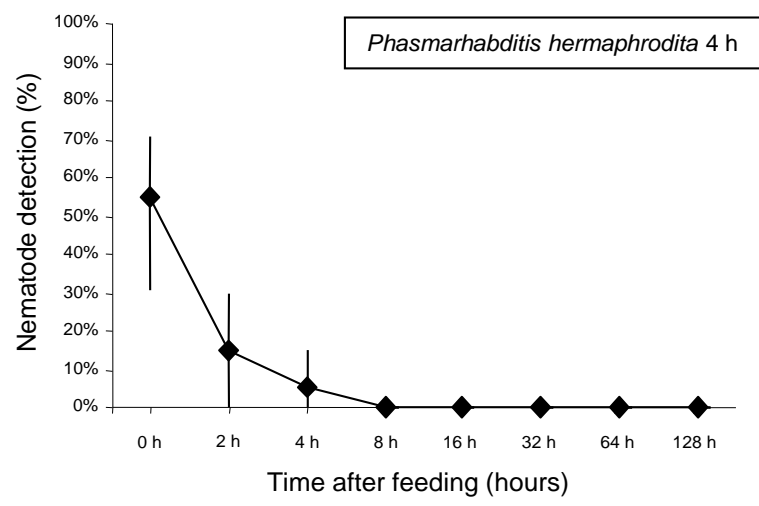

d)

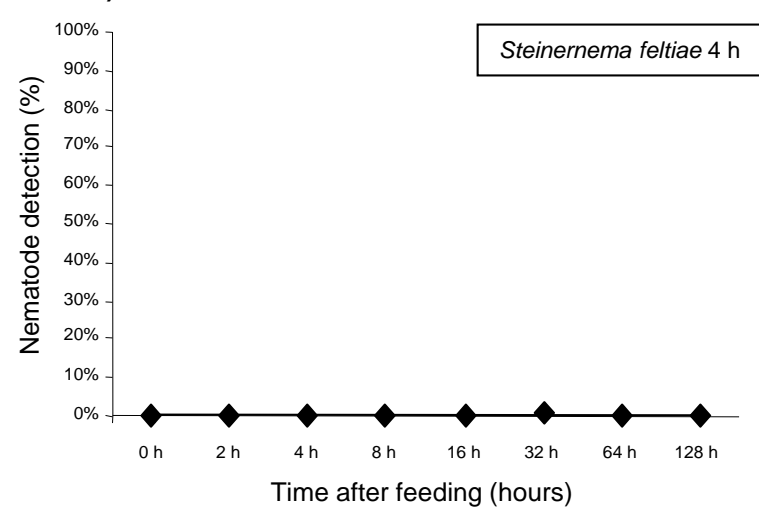

Figure 1: Detectability of Steinernema feltiae and Phasmarhabditis hermaphrodita DNA (part of the COI gene) in the gut of Steganacarus magnus after $0,2,4,8,16,32,64$ and $128 \mathrm{~h}$ after feeding. The mites were fed for $48 \mathrm{~h}(\mathrm{a}, \mathrm{c})$ and for $4 \mathrm{~h}(\mathrm{~b}, \mathrm{~d})$ with the two nematode species. 20 individuals of $S$. magnus were tested per time-point. Data represent percentages of mite individuals in which nematode DNA were detected. The upper and lower confidence limits are indicated as error bars; for statistical analysis see text.

\subsection{Laboratory experiment}

Positive detection of nematode DNA in predator gut (in the following termed 'feeding' or 'consumption') significantly differed between mite species $\left(X^{2}=31.8\right.$, df $=8, P<0.0001$; Fig. 2). Feeding on the two nematode species generally did not differ significantly $\left(X^{2}=0.56, d f=\right.$ $1, P>0.05)$. All individuals of the oribatid mite species $D$. riparius and $S$. magnus consumed the nematode $P$. hermaphrodita; the other nematode species, $S$. feltiae, was only consumed occasionally by these two mite species. A. longisetosus preyed occasionally on $P$. 
hermaphrodita, but consumed S. feltiae in all cases studied. $H$. aculeifer preyed occasionally on both nematode species ( $40 \%$ on $P$. hermaphrodita and $20 \%$ on S. feltiae). Only $20 \%$ of the investigated $A$. striculus consumed $P$. hermaphrodita but never $S$. feltiae, and $H$. rufulus occasionally consumed $S$. feltiae ( $40 \%$ of the tested individuals) but never $P$. hermaphrodita. A. coleoptrata, C. coriaceus and E. plicatus were not tested positive for any of the two offered nematode species.

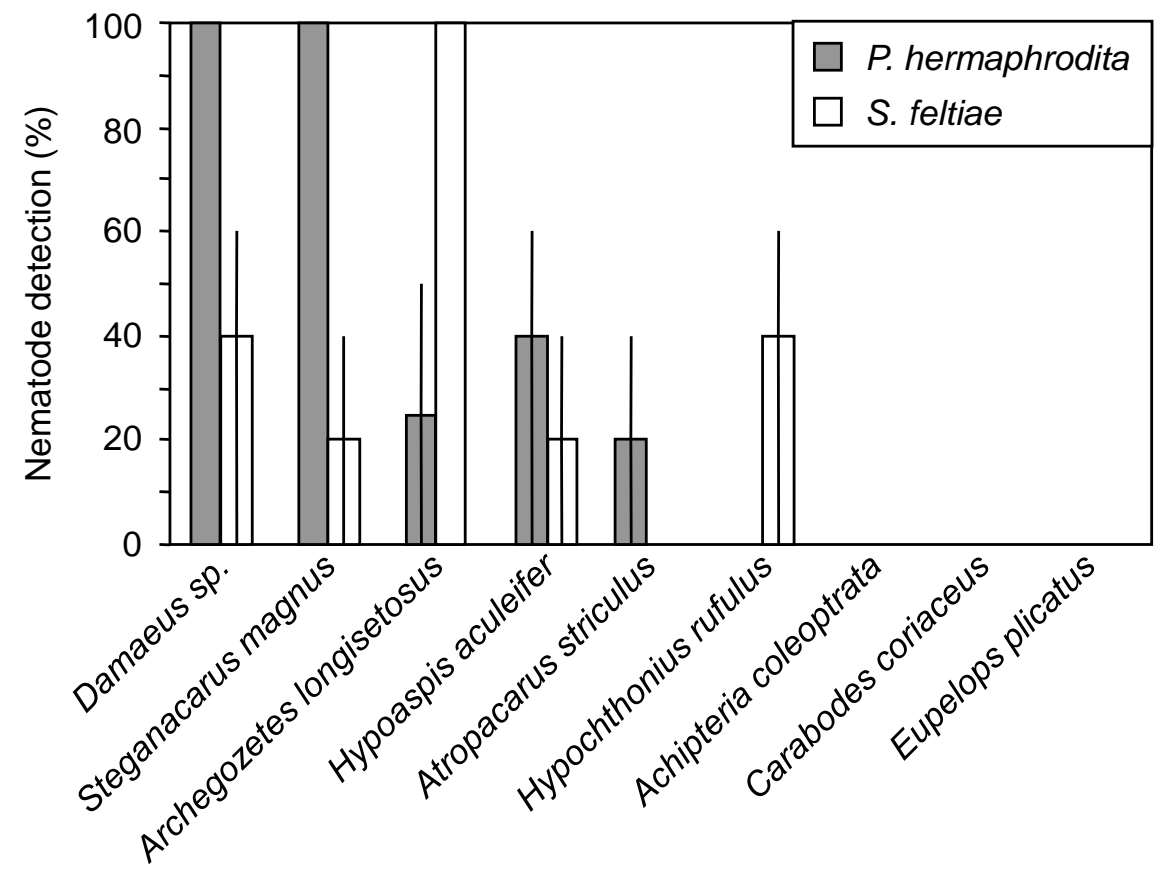

Figure 2: Detection of Steinernema feltiae and Phasmarhabditis hermaphrodita in the gut of nine mite species in no-choice laboratory experiments using part of the COI gene as molecular marker. Data represent percentages of mite individuals in which nematodes had been detected in the gut. The upper and lower confidence limits are indicated as error bars; for statistical analysis see text.

\subsection{Field experiments}

\subsubsection{Experiment with living P. hermaphrodita and dead S. feltiae}

DNA of the living $P$. hermaphrodita was more frequently detected in all studied mite species than that of the dead $S$. feltiae $\left(X^{2}=92.98\right.$, df $=1, P<0.0001$; Fig. 3a). The analyzed mite species fed differently on the two nematode species $\left(X^{2}=107.74\right.$, $\left.d f=6, P<0.0001\right)$, and consumption tended to vary between the two nematode species $\left(X^{2}=18.36\right.$, df $=6, P<$ 0.054). Of the tested individuals of the gamasid mite $P$. septentrionalis $66 \%$ fed on the living 
( $P$. hermaphrodita) and $32 \%$ on the dead nematode species (S. feltiae).U. cassidea fed frequently on $P$. hermaphrodita (85\%) and somewhat less on $S$. feltiae (55\%). Of the investigated individuals of $L$. subterraneus $85 \%$ fed on $P$. hermaphrodita and $92 \%$ on $S$. feltiae. A total of $40 \%$ of $P$. peltifer and $61 \%$ of $N$. silvestris preyed on the living nematode species and only $3 \%$ of $P$. peltifer on $S$. feltiae. No consumption of the dead nematode species was detected in N. silvestris and S. magnus. S. magnus only fed on P. hermaphrodita (39\% of the tested individuals). Of the tested individuals of $C$. voigtsi $43 \%$ preyed on $P$. hermaphrodita and only $10 \%$ on $S$. feltiae.

\subsubsection{Experiment with dead P. hermaphrodita and living S. feltiae}

The dead nematode species was more frequently consumed by all mite species than the living one $\left(X^{2}=92.85, \mathrm{df}=1, \mathrm{P}<0.0001\right.$; Fig. $\left.3 b\right)$. The analyzed mite species fed differently on the two nematode species $\left(X^{2}=57.66 ; d f=6 ; P<0.0001\right)$, and consumption varied between the two nematode species $\left(X^{2}=12.80, \mathrm{df}=6, P<0.0463\right)$. The gamasid mite $P$. septentrionalis fed frequently (67\% of the tested individuals) on the dead ( $P$. hermaphrodita) and less $(24 \%)$ on the living nematode species (S. feltiae). The uropodid mite (U. cassidea) only consumed $P$. hermaphrodita (about $25 \%$ of the individuals) and never the living $S$. feltiae. The oribatid mites L. subterraneus, S. magnus and C. voigtsi fed frequently on $P$. hermaphrodita (100, 67 and $18 \%$, respectively), but never the living nematode species. A total of $30 \%$ of the tested individuals of $P$. peltifer and $30 \%$ of $N$. silvestris consumed the dead nematode species and less the living one ( $7 \%$ and $6 \%$, respectively). 
a)
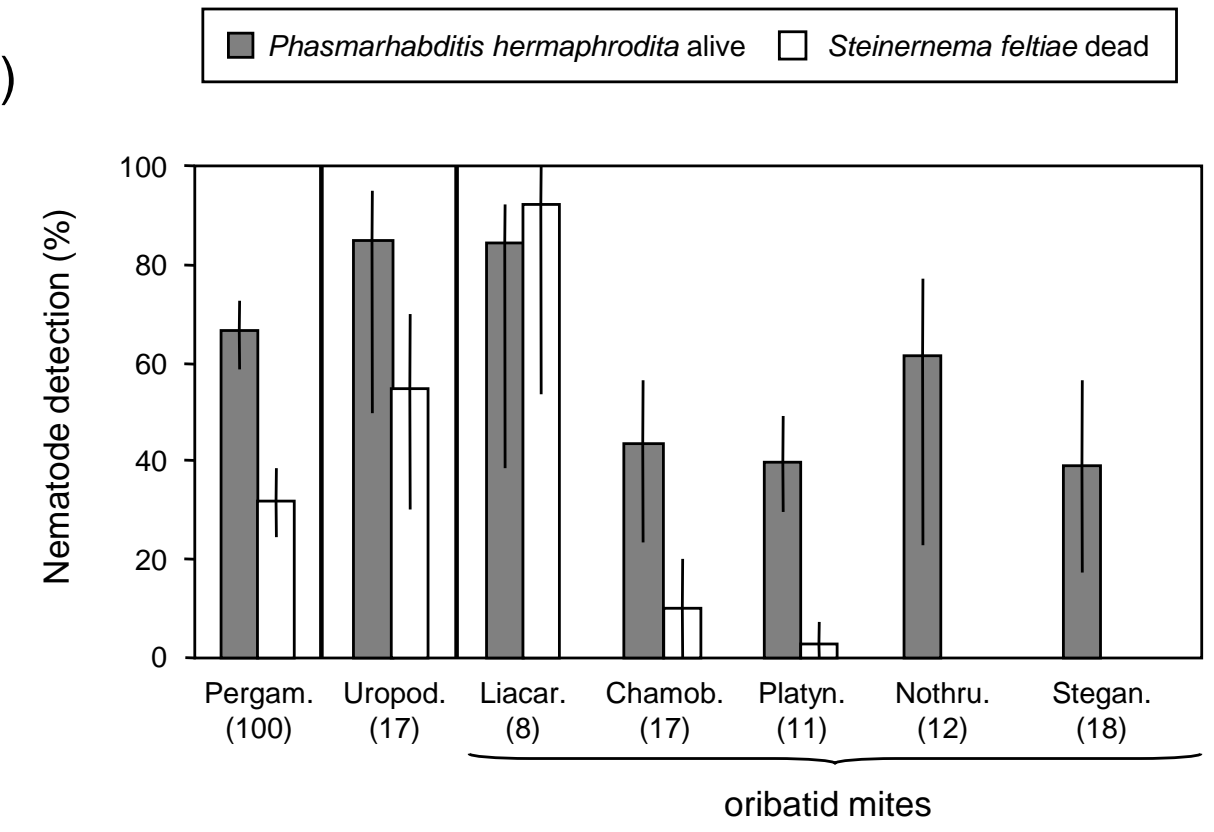

b)
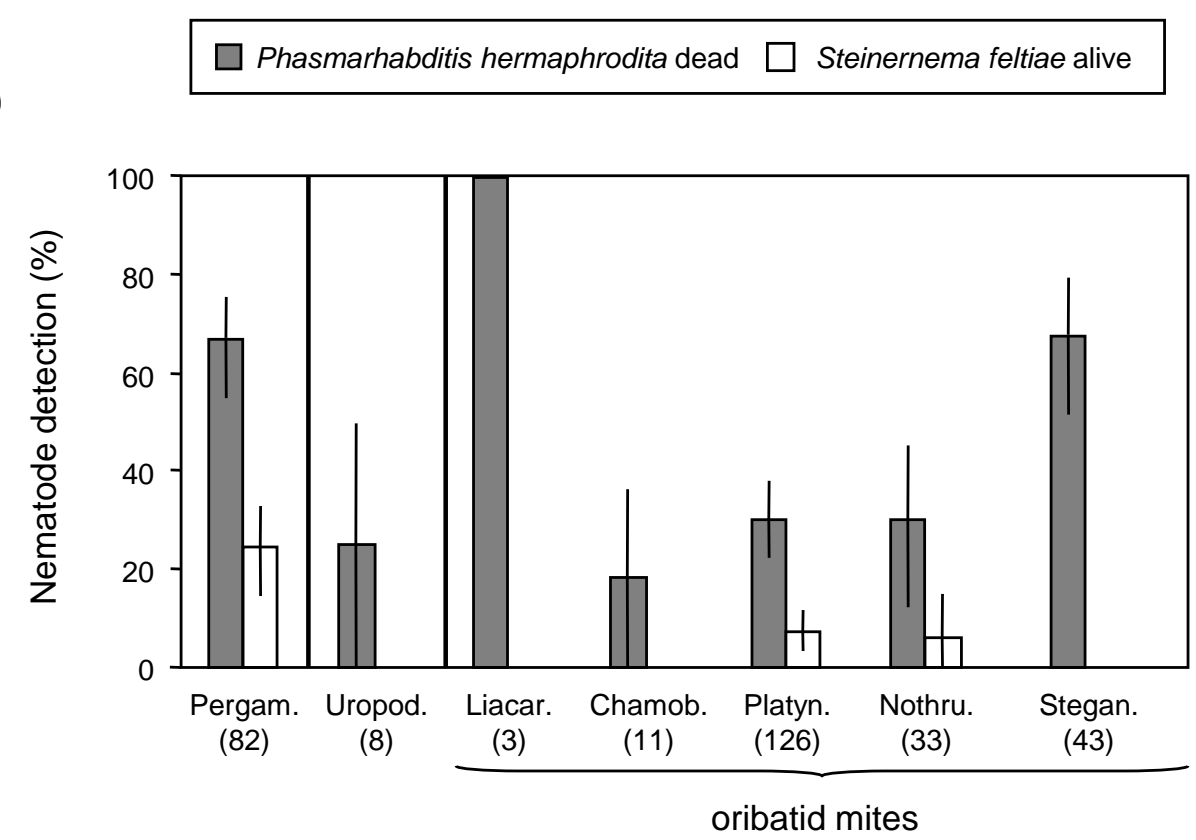

Figure 3: Detection of (a) living Phasmarhabditis hermaphrodita and dead Steinernema feltiae and (b) living Steinernema feltiae and dead Phasmarhabditis hermaphrodita in the gut of seven mite species (Pergam. = Pergamasus septentrionalis, Uropod. = Uropoda cassidea, Liacar. = Liacarus subterraneus, Platyn. $=$ Platynothrus peltifer , Nothru.$=$ Nothrus silvestris, Stegan. $=$ Steganacarus magnus, Chamob. = Chamobates voigtsi) in the field using part of the COI gene as molecular marker. Data represent percentages of mite individuals in which nematodes were detected in the gut (the number of tested individuals is given in brackets). The upper and lower confidence limits are indicated as error bars; for statistical analysis see text. 


\subsection{Bipartite network}

The bipartite network shows that living $P$. hermaphrodita were more frequently consumed than dead $P$. hermaphrodita and dead $S$. feltiae; living $S$. feltiae were hardly consumed by any mite species (Fig. 4). Feeding on nematodes was most pronounced in the gamasid mite $P$. septentrionalis and less pronounced in uropodid and oribatid mite species. In a number of cases the mite species did not feed on the nematode species offered.

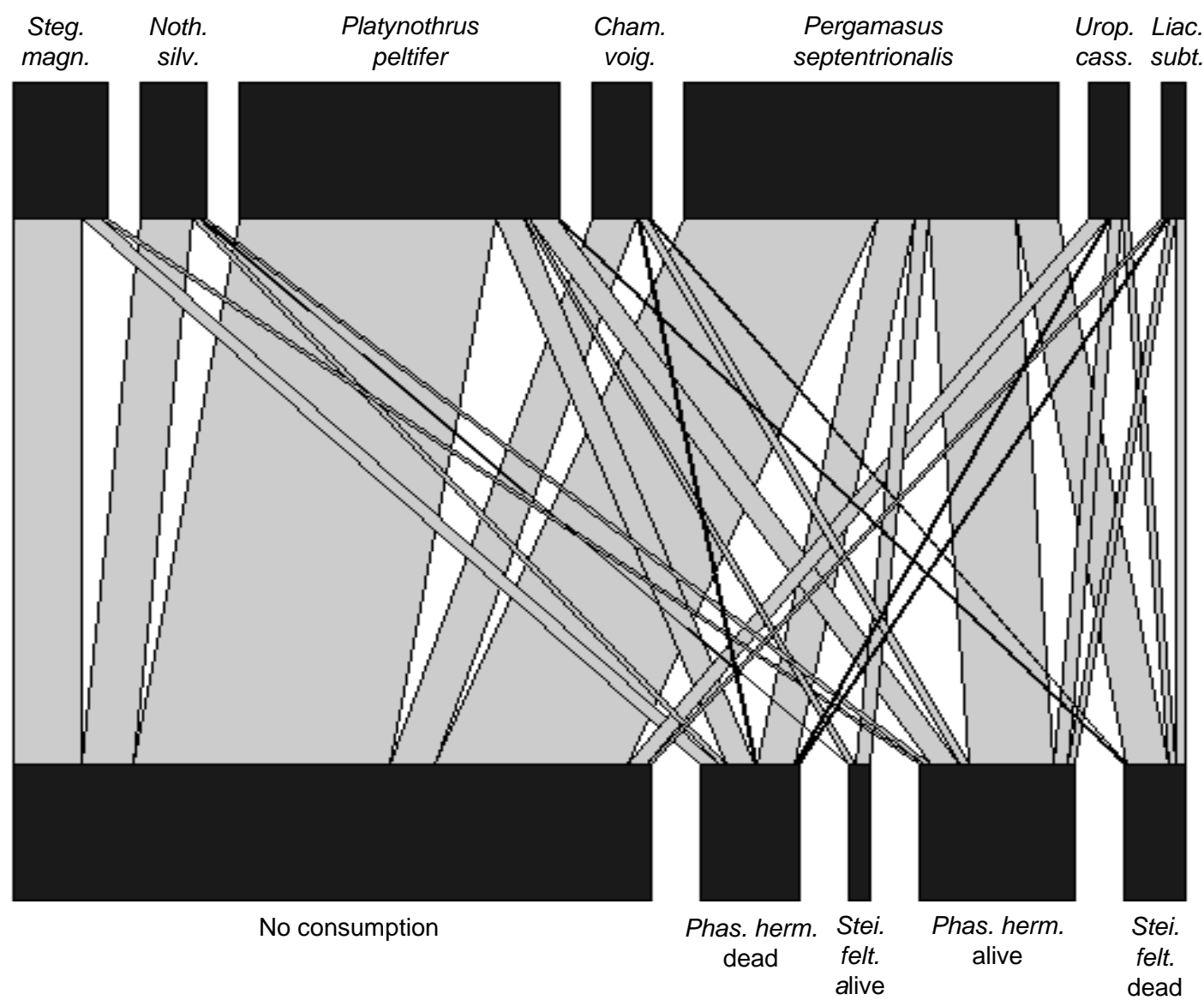

Figure 4: Visualization of predator-prey interactions as observed in the field experiment between seven mite species (Steg. magn. = Steganacarus magnus, Noth. silv. = Nothrus silvestris, Cham. voig. = Chamobates voigtsi, Urop. cass. $=$ Uropoda cassidea, Liac. subt. $=$ Liacarus subterraneus) and two nematode species $($ Phas. herm. $=$ Phasmarhabditis hermaphrodita, Stei. felt. $=$ Steinernema feltiae) using the R-package 'bipartite'. Upper bars represent the relative proportion of the respective taxa of the total number of investigated mite individuals. Lower bars represent the relative proportion of the consumed (or non-consumed) nematodes of all gut content measurements tested by PCR. 


\section{Discussion}

\subsection{Nematode predation in the field}

Our findings indicate that typical detritivore microarthropods such as certain oribatid mite species indeed consume nematodes and thereby function as predators. Based on direct observations (Riha 1951) and stable isotope ratios (Pollierer et al. 2009) this has been hypothesized before but our data for the first time proof that it is indeed true in the field. These findings have major implications for the structure and functioning of detritivore food webs, e.g. they suggest that grouping of oribatid mites as single trophic/functional group is inadequate and that species identity matters for understanding soil food web dynamics. Using molecular markers Read et al. (2006) proved another abundant soil mesofauna group, Collembola (Isotoma viridis, Isotomurus palustris), to also feed on nematodes in the field suggesting that many putative detritivores in fact function as predators or scavengers.

Several of the oribatid mite species studied frequently consumed nematodes including $L$. subterraneus, $P$. peltifer and $S$. magnus even though they could have selected different food in the field. Other species of the genus Liacarus have been observed to feed on nematodes (Muraoka \& Ishibashi 1976) but stable isotope analysis suggests that they predominantly live as detritivores (Schneider et al. 2004). The same applies to P. peltifer and S. magnus. Presumably, these species are opportunistic feeders that also feed on nematodes. N. silvestris and $C$. voigtsi only occasionally fed on nematodes suggesting that these species predominantly feed on fungi and dead organic matter as assumed previously (Pande \& Berthet 1973; Muraoka \& Ishibashi 1976; Schneider et al. 2004).

As expected the predatory gamasid and uropodid mites, P. septentrionalis and U. cassidea, consumed nematodes whether dead or alive, supporting the hypothesis that they function as predators and scavengers in belowground systems (Peschel et al. 2006; Walter \& Proctor 1998).

Overall our results suggest that $P$. hermaphrodita was more frequently consumed than $S$. feltiae. This can be due to behavioural differences since infective juveniles of pathogenic nematodes use different dispersal patterns to find their hosts. $P$. hermaphrodita performs cruise foraging, i.e. moves actively in search for hosts (MacMillan et al. 2009) whereas host finding of S. feltiae follows a sit and wait strategy (Susurluk 2009). These differences are likely to affect encounter rates with predators and the outcome of predator-prey interactions. Secondly, entomopathogenic nematodes such as $S$. feltiae contain specific symbiotic bacteria, necessary to kill the insect host. The symbiont of $S$. feltiae is the gram-negative bacterium Xenorhabdus bovienii (Kaya \& Gaugler 1993). This bacterium produces metabolites, such as 
antibiotics or intercellular protein crystals, and several Xenorhabdus strains have been observed to be toxic to Acari, e.g. the mushroom mite Luciaphorus sp. (Bussaman et al. 2006). Unlike entomopathogenic nematodes the snail-parasitic P. hermaphrodita is not associated with symbiotic bacteria. Frequently, Moraxella osloensis is present but it is unknown if this bacterium affects nematode predation (Tan \& Grewal 2001). Overall, the presence of mutualistic bacteria producing insect toxins likely has affected the use of $S$. feltiae as food source negatively.

\subsection{Scavenging}

By feeding on animal carcasses scavengers live on an easy available energy-rich resource that does not defend itself (Foltan et al. 2005). From a matter flux perspective scavenging and predation differ little. However, in contrast to predation, scavenging does not contribute to population regulation of the species consumed. Therefore, from a food web perspective differentiating between predation and scavenging is essential. In molecular gut content analyses predation and scavenging are difficult to separate (Juen \& Traugott 2005). By using two similar prey species and offering the one dead and the other alive this problem can be resolved. Adopting this approach we separated for the first time between scavenging and predation under field conditions.

A large number of microarthropods including several typical primary detritivorous species had nematode DNA from dead nematodes in their guts indicating that scavenging is important in soil food webs and that dead animals may be an important component of their diet. Scavenging has only rarely been studied using molecular gut content analyses (Foltan et al. 2005). High incidence of scavenging in some species of oribatid mites may explain the high stable isotope signatures in these species (Schneider et al. 2004). Interestingly, dead $P$. hermaphrodita were intensively consumed whereas dead $S$. feltiae were only consumed rarely. This indicates that mites selectively feed on the two species even if they are dead, and that the defense mechanisms of $S$. feltiae against predation, likely mediated by the symbiotic bacterium $X$. bovienii, continue to function in dead specimens.

Secondary predation can be an important problem in the field when using PCR because of the high sensitivity of the method (Sheppard et al. 2005). However, as the two studied nematode species are rather large and the exposure in the field was short secondary predation unlikely contributed to the observed prey DNA in consumers as oribatid mites are unlikely to be able to overdo consumers of the nematode species used. 


\subsection{Detection time of prey DNA}

Prey DNA detection was still possible after $128 \mathrm{~h}$ post feeding in the trials where nematodes were offered for $48 \mathrm{~h}$ to $S$. magnus. Previous studies also found long detection times for invertebrate prey (Zaidi et al. 1999; Agusti et al. 2003; Sheppard et al. 2005). This indicates that prey can still be detected in the predator with molecular methods after a rather long period of time, much longer than $10 \mathrm{~h}$ heat extraction and collection as in our field trial. This implies that the detection rates of prey DNA in mites from our study represent the lower limit of feeding events. Prey DNA detection was rare or impossible after $128 \mathrm{~h}$ post feeding in the trials where nematodes were offered for only $4 \mathrm{~h}$ to $S$. magnus indicating that it takes a certain period of time to handle and ingest the nematodes.

Overall, the detection time for $P$. hermaphrodita was much longer than that of $S$. feltiae indicating that either $S$. feltiae is digested faster than $P$. hermaphrodita or that $S$. feltiae is consumed less frequently than $P$. hermaphrodita. We assume the later to be more likely since S. feltiae DNA was not detectable after exposure to prey for $4 \mathrm{~h}$ but was detected in $100 \%$ of the individuals of $S$. magnus exposed to prey for $48 \mathrm{~h}$. Generally, prey detection time depends on prey species, predator species, temperature, the length of the amplified fragments and other factors. Additionally, it has to be noted that DNA in dead individuals already starts degenerating before it is ingested affecting DNA detection time.

\subsection{Laboratory experiment}

Results of the laboratory feeding experiment indicate that some oribatid mite species $(D$. riparius, $S$. magnus, $A$. longisetosus) frequently consume nematodes, whereas others $(A$. striculus, $H$. rufulus) at least occasionally consume nematodes. $D$. riparius is known to consume fungi (Maraun et al. 1998); feeding on nematodes had not been observed before. $A$. longisetosus is a tropical oribatid mite that occurs in a variety of habitats and consumes different materials (Smrz \& Norton 2004). This opportunistic feeding is confirmed by the results of our study. Feeding on nematodes by $A$. striculus and $S$. magnus was unexpected since Phthiracaridae have never been observed feeding on nematodes before (Pande \& Berthet 1973). Additionally, ${ }^{15} \mathrm{~N}$ signatures of $S$. magnus indicate that it predominantly feeds on litter (Schneider et al. 2004). H. rufulus has high stable isotope $\left({ }^{15} \mathrm{~N} /{ }^{14} \mathrm{~N}\right)$ ratios (Schneider et al. 2004; Pollierer et al. 2009) and has been observed feeding on dead Collembola and 'worms' (Riha 1951) supporting the assumption that this species at least in part lives as scavenger. Notably, the gamasid mite $H$. aculeifer consumed less nematodes than some of the oribatid mite species. This may be due to its small body size and the large size of the two nematode 
species used in this study. Three oribatid mite species (A. coleoptrata, C. coriaceus, $E$. plicatus) did not consume nematodes. A. coleoptrata and $C$. coriaceus have low ${ }^{15} \mathrm{~N}$ signatures indicating that they predominantly feed on decaying plant material (Schneider et al. 2004). E. plicatus is a soil and bark living species with specialized long and thin mouthparts that can be used for feeding on plant parenchyma and presumably also on fungi but likely not on nematodes as assumed by Erdmann et al. (2007). Generally, feeding on the two nematode species did not differ significantly. This suggests that consumption of nematodes by mites is little affected by nematode size. Further, the thicker cuticle of $S$. feltiae as compared to $P$. hermaphrodita did not prevent predation by mites.

\subsection{Suitability of the method}

Molecular gut content analyses of soil animals are difficult and prone to errors (King et al. 2008). Possible errors start with a harsh extraction of the animals from the soil, where the individuals can be injured and contamination of other individuals is possible. Therefore, in this study soil microarthropods were extracted by heat and slowly moved out of the soil and fell onto moist filter paper in cooled collection boxes. Further, they were separated quickly to avoid contamination (King et al. 2008). Another critical aspect is the storage of the animals before DNA extraction. In our study the mites were killed and stored at $-20^{\circ} \mathrm{C}$ in $96 \%$ ethanol at the laboratory study and at $-80^{\circ} \mathrm{C}$ in $180 \mathrm{ml}$ ATL-Buffer from the DNeasy ${ }^{\circledR}$ Blood \& Tissue Kit (Qiagen) in all other experiments to avoid destabilization of the DNA during thawing. Furthermore, nematodes may be attached to the surface of mites, and animals may regurgitate their gut content when they die which may contaminate the whole sample. Therefore, mites were checked for attached nematodes and afterward placed individually into microcentrifuge tubes. Although tested specific primers for the nematodes were used (Read et al. 2006), a PCR bias cannot be excluded. In the experiments the PCR was replicated two times to minimize false negatives. Weak bands from the field experiment were always sequenced. In the laboratory trials every sample with a band was sequenced to avoid false positives.

\section{Conclusions}

Results of this study suggest that dead and living nematodes are an important component of the diet of soil microarthropods which previously have been assumed to live as litter and fungal feeders. Since many nematode species feed on bacteria and fungi the bacterial and fungal food chain in soil may be more interlinked than previously assumed. Detection of 
nematodes in the diet of a number of oribatid mite species suggests that the role of nematodes in the diet of detritivorous microarthropods has been underestimated. In particular, scavenging and predation may be more important for soil microarthropod nutrition than previously assumed and deserves more attention in soil food web studies in future. Further, as soil microarthropod species differentially fed on the two offered nematode species the role of nematode species identity needs to be explored in more detail. A number of other issues deserve further attention, e.g. the effect of season on microarthropod diets, the role of predatorprey body size ratios for prey consumption, and variations in DNA detection times due to predator and prey species identity. Despite these challenges molecular gut content analyses offer the unique opportunity to address one of the most challenging frontiers in ecology, the structure and functioning of belowground food webs.

\section{Acknowledgments}

This work was funded by the Darmstadt University of Technology and the German Research Foundation (DFG). We thank Georgia Erdmann, Melanie M. Pollierer, Bernhard Klarner and Nicole Scheunemann for collection and identification of mite and collembolan species, Bernhard Eitzinger for help with the bootstrap analysis and for providing the nontarget macrofauna species, Nico Blüthgen and Carsten F. Dormann for instructions to 'bipartite' and Michael Traugott for helpful comments on an earlier version of the ms and help with the bootstrap analysis. 


\section{References}

Agusti N, de Vicente MC, Gabarra R (1999) Development of sequence characterized amplified region (SCAR) markers of Helicoverpa armigera: a new polymerase chain reaction-based technique for predator gut analysis. Molecular Ecology, 8, 1467-1474.

Agusti N, Shayler SP, Harwood JD, Vaughan IP, Sunderland KD, Symondson WOC (2003) Collembola as alternative prey sustaining spiders in arable ecosystems: prey detection within predators using molecular markers. Molecular Ecology, 12, 3467-3475.

Baxter M (2003) Counting angels with DNA. Nature, 421, 122-124.

Bongers T, Ferris H (1999) Nematode community structure as a bioindicator in environmental monitoring. Trends in Ecology and Evolution, 14, 224-228.

Bussaman P, Sermswan RW, Grewal PS (2006) Toxicity of the entomopathogenic bacteria Photorhabdus and Xenorhabdus to the mushroom mite (Luciaphorus sp., Acari: Pygmephoridae). Biocontrol Science and Technology, 16, 245-256.

Dormann CF, Gruber B, Fründ J (2008) Introducing the bipartite package: analysing ecological networks. R News, 8, 8-11.

Erdmann G, Otte V, Langel R, Scheu S, Maraun M (2007). The trophic structure of bark-living oribatid mite communities analysed with stable isotopes $\left({ }^{15} \mathrm{~N} ;{ }^{13} \mathrm{C}\right)$ indicates strong niche differentiation. Experimental and Applied Acarology, 41, 1-10.

Folmer O, Black M, Hoeh W, Lutz R, Vrijenhoek R (1994) DNA primers for amplification of mitochondrial cytochrome c oxidase subunit I from diverse metazoan invertebrates. Molecular Marine Biology and Biotechnology, 3, 294-299.

Foltan P, Sheppard S, Konvicka M, Symondson WOC (2005) The significance of facultative scavenging in generalist predation nutrition: detecting decayed prey in the guts of predators using PCR. Molecular Ecology, 14, 4147-4158.

Hoogendorn M, Heimpel GE (2001) PCR-based gut content analysis of insect predators: using ribosomal ITS-1 fragments from prey to estimate predation frequency. Molecular Ecology, 10, 2059-2067.

Hosmer DW, Lemeshow S (1989) Applied Logistic Regression. Wiley, New York.

Juen A, Traugott M (2005) Detecting predation and scavenging by DNA gut content analyses: a case study using a soil insect predator-prey system. Oecologia, 142, 344-352. 
Juen A, Traugott M (2007) Revealing species-specific trophic links in soil food webs: molecular identification of scarab predators. Molecular Ecology, 16, 1545-1557.

Kempson D, Lloyd M, Ghelardi R (1963) A new extractor for woodland litter. Pedobiologia, 3, $1-21$.

Karg W (1989) Acari (Acarina), Milben; Parasitiformes (Anactinochaeta), Uropodina Kramer Schildkrötenmilben. Die Tierwelt Deutschlands. G. Fischer-Verlag, Jena.

Kaya HK, Gaugler R (1993) Entomopathogenic nematodes. Annual Review of Entomology, 38, 181-206.

King RA, Read DS, Traugott M, Symondson WOC (2008) Molecular analysis of predation: a review of best practice for DNA-based approaches. Molecular Ecology, 17, 947-963.

Koehler HH (1997) Mesostigmata (Gamasida, Uropodina), efficient predators in agroecosystems. Agriculture, Ecosystems and Environment, 62, 105-117.

Kuusk AK, Cassel-Lundhagen A, Kvarnheden A, Ekbom B (2008) Tracking aphid predation by lycosid spiders in spring-sown cereals using PCR-based gut content analysis. Basic and Applied Ecology, 9, 718-725.

Maraun M, Scheu S (2000) The structure of oribatid mite communities (Acari, Oribatida): patterns, mechanisms and implications for future research. Ecography, 23, 374-383.

Maraun M, Migge S, Schaefer M, Scheu S (1998) Selection of microfungal food by six oribatid mite species (Oribatida, Acari) from two different beech forests. Pedobiologia, 42, 232-240.

Maraun M, Heethoff M, Scheu S, Weigmann G, Norton RA, Thomas RH (2003) Radiation in sexual and parthenogenetic oribatid mites (Oribatida, Acari) as indicated by genetic divergence of closely related species. Experimental and Applied Acarology, 29, 265-277.

MacMillan K, Haukeland S, Rae R, Young I, Crawford J, Hapca S, Wilson M (2009) Dispersal patterns and behaviour of the nematode Phasmarhabditis hermaphrodita in mineral soils and organic media. Soil Biology and Biochemistry, 41, 1483-1490.

Milton Y, Kaspari M (2007) Bottom-up and top-down regulation of decomposition in a tropical forest. Oecologia, 153, 163-172.

Moore JC, McCann K, Setälä H, De Ruiter PC (2003) Top-down is bottom-up: does predation in the rhizosphere regulate aboveground dynamics? Ecology, 84, 846-857. 
Muraoka M, Ishibashi N (1976) Nematode-feeding mites and their feeding behaviour. Applied Entomology and Zoology, 11, 1-7.

Pande YD, Berthet P (1973) Studies on the food and feeding habits of soil Oribatei in a black pine plantation. Oecologia, 12, 413-426.

Peschel K, Norton RA, Scheu S, Maraun M (2006) Do oribatid mites live in enemy-free space? Evidence from feeding experiments with the predatory mite Pergamasus septentrionalis. Soil Biology and Biochemistry, 38, 2985-2989.

Pollierer M, Langel R, Scheu S, Maraun M (2009) Compartmentalization of the soil animal food web as indicated by dual analysis of stable isotopes $\left({ }^{15} \mathrm{~N} /{ }^{14} \mathrm{~N}\right.$ and $\left.{ }^{13} \mathrm{C} /{ }^{12} \mathrm{C}\right)$. Soil Biology and Biochemistry, 41, 1221-1226.

Raut SK, Panigrahi A (1991) The mite Fuscuropoda marginata (C.L. Koch) for the control of pest slugs Laevicaulis alte (Férussac). In: Dusbabek F, Bukva V (Eds.), Modern Acarology, vol. 2. Academia, Prague and SPB Acad. Publ., The Hague, pp. 683-687.

R Development Core Team (2009) R: A Language and Environment for Statistical Computing. R Foundation for Statistical Computing, Vienna, Austria, ISBN 3- 900051-07-0. Available from. http://www.R-project.org.

Read DS, Sheppard SK, Bruford MW, Glen DM, Symondson WOC (2006) Molecular detection of predation by soil microarthropods on nematodes. Molecular Ecology, 15, 1963-1972.

Riha G (1951) Zur Ökologie der Oribatiden in Kalksteinböden. Zoologische Jahrbücher Abteilung für Systematik, Ökologie und Geographie der Tiere, 80, 407-450.

Scheu S, Falca M (2000) The soil food web of two beech forests (Fagus sylvatica) of contrasting humus types: stable isotope analysis of a macro- and a mesofauna dominated system. Oecologia, 123, 285-296.

Schneider K, Migge S, Norton RA, Scheu S, Langel R, Reineking A, Maraun M (2004) Trophic niche differentiation in oribatid mites (Oribatida, Acari): evidence from stable isotope ratios $\left({ }^{15} \mathrm{~N} /{ }^{14} \mathrm{~N}\right)$. Soil Biology and Biochemistry, 36, 1769-1774.

Schneider K, Scheu S, Maraun M (2007) Microarthropod density and diversity respond little to spatial isolation. Basic and Applied Ecology, 8, 26-35. 
Sheppard SK, Bell J, Sunderland KD, Fenlon J, Skervin D, Symondson WOC (2005) Detection of secondary predation by PCR analyses of the gut contents of invertebrate generalist predators. Molecular Ecology, 14, 4461-4468.

Smrz J, Norton RA (2004) Food selection and internal processing in Archegozetes longisetosus (Acari: Oribatida). Pedobiologia, 48, 111-120.

Sokal RR, Rohlf FJ (1995) Biometry. WH Freeman and Co., New York.

Susurluk Al (2009) Seasonal and vertical distribution of the entomopathogenic nematodes Heterorhabditis bacteriophora (TUR-H2) and Steinernema feltiae (TUR-S3) in turf and fallow areas. Nematology, 11, 321-327.

Symondson WOC (2002) Molecular identification of prey in predator diets. Molecular Ecology, 11, 627-641.

Tan L, Grewal PS (2001) Pathogenicity of Moraxella osloensis, a bacterium associated with the nematode Phasmarhabditis hermaphrodita, to the slug Deroceras reticulatum. Applied and Environmental Microbiology, 67, 5010-5016.

Terborgh J, Estes JA (2010) Trophic cascades and the changing dynamics of nature. Island Press, Washington.

Tylianakis JM, Didham RK, Bascompte J, Wardle DA (2008) Global change and species interactions in terrestrial ecosystems. Ecology Letters, 11, 1351-1363.

Walter DE, Proctor HC (1998) Feeding behaviour and phylogeny: observations on early derivative Acari. Experimental and Applied Acarology, 22, 39-50.

Yeates GW, Bongers T, DeGoede RGM, Freckman DW, Georgieva SS (1993) Feeding-habits in soil nematode families and genera e an outline for soil ecologists. Journal of Nematology, 25, 315-331.

Yeates GW, Hawke MF, Rijkse WC (2000) Changes in soil fauna and soil conditions under Pinus radiata agroforestry regimes during a 25-year tree rotation. Biology and Fertility of Soils, 31, 391-406.

Zaidi RH, Jaal Z, Hawkes NJ, Hemingway J, Symondson WOC (1999) Can multiple-copy sequences of prey DNA be detected amongst the gut contents of invertebrate predators? Molecular Ecology, 8, 2081-2087. 


\section{Supporting information}

Table 1: 74 non-target-species were tested with the specific primers for Steinernema feltiae and Phasmarhabditis hermaphrodita. - no band occurred; + band occurred on the agarosegel.

Taxon
Supraspecific

Taxon

Acari

Holoparasitus stramenti Oudemans, 1936

Hypoaspis aculeifer (Canestrini, 1883)

Parasitus lunulatus (J. Müller, 1859)

Veigaia nemorensis (C.L.Koch, 1836)

Zercon gurensis Mihelčič, 1962

Zercon vagabundus Karg, 1971

Achipteria coleoptrata (Linné, 1758)

Archegozetes longisetosus Aoki, 1965

Atropacarus striculus (Koch, 1835)

Carabodes coriaceus Koch, 1835

Chamobates voigtsi (Oudemans, 1902)

Damaeus riparius Nicolet, 1855

Eupelops plicatus (Koch, 1835)

Galumna sp.

Hypochthonius rufulus Koch, 1835

Liacarus subterraneus (Koch, 1844)

Nothrus palustris (C. L. Koch 1839)

Nothrus silvestris Nicolet, 1855

Oribatella calcarata (C. L. Koch, 1836)

Oribatella quadricornuta (Michael, 1880)

Platynothrus peltifer (Koch, 1839)

Steganacarus magnus (Nicolet, 1855)

Trachytes aegrota (C. L. Koch, 1841)

Uropoda athiasae (Hirschmann \& Zirngiebl-Nicol, 1969)

Uropoda cassidea (Hermann, 1804)

Uroseius cylindricus (Berlese, 1916)

Araneae

Coelotes inermis (L. Koch, 1855)

Clubiona terrestris Westring, 1851

Tropiphorus sp.

Micrargus herbigradus (Blackwall, 1854)

Tapinocyba insecta (L. Koch, 1869)

Walckenaeria cucullata (C. L. Koch, 1836)

Walckenaeria obtusa Blackwall, 1836
Gamasida

Gamasida

Gamasida

Gamasida

Gamasida

Gamasida

Oribatida

Oribatida

Oribatida

Oribatida

Oribatida

Oribatida

Oribatida

Oribatida

Oribatida

Oribatida

Oribatida

Oribatida

Oribatida

Oribatida

Oribatida

Oribatida

Uropodida

Uropodida

Uropodida

Uropodida

Amaurobiidae

Clubionidae

Curculionidae

Linyphiidae

Linyphiidae

Linyphiidae

Linyphiidae 
Chilopoda

Strigamia acuminata (Leach, 1815)

Lithobius aulacopus Latzel, 1880

Lithobius lapidicola Meinert, 1872

Lithobius mutabilis L. Koch, 1862

Lithobius muticus (C.L. Koch, 1847)

Lithoibius nodupilipes Latzel, 1881

Lithobius crassipes L. Koch, 1862

Geophilomorpha
Lithobiidae
Lithobiidae
Lithobiidae
Lithobiidae
Lithobiidae
Lithobiidae

Collembola

Heteromurus nitidus (Templeton, 1835)

Entomobryidae

Orchesella flavescens (Bourlet, 1839)

Entomobryidae

Ceratophysella armata (Nicolet, 1841)

Hypogastruridae

Hypogastrura burkilli (Bagnall, 1940)

Hypogastruridae

Neanura muscorum (Templeton, 1835)

Neanuridae

Protaphorura armata (Tullberg, 1869)

Onychiuridae

Supraphorura furcifera (Börner, 1901)

Pogonognathellus (Tomocerus) cf. longicornis (Müller, 1776)

Onychiuridae

Tomoceridae

Coleoptera

Malthodes sp.

Cantharidae

Abax ovalis (Duftschmid, 1812)

Carabidae

Abax parallelipipedus (Piller \& Mitterbacher, 1783)

Carabidae

Notiophilus rufipes Curtis, 1829

Carabidae

Pterostichus burmeisteri Heer, 1841

Carabidae

Pterostichus oblongopunctatus (Fabricius, 1787)

Carabidae

Trechus nigrinus Putzeys, 1847

Carabidae

Athous haemorrhoidalis (Fabricius, 1801)

Elateridae

Athous subfuscus (Müller, 1764)

Lamprohiza splendidula (Linnaeus, 1767)

Elateridae

Nargus anisotomoides (Spence, 1815)

Lampyridae

Leiodidae

Scydmaenidae

Scydmaenidae

Domene scabricollis (Erichson, 1840)

Staphylinidae

Habrocerus capillaricornis (Gravenhorst, 1806)

Staphylinidae

Philonthus carbonarius (Gravenhorst, 1802)

Philonthus laevicollis (Boisd. \& Lacord. 1935)

Stilicus rufipes (Germar, 1836)

Staphylinidae

Staphylinidae

Staphylinidae

Xantholinus laevihatus Jacobsen, 1849

Staphylinidae

Dermaptera

Chelidurella sp.

Dermaptera

Diplopoda

Haploporatia eremita (Verhoeff, 1909)

Diplopoda

Diplopoda

Polydesmus complanatus (Linnaeus, 1761)

Glomeridae 
Diplura

Campodea sp.

Isopoda

Ligidium cf. hypnorum (Cuvier, 1792)

Porcellio sp.

Trichoniscus pusillus Brandt, 1833

Nematoda

Acrobeloides buetschlii (de Man, 1884)

Turbatrix aceti (Müller, 1783)

Oligochaeta

Aporrectodea caliginosa (Savigny, 1826)

Lumbricus terrestris Linnaeus, 1758

Opiliones

Anelasmocephalus cambridgei (Westwood, 1874)

Trogulus nepaeformis (Scopoli, 1763)

Pseudoscorpione

Neobisium carcinoides (Hermann, 1804)
Campodeidae

Isopoda

Isopoda

Isopoda

Cephalobidae

Panagrolaimidae

Lumbricidae

Lumbricidae

Trogulidae

Trogulidae

Pseudoscorpiones 


\section{Chapter 3}

\section{The role of free-living nematodes as prey for higher trophic levels of forest soil food webs}

Kerstin Heidemann, Annika Hennies, Johanna Schakowske, Lars Blumenberg,

Liliane Ruess, Stefan Scheu, Mark Maraun

Submitted: Kerstin Heidemann, Annika Hennies, Johanna Schakowske, Lars Blumenberg, Liliane Ruess, Stefan Scheu, Mark Maraun. The role of free-living nematodes as prey for higher trophic levels of forest soil food webs. 


\begin{abstract}
Nematodes form the most abundant invertebrates in soils and are key prey in soil food webs. Uncovering their contribution to predator nutrition is essential to understand soil food webs and the way energy channels through soil systems. Molecular gut content analysis of soil microarthropods as consumers of nematodes using specific markers is a novel approach for studying predator-prey interactions in soil. We designed new primer pairs (partial 18S rDNA) for soil-living bacterial feeding nematode taxa (Acrobeloides buetschlii, Panagrellus redivivus, Plectus velox and Plectus minimus). Primer specificity against more than 100 nontarget soil organisms was tested. Further, we determined how long nematode DNA can be traced in the gut of predators. Potential predators were identified in laboratory experiments including nine soil mite (Oribatida, Gamasina and Uropodina) and ten springtail (Collembola) species. Finally, the approach was tested under field conditions by analyzing five mite and three collembola species for feeding on the three target nematode species. The results proved the three primer sets to specifically amplify DNA of the respective nematode taxa. Detection time of nematode DNA in predators varied with time of prey exposure. Further, consumption of nematodes in the laboratory varied with microarthropod species. The analysis of field sampled microarthropods for the first time proved free-living nematodes to form important prey for a wide range of species including those commonly regarded as decomposers. Overall, the results highlight the eminent role of nematodes for predator populations in soil food webs and for channeling bacterial carbon to higher trophic levels.
\end{abstract}




\section{Introduction}

The soil food web forms a major component and provides essential functions of terrestrial ecosystems (Scheu \& Setälä 2002; Bardgett \& Wardle 2010). As with all food webs it is based on predator-prey interactions channelling the flux of matter and energy to higher trophic levels (Pimm 1991; Terborgh \& Estes 2010). Soil food webs are often regarded as 'black box' since they are species-rich, the organisms typically are small and difficult to observe, and thus trophic relationships are little understood (Wardle \& Yeates 1993; Symondson 2002; Scheu et al. 2005). The major energy channels of soil food webs are the bacterial, the fungal and the plant litter channel (Moore \& Hunt 1988; Scheu et al. 2005). The transfer of carbon to higher trophic levels is assumed to be fastest via the bacterial energy channel (van Hees et al. 2005; Strickland et al. 2012), and recent studies using fatty acid analyses suggest that a wide range of predators rely on carbon out of this channel (Pollierer et al. 2012). However, carbon transfer from low to high trophic levels still is little understood, but one of the most important links presumably are bacterial-feeding nematodes (Freckman 1988; Crotty et al. 2011; Ferlian et al. 2012).

Free-living soil nematodes feed on a wide range of resources, e.g. dead organic material, bacteria, fungi, algae, plants or live as predators or omnivores (Yeates et al. 1993). They reach densities of several million individuals per square metre and nematode communities of forests often comprise more than 100 species (Yeates et al. 2000), thereby functioning as key players in soil food webs (Moore et al. 2003; Ferris 2010; Yeates 2010). Nematodes serve as prey for many soil animals including mites and collembolans (Rockett \& Woodring 1966; Muraoka \& Ishibashi 1976; Walter 1988a,b; Read et al. 2006; Heidemann et al. 2011). Bacterial feeding nematodes typically account for $>50 \%$ of total free-living nematodes, but in hotspots of microbial activity this may rise to $>90 \%$; together with protists they form the most important bacterial grazers in soil (Griffiths 1990; Zunke \& Perry 1997; Scheu et al. 2005; Mulder \& Vonk 2011). Investigating nematodes as prey for soil animals is difficult since only solid structures such as mouthparts and grinders are left as remnants in the gut of predators (Walter 1988a; Sunderland 1988), thereby nematodes form 'invisible' prey.

Microarthropods, such as mites and collembolans, are abundant and diverse in belowground systems (Petersen \& Luxton 1982; Maraun et al. 1998; Rusek 1998; Schatz 2002). Most soil microarthropod species have been assumed to function as decomposers, i.e. to feed on dead organic material, bacteria and fungi but gamasid and uropodid mites are known to live as predators. However, recent studies using fatty acid and stable isotope analysis indicate that many putative decomposer species also live as predators or scavengers (Ruess et al. 2004; Schneider et al. 2004; Chahartaghi et al. 2005). Therefore, animal diets presumably form an 
essentially component of the trophic niche of many 'decomposer' soil invertebrates thereby contributing to their high local diversity (Anderson 1975; Scheu \& Setälä 2002; Maraun et al. 2003a).

Molecular gut content analysis is a new and promising tool for studying neglected trophic interactions (Symondson 2002; King et al. 2008), such as feeding of microarthropods on nematodes. It allows to sensitively detect even small amounts of DNA in the gut of consumers over long periods of time (Sheppard et al. 2005; King et al. 2008; Eitzinger \& Traugott 2011). Specific primers i.e., primers that only bind to certain genera or species, allow screening of predator communities for certain prey taxa or species. For tracing bacterial feeding nematodes in soil predators we designed novel primers and tested their specificity. Until today, only three primer pairs specific for entomopathogenic nematodes species have been used to detect nematode predators in soil food webs (Read et al. 2006; Heidemann et al. 2011).

We aimed at developing tools for detecting field-living bacterial feeding nematode species in predators of soil food webs of temperate deciduous forest ecosystems by molecular gut content analysis. For achieving this goal we (1) designed specific and sensitive primer pairs for four field-living abundant bacterial feeding nematode taxa, (2) tested them for specificity, (3) investigated the detection time of prey DNA in the gut of predators, (4) identified microarthropod predators of these nematode taxa in laboratory, and (5) in the field.

\section{Materials and Methods}

\subsection{The organisms}

Four free-living bacterial feeding soil nematode species, Acrobeloides buetschlii (de Man, 1884), Panagrellus redivivus Goodey, 1945, Plectus minimus Cobb, 1893 and Plectus velox Bastian, 1865, were investigated as microarthropod prey. All four species have a cosmopolitan distribution and cover the size range of nematodes typically found in soil. $A$. buetschlii lives in forest soils and reaches a length of $\sim 0.3-0.5 \mathrm{~mm}$. $P$. redivivus has a length of 1-2 $\mathrm{mm}$ and lives ovoviviparously in decaying and fermenting materials. $P$. velox is larger $(\sim 1-1.2 \mathrm{~mm})$ than $P$. minimus ( $0.35 \mathrm{~mm}$ ); both species live in forest soils but also occur in mosses and lichens. $P$. velox is described as being synonymous to $P$. parietinus (http://nematode.unl.edu), but we followed Holovachov (2006) keeping the validity of $P$. velox. Large numbers of nematodes were needed for design of the molecular markers, the optimization of the method and for the laboratory experiments. This is only possible with laboratory mass cultures (Goodey 1963). As these are difficult to obtain for free living nematodes, existing axenic laboratory cultures from widespread soil nematode species were used. However, this selection did not reflect their 
relative abundance in the soil of the investigated field site. $P$. minimus and $P$. velox were supplied by René Seiml-Buchinger (HU Berlin, Germany), P. redivivus by Interaquaristik.de Shop (www.interaquaristik.de, Biedenkopf-Breidenstein, Germany) and A. buetschlii was taken from cultures of one of the authors (L. Ruess).

A total of 24 microarthropod species were investigated as potential predators of nematodes. In the laboratory we studied the gamasid mite Pergamasus septentrionalis (Oudemans, 1902), the uropodid mites Trachytes aegrota (C.L. Koch, 1841), Uropoda cassidea (Hermann, 1804) and its deutonymph, the oribatid mites Achipteria coleoptrata (Linné, 1758), Carabodes sp., Galumna sp., Platynothrus peltifer (Koch, 1839) and Steganacarus magnus (Nicolet, 1855) as potential predators of the four nematode species and the collembolans Folsomia candida Willem, 1902, Heteromurus nitidus Templeton, 1835, Hypogastrura purpurescens Lubbock, 1867, Lepidocyrtus cyaneus Tullberg, 1871, Proisotoma minuta Tullberg, 1871, Protaphorura armata Tullberg, 1869, Sinella coeca Schott, 1896, Sinella curviseta Brook, 1882 and Tomocerus minor Lubbock, 1862 as potential predators of $P$. velox and $P$. minimus. All species are inhabitants of European forest soils except F. candida, S. coeca and S. curviseta which typically live in disturbed habitats. In the field experiment we investigated predation on nematodes in U. cassidea and the oribatid mites Chamobates subglobulus (Oudemans, 1900), Nothrus palustris (C. L. Koch, 1839), N. silvestris Nicolet, 1855 and S. magnus, and the collembolans Entomobrya muscorum Nicolet, 1842, Orchesella villosa (Geoffroy, 1764) and T. vulgaris Tullberg, 1871. Each of them is abundant in soil food webs of deciduous forests.

\subsection{Study site}

Microarthropods for the laboratory experiments were sampled from the Hainich forest (near Birkungen, Thüringen, Germany), the Göttinger forest (Göttingen, Lower Saxony, Germany), and from an agricultural experimental field of the Georg August University Göttingen near the Klostergut Reinshof (Göttingen, Lower Saxony, Germany). The samples for the field experiment were taken in October 2011 from the Hainich forest.

The Hainich is the largest coherent deciduous forest of Germany and is dominated by Fagus sylvatica interspersed with ash (Fraxinus excelsior), lime (Tilia europaea), maple (Acer platanoides and $A$. pseudoplatanus) and wild service trees (Sorbus torminalis). Parent rock is Triassic limestone; the main soil types are Luvisols, Cambisols and Stagnosols with an average $\mathrm{pH}$ of 4.6. The Göttinger forest ('Göttinger Wald') is a 140 year old beech forest interspersed with maple and ash. Parent rock is limestone; Leptosols with mull humus predominate with an average $\mathrm{pH}$ of 5.3 (Schaefer 1990). The wheat field is located in the 
Leinegraben and its dominant soil types are Cambisols, Luvisols and stagnic Luvisols. Annual precipitation at the study sites varies between 500 and $800 \mathrm{~mm}$, and mean annual temperature between 6.5 and $8^{\circ} \mathrm{C}$ (Erdmann et al. 2012; Kramer et al. 2012).

\subsection{Alignment, primer design and primer sensitivity}

We assembled a dataset with 163 sequences from National Center for Biotechnology Information (NCBI; www.ncbi.nlm.nih.gov) of the 18S rDNA of bacterial feeding nematodes using a species list of the study region (Alphei 1995). The datasets included different species of the nematode genera Acrobeloides, Panagrellus and Plectus including the species $A$. buetschlii, $P$. redivivus and $P$. minimus. Our own sequences of the $18 \mathrm{~S}$ rDNA gene of the species $A$. buetschlii, $P$. minimus and $P$. velox from our cultures were added. Sequence alignment and editing was carried out using BioEdit v7.0.5. The secondary alignment was carried out using the ClustalW multiple alignment function of the program (Hall 1999).

Sequence data were used to design specific primer pairs amplifying short parts of the $18 \mathrm{~S}$ rDNA for the three nematode targets $A$. buetschlii, $P$. redivivus and Plectus spp. ( $P$. minimus and $P$. velox; Table S1, Supporting Information) by eye following the guidelines of King et al. (2008). The annealing temperature was optimized by a temperature gradient PCR of the designed primers with the respective single nematode DNA. We optimized the PCR reaction, the used template DNA concentration and the PCR program for each primer set to maximize nematode detection and to avoid false negative results. Microarthropods were fed for four days with the respective nematodes and tested with the designed primers to confirm that amplification of the target species after consumption by a predator is possible.

Primer sensitivity was determined for all three primer pairs by a two-fold serial dilution of target DNA to test for amplification success using DNA of the nematodes A. buetschlii, $P$. redivivus and $P$. velox and the oribatid mite $S$. magnus. DNA concentration in the original extracts was measured using a Qubit $^{\circledR} 2.0$ Fluorometer (Life Technologies ${ }^{\mathrm{TM}}$, Carlsbad, California, USA), adjusted to $100 \mathrm{pg} / \mu \mathrm{L}$ for $A$. buetschlii, $500 \mathrm{pg} / \mu \mathrm{L}$ for $P$. redivivus and 50 $\mathrm{pg} / \mu \mathrm{L}$ for $P$. velox, and twofold serially diluted by adding RNase free water. We used the serial diluted target DNA as template in the PCR assays at concentrations of 250 for A. buetschlii and $P$. redivivus, and 125, 62.5, 31.25, 15.62, 7.82, 3.91, 1.96, 0.98, 0.49, 0.25, 0.13, 0.05 and $0.025 \mathrm{pg}$ of target DNA per $\mu \mathrm{L}$ PCR for each of the three nematode species. A further assay was performed by adding $250 \mathrm{pg} / \mu \mathrm{L}$ DNA of $S$. magnus to $P$. redivivus and $200 \mathrm{pg} / \mu \mathrm{L}$ DNA of $S$. magnus to $A$. buetschlii and $P$. velox in each PCR to check for possible inhibition of nematode DNA detection in the presence of predator DNA. 


\subsection{Primer specificity}

We tested the specific primer pairs for $A$. buetschlii, $P$. redivivus and Plectus spp. $(P$. minimus and $P$. velox) in a cross-reaction test with 108 non-target species, including the respective nematode species as positive control, the twelve mite and the twelve collembola species used in this study (Table S2, Supporting Information). Therefore, the animals were starved for seven days and stored separately at $-80^{\circ} \mathrm{C}$ in $180 \mathrm{~mL}$ buffer ATL of the extraction kit DNeasy ${ }^{\circledR}$ Blood \& Tissue Kit (Qiagen).

\subsection{Detection time of prey DNA}

Detection time of prey DNA in consumers was investigated using the oribatid mite $S$. magnus with $P$. redivivus, $P$. minimus and $P$. velox as nematode prey and the gamasid mite $P$. septentrionalis with $A$. buetschlii as nematode prey. All mites were extracted from soil and litter of the Göttinger forest and Hainich forest by heat (Kempson et al. 1963). We starved predator individuals for seven days. Thereafter, the four nematode species were offered separately to 20 mite individuals for $4 \mathrm{~h}$. During the experiment mites were kept in darkness at $13^{\circ} \mathrm{C}$. Since a longer feeding interval can increase the detection time of nematode prey (Heidemann et al. 2011) S. magnus was also fed with $P$. minimus and $P$. velox for $48 \mathrm{~h}$. Thereafter, mites were checked for attached nematodes and starved for $0,2,4,8,16,32,64$ and $128 \mathrm{~h}$. Then, living mites were transferred into $180 \mathrm{~mL}$ buffer ATL of the extraction kit DNeasy ${ }^{\circledR}$ Blood \& Tissue Kit (Qiagen) and stored at $-80^{\circ} \mathrm{C}$.

\subsection{Laboratory feeding experiments}

In the laboratory eight mite species ( $P$. septentrionalis, T. aegrota, U. cassidea, $A$. coleoptrata, Carabodes sp., Galumna sp., P. peltifer and S. magnus) and the deutonymph of $U$. cassidea were tested for feeding on the nematodes $A$. buetschlii, $P$. redivivus, $P$. minimus and $P$. velox in no-choice experiments. Additionally, we tested $P$. minimus and $P$. velox as prey for ten collembola species ( $L$. cyaneus, $T$. vulgaris, F. candida, $H$. nitidus, $H$. purpurescens, $P$. armata, P. minuta, S. coeca, S. curviseta and T. minor). We starved ten individuals of each microarthropod species for seven days and offered the nematode prey species separately to the microarthropods for four days. Starving and feeding occurred in darkness at $13^{\circ} \mathrm{C}$. Thereafter, we checked the mites and collembolans under a stereomicroscope for attached nematodes to avoid false positives; no nematodes were attached. Two unfed individuals of each species were used as control and tested with the specific primers to exclude 
contamination during handling of the samples. Mite and collembola individuals were stored separately at $-80^{\circ} \mathrm{C}$ in $180 \mathrm{~mL}$ buffer ATL of the extraction kit DNeasy ${ }^{\circledR}$ Blood \& Tissue Kit (Qiagen).

\subsection{Field experiment}

In the field experiment we tested five mite and three collembola species for feeding on $A$. buetschlii, $P$. redivivus and Plectus spp. In October 2011 we collected animals in mosses (1 $\mathrm{m}^{2}$ ) of three sites (plot 1-3) in the Göttinger forest where Plectus spp. and A. buetschlii are abundant (Alphei 1995). We analysed the density and species composition of soil animals at each plot by taking two soil cores for microarthropods and nematodes. Microarthropod cores (5 $\mathrm{cm} \varnothing)$ were split into organic and soil layer ( $4 \mathrm{~cm}$ thickness), and the animals extracted by heat (Macfadyen 1961); for determination of densities both layers were pooled. Nematode cores (2.5 cm Ø) were extracted by modified Baermann method (see Ruess 1995), counted and the densities of $A$. buetschlii, $P$. redivivus and Plectus spp. were determined.

Microarthropods studied in the field experiment were extracted by heat (Kempson et al. 1963) with the extraction lasting for three hours, identified to species and checked for attached nematodes; no nematodes were detected. Overall, 63 individuals of eight species were analysed including $C$. subglobulus $(\mathrm{n}=4)$, E. muscorum $(\mathrm{n}=3), N$. silvestris $(\mathrm{n}=10), N$. palustris $(n=5)$, O. villosa $(n=17)$ S. magnus $(n=3)$, T. vulgaris $(n=19)$ and $U$. cassidea $(n=2)$. The animals were placed individually in $180 \mu \mathrm{l}$ buffer ATL of the DNeasy ${ }^{\circledR}$ Blood \& Tissue Kit (Qiagen) and stored at $-80^{\circ} \mathrm{C}$. Animals were frozen within $7 \mathrm{~h}$ after sampling in the field.

\subsection{DNA extraction, PCR and sequencing}

DNA from whole individuals of soil microarthropods and nematodes was extracted following the protocol of the DNeasy ${ }^{\circledR}$ Blood \& Tissue Kit (Qiagen). To verify the success of the DNA extractions and to exclude inhibition of the DNA amplification we performed a PCR with D3 primers amplifying a $320 \mathrm{bp}$ fragment of the 28S rDNA for every sample (Maraun et al. 2003b). PCRs with D3 primers and thermal cycle parameters were carried out as described in Heidemann et al. (2011). The PCR success of the macrofauna samples used to test for primer specificity was confirmed by using the primers of Folmer et al. (1994) amplifying a 710 bp fragment of the cytochrome oxidase I (COI). To avoid false negative amplification results only samples with a PCR product were included in the study. 
Sequences of $A$. buetschlii, $P$. minimus and $P$. velox from our cultures were obtained using general 18S rDNA primers and thermal cycle parameters of Domes et al. (2007). The primers amplify a $\sim 1750 \mathrm{bp}$ fragment of $18 \mathrm{~S}$ rDNA. The sequences were added to the dataset for the design of the specific primers. Every PCR contained $1 \mu \mathrm{L}$ (concentration $100 \mathrm{pmol} / \mathrm{mL}$ ) of each primer (Eurofins MWG Operon, Ebersberg, Germany), $1 \mu \mathrm{L}$ of BSA (3\%), $1 \mu \mathrm{L}$ of $25 \mathrm{mM} \mathrm{MgCl} 2$ (Genaxxon BioScience GmbH, Ulm, Germany), $12.5 \mu \mathrm{L}$ 2x SuperHot Mastermix (Genaxxon BioScience $\mathrm{GmbH}$, Ulm, Germany) including polymerase, $5 \mu \mathrm{L}$ template DNA and were filled up to $25 \mu \mathrm{L}$ with RNase free water.

Nematode DNA was targeted using specific primers for $A$. buetschlii amplifying a 287 bp fragment [Acro-F-197 (forward primer) 5'- CGG CTT CGG CTG TTT CTG GTT -3'; Acro-R484 (reverse primer) 5'- GAT GAC CGG CCT CAT AAG AGA ACG GTC TC -3'], P. redivivus amplifying a 217 bp fragment [Pana-F-278 (forward primer) 5'- CCA ACG GCA GTG TAT TGT CCT GAC G -3'; Pana-R-494 (reverse primer) 5'- TAG GAA GGT TGT AAA TTC -3'] and Plectus spp. amplifying a 156 bp fragment $[(P$. minimus and $P$. velox); Plec-F-644 (forward primer) 5'- CTG RGA TCC AAG GCT TAT ACT GC -3'; Plec-R-799 (reverse primer) 5'- TAG ARC CGT GGT CTT ATT CT -3']. Each of the three primer pairs amplifies parts of the $18 \mathrm{~S}$ rDNA. Every PCR contained $2 \mu \mathrm{L}$ (concentration $100 \mathrm{pmol} / \mathrm{mL}$ ) of each primer (Eurofins MWG Operon, Ebersberg, Germany), $1 \mu \mathrm{L}$ of BSA (3\%) for A. buetschlii (2 $\mu \mathrm{L}$ for $P$. redivivus and for Plectus spp.), $1 \mu \mathrm{L}$ of $25 \mathrm{mM} \mathrm{MgCl}_{2}$ for A. buetschlii (2 $\mu \mathrm{L}$ for P. redivivus and for Plectus spp.; Genaxxon BioScience $\mathrm{GmbH}$, Ulm, Germany), $12.5 \mu \mathrm{L} 2 x$ SuperHot Mastermix (Genaxxon BioScience $\mathrm{GmbH}$, Ulm, Germany) including polymerase, $2.5 \mu \mathrm{L}$ template DNA for A. buetschlii ( $0.5 \mu \mathrm{L}$ for $P$. redivivus and $2.5 \mu \mathrm{L}$ for Plectus spp.) and were filled up to $25 \mu \mathrm{L}$ with RNase free water. Thermal cycle parameters included an initial denaturation step of 10 min at $95^{\circ} \mathrm{C}$ followed by 35 cycles of $30 \mathrm{~s}$ at $95^{\circ} \mathrm{C}, 60 \mathrm{~s}$ at $62^{\circ} \mathrm{C}$ for $A$. buetschlii $\left(45 \mathrm{~s}\right.$ at $63^{\circ} \mathrm{C}$ for $P$. redivivus and $45 \mathrm{~s}$ at $62^{\circ} \mathrm{C}$ for Plectus spp.) and $30 \mathrm{~s}$ at $72^{\circ} \mathrm{C}$, and a final extension stage of $10 \mathrm{~min}$ at $72^{\circ} \mathrm{C}$. PCR products were visualised using the capillary electrophoresis system QIAxcel (Qiagen). Fifty percent of all positive samples of the laboratory trials and all positive samples of the field trial were sequenced by Macrogen Inc. (Seoul, South Korea) or by the Göttingen Genomics Laboratory at the Institute of Microbiology and Genetics of the Georg August University Göttingen and compared to NCBI (www.ncbi.nlm.nih.gov) to confirm the species identity of amplified fragments.

\subsection{Statistical analysis}

We calculated means and standard derivations of nematode detection rates by using the package 'simpleboot' in R (Simple Bootstrap Routines. R-package version 1.1-3; Roger D. 
Peng 2008; R Development Core Team 2009). Additionally, 95\% confidence limits were calculated by 9999 bootstrap resamples for each predator feeding on a certain prey.

We used logistic regression (Hosmer \& Lemeshow 1989; Sokal \& Rohlf 1995) for the laboratory and field experiment to analyze if (i) the microarthropod species differently consumed the nematode prey offered, (ii) the offered nematode species were differently consumed, and (iii) the detection of each nematode species varied between different microarthropod species. The analyses were carried out for each treatment separately using SAS 9.3 (SAS Institute Inc., Cary, USA).

\section{Results}

\subsection{Primer design and sensitivity}

Fragments of the 18S rDNA between 1556 and 1760 bp were successfully amplified from 10 individuals per sample of each $A$. buetschlii, P. minimus and P. velox, sequenced (GenBank accession numbers KC206039, KC206040 and KC206041, respectively) and included in our dataset to the 163 sequences from NCBI of the 18S rDNA of bacterial feeding nematodes. Three primer pairs were designed amplifying taxon-specific DNA fragments (inclusive the primer region) of $287 \mathrm{bp}$ from $A$. buetschlii, $217 \mathrm{bp}$ from $P$. redivivus and $156 \mathrm{bp}$ from Plectus spp. ( $P$. minimus and $P$. velox; Figures S1 and S3 and Table S1, Supporting Information) of the 18S rDNA in the guts of microarthropods after feeding on the respective nematode species. If the primer sets for $A$. buetschlii and $P$. redivivus amplify their target on species or genus level remains unclear since no other species of these two genera were available for non-target tests. However, $P$. minimus and $P$. velox were amplified by one primer pair, therefore we defined these primers as specific to Plectus spp. ( $P$. minimus and $P$. velox). Often, the primer set for $P$. redivivus amplified a second fragment of $\sim 160$ bp which was missing when DNA of $P$. redivivus was absent. However, as the target fragment could be easily recognised this did not pose any problem for the analysis.

The primer set for $A$. buetschlii had a minimum detection limit of $0.05 \mathrm{pg} / \mu \mathrm{L}$ of target DNA; with $200 \mathrm{pg} / \mu \mathrm{L}$ of DNA of $S$. magnus present the minimum amount detected was $0.025 \mathrm{pg} / \mu \mathrm{L}$ (Figure S2, Supporting Information). For $P$. redivivus the minimum amount nematode DNA detected was $0.05 \mathrm{pg} / \mu \mathrm{L}$ which holds in presence of $250 \mathrm{pg} / \mu \mathrm{L}$ DNA of $S$. magnus. For $P$. velox the minimum amount of nematode DNA detected was $0.025 \mathrm{pg} / \mu \mathrm{L}$ and this was also true in presence of $200 \mathrm{pg} / \mu \mathrm{l}$ DNA of $S$. magnus. 


\subsection{Primer specificity}

A total of 108 non-target taxa including the nematode species $A$. buetschlii, $P$. redivivus, $P$. minimus and $P$. velox, were tested with the respective primer sets to check for cross-reactions (Table S2, Supporting Information). The primer set for $A$. buetschlii showed one cross-reaction to Octolasion cyaneum (Savigny, 1826).

Cross-reactions of the primer set for $P$. redivivus occurred for 16 non-target species: Clubiona terrestris Westring, 1851, Microneta viaria (Blackwall, 1841), Strigamia acuminata (Leach, 1815), Lithoibius nodupilipes Latzel, 1881, Abax parallelepipedus (Piller \& Mitterbacher, 1783), Hypogastrura burkilli (Bagnall, 1940), Haploporatia eremita (Verhoeff, 1909), Musca domestica Linnaeus, 1758, Ligidium hypnorum (Cuvier, 1792), Porcellio sp., Trichoniscus pusillus Brandt, 1833, Galleria sp., Steinernema feltiae (Filipjev, 1934), Aporrectodea caliginosa (Savigny, 1826), Lumbricus terrestris Linnaeus, 1758 and Octolasion cyaneum (Savigny, 1826).

The non-target test with the primers for Plectus spp. showed cross-reactions for ten taxa: Dendrobaena octaedra (Savigny, 1826), Eupelops sp., Galleria sp., Hypogastrura burkilli (Bagnall, 1940), Liacarus xylariae (Schrank, 1803), Lithobius lapidicola Meinert, 1872, Lophopilio palpinalis (Herbst, 1799), Lumbricus terrestris Linnaeus, 1758, Pratylenchus zeae Graham, 1951 and Trichorhina tomentosa (Budde-Lund, 1893). However, not all individuals of Eupelops sp. showed cross-reactions indicating that cross-reactivity differs between species of that genus.

All three primer sets did not show cross-reactions with the mite and collembola species used in our study. We sequenced about $50 \%$ of the positive prey bands of the laboratory experiments and all of the field trial and never found any of the above or other species in the gut of the microarthropod species. We always only detected Plectus spp. and A. buetschlii or Acrobeloides sp. with the respective primer pair. We therefore assume that the positive crossreactions are not relevant for our study.

In some cases the primer set for $A$. buetschlii amplified a shorter fragment of $\sim 90 \mathrm{bp}$ which was clearly distinguishable from the target and occurred as single or second band. NCBI blast search identified this fragment as short fragment of the 18S rDNA of $A$. buetschlii; amplifications of this fragment were ignored. 


\subsection{Detection time of prey DNA}

We determined the detection time of nematode prey in the gamasid mite $P$. septentrionalis after feeding on $A$. buetschlii and in the oribatid mite $S$. magnus after feeding on $P$. redivivus, $P$. minimus and $P$. velox for $4 \mathrm{~h}$. Immediately post feeding on $A$. buetschlii prey DNA was detected in $10 \%$ of the individuals of $P$. septentrionalis and this increased to $30 \%$ and $50 \% 2$ and $4 \mathrm{~h}$ later but then dropped to $0-20 \% 8$ to $128 \mathrm{~h}$ post feeding (Figure 1a). In contrast, only $10 \%$ of S. magnus were tested positive for $P$. redivivus directly post feeding, which further decreased to $0-5 \%$ with time (Figure $1 \mathrm{~b}$ ). For $P$. minimus $80 \%$ of the individuals of $S$. magnus were tested positive immediately post feeding which dropped continuously to $0 \%$ after 32 and $64 \mathrm{~h}$ but increased to $30 \%$ at $128 \mathrm{~h}$ (Figure 1c). P. velox was detected in only $0-10 \%$ of $S$. magnus throughout the $128 \mathrm{~h}$ of the experiment (Figure 1d).

When feeding on nematodes for $48 \mathrm{~h} 35 \%$ of the individuals of $S$. magnus were tested positive for DNA of $P$. minimus immediately and $2 \mathrm{~h}$ post feeding; thereafter, prey detection varied between 5 and $30 \%$ and apparently increased until $64 \mathrm{~h}$ post feeding (Figure 1e). When feeding on $P$. velox for $48 \mathrm{~h}$ detection of prey DNA in $S$. magnus was high and varied between 55 and $100 \%$ immediately and $2 \mathrm{~h}$ post feeding, respectively; detection remained high until $128 \mathrm{~h}$ with 35 to $60 \%$ (Figure $1 \mathrm{f}$ ). 

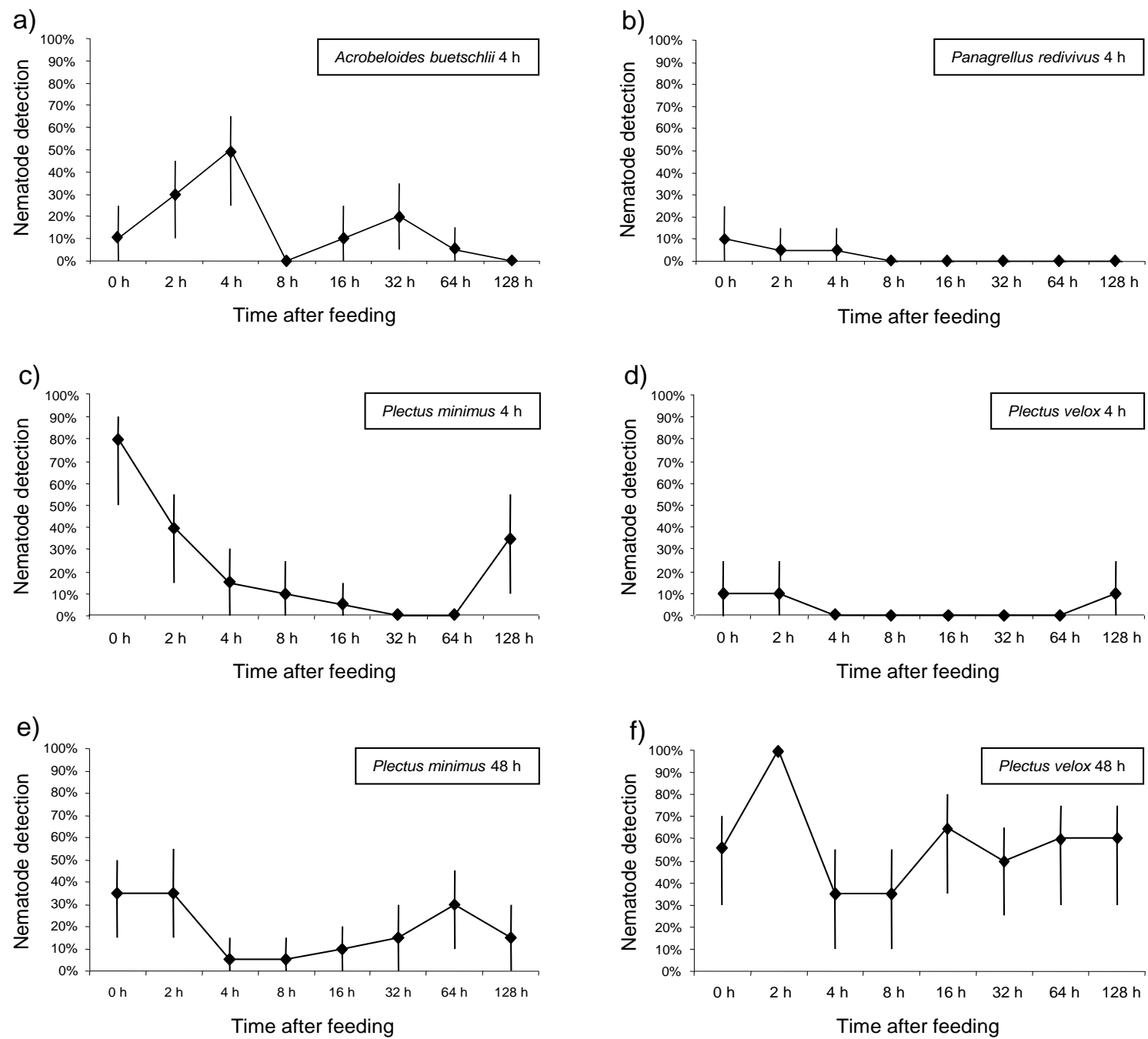

Figure 1: Prey DNA detection at different time points post feeding of Pergamasus septentrionalis for 4 $\mathrm{h}$ on (a) Acrobeloides buetschlii, and of S. magnus on (b) Panagrellus redivivus, (c) Plectus minimus and (d) Plectus velox and post feeding of Steganacarus magnus for $48 \mathrm{~h}$ on (e) $P$. velox and (f) $P$. minimus. Data represent percentages of 20 mite individuals tested positive per time point. Error bars represent confidence limits; for statistical analysis see text.

\subsection{Laboratory feeding experiments}

Detection of DNA of the four nematode species $A$. buetschlii, $P$. redivivus, $P$. minimus and $P$. velox in the eight species of mites and the deutonymph of $U$. cassidea studied varied between mite species $\left(X^{2}=38.97, d f=8, P<0.0001\right)$ and also between nematode species $\left(X^{2}\right.$ $=15.04, \mathrm{df}=3, \mathrm{P}=0.0018)$. Moreover, feeding on individual nematode species also differed between mite species (significant mite species $\times$ nematode species interaction; $X^{2}=57.72$, df $=24, \mathrm{P}=0.0001$; Figure $2 \mathrm{a})$. On average, detection of nematode DNA in mites declined from P. minimus (42\%) to P. velox (29\%) to A. buetschlii (27\%) to P. redivivus (18\%). 
In uropodid mites $50 \%$ of the individuals of $T$. aegrota were tested positive for $A$. buetschlii, $20 \%$ for $P$. redivivus, $40 \%$ for $P$. minimus and $90 \%$ for $P$. velox. In $U$. cassidea DNA of $A$. buetschlii and $P$. minimus (both $60 \%$ ) were more often detected than DNA of $P$. redivivus $(40 \%)$ and $P$. velox (30\%). Almost all individuals of deutonymphs of $U$. cassidea were tested positive for $P$. minimus (90\%), less for $P$. velox (40\%) and only $10 \%$ for $A$. buetschlii and $P$. redivivus. In the gamasid mite $P$. septentrionalis detection of prey DNA was high for $P$. velox $(80 \%)$ and A. buetschlii (50\%) but low for $P$. redivivus (20\%) and $P$. minimus $(0 \%)$. In oribatid mites $70 \%$ of $S$. magnus were tested positive for DNA of $P$. minimus, $40 \%$ for $P$. redivivus, $20 \%$ for $A$. buetschlii and only $10 \%$ for $P$. velox. Detection of $A$. buetschlii and $P$. redivivus was similar in Galumna spp., $P$. peltifer and Carabodes spp. (10\% each). As in S. magnus more individuals were tested positive for P. minimus (40\%) than for P. velox (10\%) in Galumna spp. Only few individuals of $P$. peltifer, Carabodes spp. and $A$. coleoptrata were tested positive for nematode DNA, in each of the species most frequently for $P$. minimus (30\%, $20 \%$ and $30 \%$, respectively).

Similar to mites detection of nematode DNA in the eight collembola species studied also significantly varied with collembola species $\left(X^{2}=48.17\right.$, df $=9, P<0.0001$; Figure $\left.2 b\right)$. However, in contrast to mites nematode DNA detection did not differ significantly between the two nematode species investigated $\left(P\right.$. minimus and $P$. velox; $\left.x^{2}=2.63, \mathrm{df}=1, \mathrm{P}=0.105\right)$ and prey detection in collembola species did not vary with nematode species $\left(X^{2}=7.80, d f=9, P\right.$ $=0.554$ ). On average, $29 \%$ of the studied collembola were tested positive for nematode DNA. Detection frequency declined from $S$. coeca and $H$. nitidus (both on average 65\%) to $T$. vulgaris (45\%) to P. armata (35\%) to T. minor (25\%) to S. curviseta and F. candida (both $20 \%$ ), and $H$. purpurescens (15\%). No nematode DNA was detected in L. cyaneus and P. minuta. 

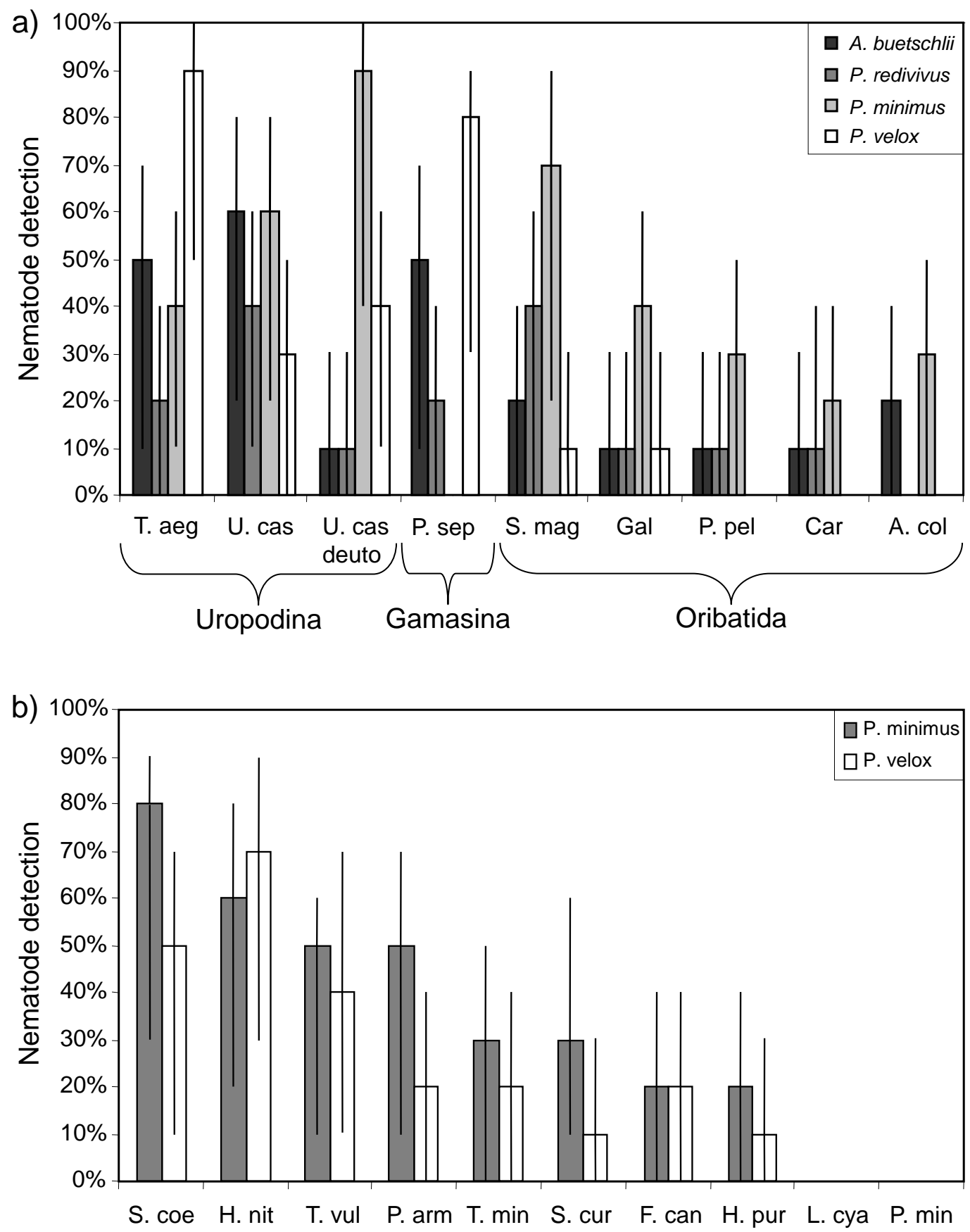

Figure 2: Frequency of detection of (a) Acrobeloides buetschlii, Panagrellus redivivus, Plectus minimus and Plectus velox in soil mite species, and (b) $P$. minimus and $P$. velox in collembola species by molecular gut content analysis in no-choice laboratory experiments. $\mathrm{T}$. aeg = Trachytes aegrota, $\mathrm{U}$. cas = Uropoda cassidea, U. cas. deuto = deutonymph of U. cassidea, P. sep = Pergamasus septentrionalis, S. mag $=$ Steganacarus magnus, Gal $=$ Galumna sp., P. pel $=$ Platynothrus peltifer, Car $=$ Carabodes sp., A. col = Achipteria coleoptrata, $\mathrm{S}$. coe $=$ Sinella coeca, $\mathrm{H}$. nit $=$ Heteromurus nitidus, $\mathrm{T}$. vul $=$ Tomocerus vulgaris, $\mathrm{P}$. arm $=$ Protaphorura armata, $\mathrm{T} . \mathrm{min}=$ Tomocerus minor, $\mathrm{S}$. cur $=$ Sinella curviseta, F. can = Folsomia candida, H. pur = Hypogastrura purpurescens, L. cya $=$ Lepidocyrtus cyaneus, P. $\min =$ Proisotoma minuta. Error bars represent upper and lower confidence limits; for statistical analysis see text. 


\subsection{Field study}

The frequency of detection of nematode DNA in microarthropods differed significantly between the eight studied microarthropod species $\left(X^{2}=29.16, d f=7, P=0.0001\right)$, and varied between the three studied nematode species $\left(X^{2}=71.14, d f=2, P<0.0001\right)$. Further, detection of nematode DNA in microarthropod species varied among nematode species (significant mite species $\times$ nematode species interaction; $\mathrm{X}^{2}=60.02, \mathrm{df}=14 ; \mathrm{P}<0.0001$; Figure 3$)$. On average, $70 \%$ of the studied microarthropods were tested positive for Plectus spp., $12 \%$ for A. buetschlii and none for $P$. redivivus.

In detail, DNA of $A$. buetschlii was detected in $33 \%$ of the investigated individuals of $S$. magnus and E. muscorum, and in $20 \%$ and $10 \%$ of the specimens of N. palustris and N. silvestris, respectively. DNA of Plectus spp. was detected in all of the studied individuals of $U$. cassidea, S. magnus, $N$. silvestris and C. subglobulus, in 80,42 and $35 \%$ of the specimens of $N$. palustris, $T$. vulgaris and $O$. villosa, respectively, but in none of the individuals of $E$. muscorum. $P$. redivivus was detected in none of the tested microarthropod individuals.

Nematode density at the study site was $543,200 \mathrm{ind} / \mathrm{m}^{2}$, thereof Plectus spp. contributed $12,894 \mathrm{ind} / \mathrm{m}^{2}$ and Acrobeloides spp. 6,498 ind $/ \mathrm{m}^{2}$; no individuals of the genus Panagrellus spp. were observed. Collembola density was $12,220 \mathrm{ind} / \mathrm{m}^{2}$ and that of Acari (predominantly Oribatida) $8,850 \mathrm{ind} / \mathrm{m}^{2}$. 


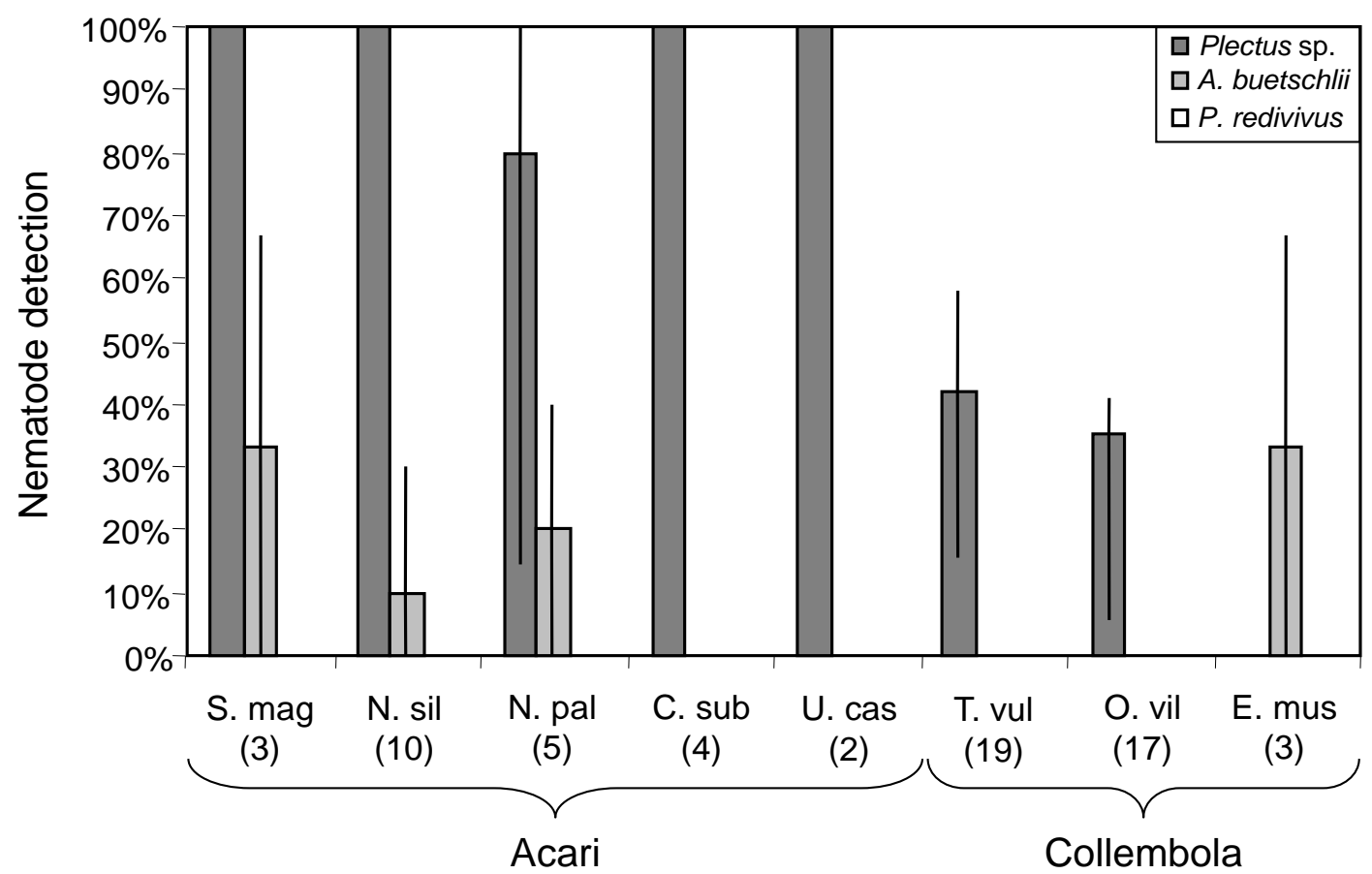

Figure 3: Frequency of detection of Acrobeloides buetschlii, Panagrellus redivivus and Plectus spp. in soil mite and collembola species by molecular gut content analyses in the field. U. cas = Uropoda cassidea, S. mag = Steganacarus magnus, N. sil = Nothrus silvestris, N. pal = Nothrus palustris, C. sub = Chamobates subglobulus, $\mathrm{T}$. vul $=$ Tomocerus vulgaris, $\mathrm{O}$. vil $=$ Orchesella villosa, $\mathrm{E}$. mus $=$ Entomobrya muscorum. Error bars represent upper and lower confidence limits; for statistical analysis see text.

\section{Discussion}

\subsection{Primer design}

For nematode detection in microarthropod predators we designed and optimized specific primers that amplify short fragments of the multi-copy $18 \mathrm{~S}$ rDNA. The designed primers operated well and sensitively detected DNA of nematode prey species in the gut of microarthropods in the laboratory and the field. We choose $18 \mathrm{~S}$ rDNA for designing primers as it is a conserved gene which allowed us to develop primers for prey taxa at different taxonomic resolution (Hoogendoorn \& Heimpel 2001; Jarman et al. 2004; King et al. 2008; Kuusk \& Agustí 2008) and has been used for nematode barcoding (Floyd et al. 2002; Pompanon et al. 2011). We aimed at designing species-specific nematode primers; however, proving specificity at the level of species is difficult and needs extensive checking for cross-reactions of related and other taxa. The developed primers may be partly genus- rather than species-specific. In fact, NCBI blast search indicated that our primers for Plectus spp. ( $P$. minimus and $P$. velox) amplify a conserved fraction of the 18S rDNA of this genus suggesting resolution at genus level. In 
contrast, the primers for $A$. buetschlii and $P$. redivivus amplify a more variable fraction of the nematode $18 S$ rDNA indicating that these are indeed species-specific.

Detection of gut content is only possible when the primers detect tiny amounts of prey DNA as the amount of DNA decreases during digestion (Sint et al. 2011). Further, detection of prey DNA may be hampered by the large amount of predator DNA (King et al. 2008). We therefore performed a twofold serial dilution with and without fixed amounts of predator DNA in every reaction using our new primers (Eitzinger \& Traugott 2011). Very small quantities of prey DNA were detected in these PCR reactions ranging from 0.025 to $0.050 \mathrm{pg} / \mathrm{\mu g}$ with and without predator DNA, indicating that the presence of predator DNA did not affect the PCR reaction.

\subsection{Primer specificity}

For investigation of trophic interactions the designed primers need to be prey specific; especially when used in the field where they may bind to DNA of a large number of prey species. We tested our primers against more than 100 potential prey species in laboratory trials. Only few cross-reactions with non-target organisms were detected and no crossreactions occurred to potential predators used in this study. Moreover, primer suitability was tested by sequencing every positive reaction from the field experiment to check for potential non-target sequences. NCBI blast search of these sequences confirmed that only target species were amplified. Overall, this indicates that the detected cross-reactions of non-target species were irrelevant in our study and that our primers are suitable to assign predator-prey relationships for nematodes in the field.

\subsection{Detection time of nematode prey in predators}

After feeding on nematodes for $4 \mathrm{~h}$ each of the four nematode species was detected in predators but detection frequency varied between prey species. We minimized variations in prey detection due to different temperatures (Hoogendorn \& Heimpel 2001; von Berg et al. 2008a; Sint et al. 2011) by using the same ambient temperature during the feeding and starving of the microarthropods, and also similar annealing temperature of the three primer sets. Different detection frequencies therefore likely reflect differences in digestion of nematode species. However, prey detection may also be affected by predator behaviour, e.g. active or passive foraging or voracity (Read et al. 2006). Fed with $A$. buetschlii detection rates for $P$. septentrionalis differed from those of $S$. magnus feeding on Plectus velox, $P$. minimus and Panagrellus redivivus. Presumably, fast and aggressive predators such as gamasid mites 
ingest prey faster than slow moving species such as oribatid mites. Digestion rates of prey species have been reported to vary little among predator species (Agusti et al. 2003; Sheppard et al. 2004; Read et al. 2006), but we found detection rates to vary markedly in oribatids (but not in collembolans) fed the closely related nematode species $P$. minimus and $P$. velox indicating that prey digestion may also vary for similar prey species.

Moreover, the exposure time of nematode prey to predators had a major impact on its detection time. Overall, there was no clear difference of nematode detection in the gut of the respective predators 4 and $48 \mathrm{~h}$ after feeding on nematodes. However, generally detection frequency was higher in $S$. magnus when feeding for $48 \mathrm{~h}$ on $P$. velox compared to $4 \mathrm{~h}$, but this did not hold for $P$. minimus. This indicates that the duration of feeding on nematodes strongly impacts prey detection time in predators. Potentially, prey detection also varies with prey size as $P$. minimus is much smaller than $P$. velox and therefore may be easier to handle by oribatid mites.

Detection efficiency of nematode DNA in the gut of predators declined little and inconsistently with time; even $128 \mathrm{~h}$ post feeding prey DNA in predators was detected. This indicates that even long after feeding prey DNA can be detected in the gut of predators which is advantageous for prey screening in predators in the field (Sheppard \& Harwood 2005).

A shortcoming of this study is that we could not visually prove feeding of predators on prey. Therefore, failure to detect prey in predators may have been due to predators that did not feed on the offered prey rather than failure to detect prey present in the gut. The fact that detection rates always were below $100 \%$ suggests that some of the predators did not feed on the nematodes offered.

Overall, our results indicate that rates of detection and detection time of nematodes in mite predators vary strongly and depend on both prey species and the duration predators fed on prey. Similar to these findings prey detection frequency has been found to vary in every predator-prey combination (Zaidi et al. 1999; Hoogendorn \& Heimpel 2001; Harwood et al. 2004; Sheppard et al. 2005; Hosseini et al. 2008; Traugott \& Symondson 2008; von Berg et al. 2008a,b; Gagnon et al. 2011; Sint et al. 2011). Therefore, data on detection frequencies of prey in predators need careful interpretation (Greenstone et al. 2007).

\subsection{Trophic links as indicated by laboratory studies}

In our laboratory studies many mite and collembola species were detected positive for DNA of one or more of the four nematode species studied (in the following termed 'feeding' or 
'consumption'). Despite this may not necessarily reflect the situation in the field, the results suggest that gamasid and uropodid mites heavily feed on nematode species which is conform to previous findings (Karg 1993; Scheu \& Falca 2000; Klarner et al. 2013). Gamasid mites are mobile predators of the upper soil layer (Koehler 1999). P. septentrionalis was tested positive for each of the nematode species except the small $P$. minimus indicating that this large gamasid predator preferentially feeds on large nematode prey. Indeed, $P$. septentrionalis is known to hunt for bigger nematodes, collembolans, and little sclerotized mites (Karg 1993; Peschel et al. 2006, Heidemann et al. 2011); the small $P$. minimus therefore presumably is beyond the size range of $P$. septentrionalis.

Uropodid mites reach high densities at sites rich in organic matter which typically are colonized heavily by nematodes (Koehler 1999). T. aegrota was detected to feed on each of the four nematode species offered, but to preferentially feed on $P$. velox. This suggests that $T$. aegrota feeds on a wide range of nematode taxa including predatory nematode species of different body size explaining why small mesostigmate predators occupy high trophic positions in the soil food web (Klarner et al. 2013). U. cassidea also fed on each of the nematode species with small nematodes, i.e. P. minimus, being particularly important for deutonymphs. This indicates that the size spectrum of prey differs between developmental stages in predators which also has been suggested from data on stable isotope analyses (Klarner et al. 2013).

Similar to gamasid and uropodid mites each of the oribatid mite species fed on nematodes, however, prey detection frequency was lower than in gamasids an uropodids. Oribatid mites have been assumed to mainly feed on dead organic material (Behan-Pelletier 1999; Maraun \& Scheu 2000). However, adult S. magnus heavily fed on P. minimus and also P. redivivus, and of the oribatid mite species studied most frequently was tested positive for nematode prey. The results support earlier findings based on parasitic nematodes used as model nematode prey (Heidemann et al. 2011) and suggests that S. magnus indeed feeds on free-living soil nematodes. Each of the oribatid mite species studied, including Galumna spp., preferentially fed on small nematodes confirming earlier suggestions that if feeding on nematodes oribatid mites prefer to feed on small nematode species (Rockett \& Woodring 1966; Muraoka \& Ishibashi 1976; Rockett, 1980; Oliveira et al. 2007). Low frequency of prey detection in $P$. peltifer, A. coleoptrata and Carabodes spp. suggests that these species only occasionally feed on nematodes and predominantly act as decomposers ingesting dead organic matter (Siepel 1990, Schneider et al. 2004, Heidemann et al. 2011).

Feeding of collembolans on nematodes was only investigated for two nematode species but the results resemble those for oribatid mites. Collembolans are known to feed on dead organic material, plants and fungi (Ruess et al. 2004; Chamberlaine et al. 2006a,b), however, 
some are known to also feed on nematodes (Visser et al. 1987; Chen et al. 1995, Ruess et al. 2005; Read et al. 2006). Nematode detection frequency was high in S. coeca, H. nitidus, T. vulgaris and $P$. armata indicating that nematodes form an important part of their diet. In contrast, detection frequency of nematodes was low in T. minor, S. curviseta, F. candida and $H$. purpurescens indicating that these species only occasionally feed on nematodes (Lee \& Widden 1996; Chamberlain et al. 2006a,b; Read et al. 2006). This supports earlier suggestions on the opportunistic feeding mode and high degree of omnivory in collembolans (Chahartaghi et al. 2005). However, the differences in nematode detection rates also point to niche differentiation in collembolans, e.g., the fact that no nematode DNA was detected in L. cyaneus and $P$. minuta suggest that these species occupy distinctly different niches. Overall, the results indicate that nematodes form a significant fraction of the diet of collembolans.

\subsection{Nematodes as prey in the field}

At least one of the nematode species studied was detected in each of the microarthropod species analysed from field samples indicating that feeding on nematodes is common in both collembolans and mites including oribatid mites. The nematode genus Plectus was detected most frequently, followed by $A$. buetschlii whereas none of the studied microarthropod species fed on $P$. redivivus. Of the studied nematode species Plectus species are most abundant at the study site suggesting that microarthropods opportunistically feed on the most frequent nematodes. However, in the studied forest Plectus spp. contributed only about $2 \%$ to total nematode density suggesting that either the microarthropods feed preferentially on these nematodes or feeding on Plectus spp. represents only a small fraction of the nematodes fed by microarthropods.

Among oribatid mites S. magnus, $N$. silvestris and $N$. palustris frequently fed on Plectus spp., but occasionally also consumed $A$. buetschlii. Feeding on nematodes by $S$. magnus and $N$. palustris is rather surprising as natural variations in ${ }^{15} \mathrm{~N} /{ }^{14} \mathrm{~N}$ ratios suggest them to feed on litter materials, i.e. to function as primary decomposers (Schneider et al. 2004). In contrast, stable isotope signatures of $N$. silvestris indicated that this species at least in part lives on an animal diet. The results therefore suggest that even oribatid mite species which predominantly feed on litter occasionally also ingest nematodes. The oribatid mite $C$. subglobulus, the uropodid mite $U$. cassidea and the collembola $T$. villosa und $O$. vulgaris also were tested positive for Plectus spp., indicating that they also feed on nematodes. In addition to the mite species $S$. magnus, $N$. silvestris and $N$. palustris only the collembola species $E$. muscorum fed on $A$. buetschlii, however, due to high variation in detection rates it remains unclear whether this is due to selective feeding on certain nematode species. 
Overall, our findings indicate that many oribatid mite and collembola species, previously thought to predominantly live on litter material and microorganisms particularly fungi, also feed on free-living nematodes. Although nematodes may only comprise a small fraction of the diet of these species they likely contribute significantly to their nutrition as nematodes are of high nutritional value (Chamberlain et al. 2006a). Thus, many soil microarthropods live on a mixed diet, supporting previous assumptions that omnivory is common in soil animal food webs (Scheu and Setälä 2002). Future studies need to investigate to what extend different fractions of animal prey in decomposer animals contribute to niche separation thereby contributing to the astounding diversity of microarthropods in soil.

\section{Conclusions}

Overall, the results suggest that nematodes are an important but underestimated component of the diet of soil microarthropods previously assumed to predominantly feed on plant litter and microorganisms. Feeding on bacterial feeding nematodes by oribatid mites and collembolans, the most abundant microarthropod taxa in soil, presumably contributes significantly to the flux of energy from root exudates via bacteria to higher trophic levels including large predator species such as centipedes (Crotty et al. 2011; Ferlian et al. 2012; Pollierer et al. 2012). Notably, we only analyzed few nematode taxa and they only represented a small fraction of the nematode community at the study site. Nevertheless, they were frequently detected as prey in a range of microarthropod species suggesting that nematodes form an important part of the diet of collembola and mite species including those previously thought to live as detritivores or fungivores. The results therefore highlight that the decomposer food web is more complex than previously assumed with trophic relationships being exceptionally diverse. Novel tools such as molecular gut content analysis are indispensible if we are to understand the structure and functioning of these food webs.

\section{Acknowledgements}

This work was funded by the German Research Foundation (DFG; MA 2461/8) and performed at the Georg August University Göttingen. We thank René Seiml-Buchinger for providing the nematodes and Patrick Pachl for help during the sequence submission process. Nicole Scheunemann, Christel Fischer, Simone Cesarz and Bernhard Klarner we thank for collection and identification of Macfayden samples, nematode-, mite- and collembola species. We thank Bernhard Eitzinger for providing the non-target macrofauna species and for fruitful 
The role of free-living nematodes as prey for higher trophic levels of forest soil food webs

discussions and we thank him and Martin Rosenberger for helpful comments to the sensitivity experiments. 


\section{References}

Agusti N, Shayler SP, Harwood JD, Vaughan IP, Sunderland KD, Symondson WOC (2003) Collembola as alternative prey sustaining spiders in arable ecosystems: prey detection within predators using molecular markers. Molecular Ecology, 12, 3467-3475.

Alphei J (1995) Die freilebenden Nematoden von Buchenwäldern mit unterschiedlicher Humusform: Struktur der Gemeinschaften und Funktion in der Rhizosphäre der Krautvegetation. Berichte des Forschungszentrum Waldökosysteme (Göttingen), A 125, 45-48.

Anderson JM (1975) The enigma of soil animal species diversity. In: Vanek, J., (Ed.), Progress in Soil Ecology. Proceedings of the Fifth International Colloquium of Soil Zoology, 1973, pp. 51-58. Academica, Prague.

Bardgett RD, Wardle DA, (2010) Above-Belowground Linkages: Biotic Interactions, Ecosystem Processes, and Global Change (Oxford Series in Ecology and Evolution). Oxford University Press, New York.

Behan-Pelletier VM (1999) Oribatid mite biodiversity in agroecosystems: role for bioindication. Agriculture, Ecosystems and Environment, 74, 411-423.

Bongers T, Ferris $\mathrm{H}$ (1999) Nematode community structure as a bioindicator in environmental monitoring. Trends in Ecology and Evolution, 14, 224-228.

Chahartaghi M, Langel R, Scheu S, Ruess L (2005) Feeding guilds in Collembola based on nitrogen stable isotope ratios. Soil Biology and Biochemistry, 37, 1718-1725.

Chamberlain PM, Bull ID, Black HIJ, Ineson P, Evershed RP (2006a) The effect of diet on isotopic turnover in Collembola examined using the stable carbon isotopic compositions of lipids. Soil Biology and Biochemistry, 38, 1146-1157.

Chamberlain PM, Bull ID, Black HIJ, Ineson P, Evershed RP (2006b) Collembolan trophic preferences determined using fatty acid distributions and compound-specific stable carbon isotope values. Soil Biology and Biochemistry, 38, 1257-1281.

Chen B, Snider RJ, Snider RM (1995) Food preference and effects of food type on the life history of some soil Collembola. Pedobiologia, 39, 496-505.

Crotty FV, Blackshaw RP, Murray PJ (2011) Tracking the flow of bacterially derived ${ }^{13} \mathrm{C}$ and ${ }^{15} \mathrm{~N}$ through soil fauna feeding channels. Rapid Communication of Mass Spectromony, 25, 1503-1513. 
Domes K, Althammer M, Norton RA, Scheu S, Maraun M (2007) The phylogenetic relationship between Astigmata and Oribatida (Acari) as indicated by molecular markers. Experimental and Applied Acarology, 42, 159-171.

Eitzinger B, Traugott M (2011) Which prey sustains cold-adapted invertebrate generalist predators in arable land? Examining prey choices by molecular gut-content analysis. Journal of Applied Ecology, 48, 591-599.

Erdmann G, Scheu S, Maraun M (2012) Regional factors rather than forest type drive the community structure of soil living oribatid mites (Acari, Oribatida). Experimental and Applied Acarology, 57, 157-169.

Ferlian O, Scheu S, Pollierer MM (2012) Trophic interactions in centipedes (Chilopoda, Myriapoda) as indicated by fatty acid patterns: Variations with life stage, forest age and season. Soil Biology and Biochemistry, 52, 33-42.

Ferris $\mathrm{H}$ (2010) Contribution of nematodes to the structure and function of the soil food web. Journal of Nematology, 42, 63-67.

Floyd R, Abebe E, Papert A, Blaxter M (2002) Molecular barcodes for soil nematode identification. Molecular Ecology, 11, 839-850.

Folmer O, Black M, Hoeh W, Lutz R, Vrijenhoek R (1994) DNA primers for amplification of mitochondrial cytochrome c oxidase subunit I from diverse metazoan invertebrates. Molecular Marine Biology and Biotechnology, 3, 294-299.

Freckman DW (1988) Bacterivorous nematodes and organic-matter decomposition. Agriculture, Ecosystems and Environment, 24, 195-217.

Gagnon A-È, Doyon J, Heimpel GE, Brodeur J (2011) Prey DNA detection success following digestion by intraguild predators: influence of prey and predator species. Molecular Ecology Resources, 11, 1022-1032.

Goodey JB (1963) Laboratory methods for work with plant and soil nematodes. Technical Bulletin of the Ministry of Agriculture, Fisheries and Food, 2, 1-72.

Greenstone MH, Rowley DL, Weber DC, Payton ME, Hawthorne DJ (2007) Feeding mode and prey detectability half-lives in molecular gut-content analysis: an example with two predators of the Colorado potato beetle. Bulletin of Entomological Research, 97, 201-209.

Griffiths BS (1990) A comparison of microbial-feeding nematodes and protozoa in the rhizosphere of different plants. Biology and Fertility of Soils, 9, 83-88. 
Hall TA (1999) BioEdit: a user friendly biological sequence alignment editor and analysis program for Win 95/98/NT. Nucleic Acids Symposium Series, 41, 95-98.

Harwood JD, Sunderland K, Symondson WOC (2004) Prey selection by linyphiid spiders: molecular tracking of the effects of alternative prey on rates of aphid consumption in the field. Molecular Ecology, 13, 3549-3560.

Heidemann K, Scheu S, Ruess L, Maraun M (2011) Molecular detection of nematode predation and scavenging in oribatid mites: Laboratory and field experiments. Soil Biology and Biochemistry, 43, 2229-2236.

Holovachov O (2006) Morphology and systematics of the order Plectida Malakhov, 1982 (Nematoda). Ponsen \& Looijen BV, Wageningen.

Hoogendorn M, Heimpel GE (2001) PCR-based gut content analysis of insect predators: using ribosomal ITS-1 fragments from prey to estimate predation frequency. Molecular Ecology, 10, 2059-2067.

Hosmer DW, Lemeshow S (1989) Applied Logistic Regression. Wiley, New York.

Hosseini R, Schmidt O, Keller MA (2008) Factors affecting detectability of prey DNA in the gut contents of invertebrate predators: a polymerase chain reaction-based method. Entomologia Experimentalis et Applicata, 126, 194-202.

Jarman SN, Deagle BE, Gales NJ (2004) Group-specific polymerase chain reaction for DNAbased analysis of species diversity and identity in dietary samples. Molecular Ecology, 13, 1313-1322.

Karg W (1993) Acari (Acarina), Milben. Unterordnung Parasitiformes (Anactinochaeta). Cohors Gamasina Leach. Raubmilben. Die Tierwelt Deutschlands 59. Teil; 2. überarbeitete Auflage. Gustav Fischer, Jena, Germany.

Kempson D, Lloyd M, Ghelardi R (1963). A new extractor for woodland litter. Pedobiologia, 3, $1-21$.

King RA, Read DS, Traugott M, Symondson WOC (2008) Molecular analysis of predation: a review of best practice for DNA-based approaches. Molecular Ecology, 17, 947-963.

Klarner B, Maraun M, Scheu S (2013) Trophic diversity and niche partitioning in a species rich predator guild - natural variations in stable isotope ratios $\left({ }^{13} \mathrm{C} /{ }^{12} \mathrm{C},{ }^{15} \mathrm{~N} /{ }^{14} \mathrm{~N}\right)$ of mesostigmatid mites (Acari, Mesostigmata) from Central European beech forest. Soil Biology and Biochemistry, 57, 323-333. 
Koehler HH (1999) Predatory mites (Gamasina, Mesostigmata). Agriculture, Ecosystem and Environment, 74, 395-410.

Kramer S, Marhan S, Ruess L, Armbruster W, Butenschoen O, Haslwimmer H, Kuzyakov Y, Pausch J, Scheunemann N, Schoene J, Schmalwasser A, Totsche KU, Walker F, Scheu S, Kandeler E (2012) Carbon flow into microbial and fungal biomass as a basis for the belowground food web of agroecosystems. Pedobiologica, 55, 111-119.

Kuusk AK, Agustí N (2008) Group-specific primers for DNA-based detection of springtails (Hexapoda: Collembola) within predator gut contents. Molecular Ecology Resources, 8, 678-681.

Lee Q, Widden P (1996) Folsomia candida, a fungivorous collembolan, feeds preferentially on nematodes rather than soil fungi. Soil Biology and Biochemistry, 28, 689-690.

Macfadyen A (1961) Improved funnel-type extractors for soil arthropods. Journal of Animal Ecology, 30, 171-184.

Maraun M, Migge S, Schaefer M, Scheu S (1998) Selection of microfungal food by six oribatid mite species (Oribatida, Acari) from two different beech forests. Pedobiologia, 42, 232-240.

Maraun M, Scheu S (2000) The structure of oribatid mite communities (Acari, Oribatida): patterns, mechanisms and implications for future research. Ecography, 23, 374-382.

Maraun M, Martens H, Migge S, Theenhaus A, Scheu S (2003a) Adding to "the enigma of soil animal diversity": fungal feeders and saprophagous soil invertebrates prefer similar food substrates. European Journal of Soil Biology, 39, 85-95.

Maraun M, Heethoff M, Scheu S, Weigmann G, Norton RA, Thomas RH (2003b) Radiation in sexual and parthenogenetic oribatid mites (Oribatida, Acari) as indicated by genetic divergence of closely related species. Experimental and Applied Acarology, 29, 265-277.

Moore JC, Hunt HW (1988) Resource compartmentation and the stability of real ecosystems. Nature, 333, 261-263.

Moore JC, McCann K, Setälä H, De Ruiter PC (2003) Top-down is bottom-up: does predation in the rhizosphere regulate aboveground dynamics? Ecology, 84, 846-857.

Muraoka M, Ishibashi N (1976) Nematode-feeding mites and their feeding behaviour. Applied Entomology and Zoology, 11, 1-7. 
Mulder C, Vonk JA (2011) Nematode traits and environmental constraints in 200 soil systems: scaling within the 60-6000 $\mu \mathrm{m}$ body size range. Ecology, 92, 2004.

Oliveira AR, de Moraes GJ, Ferraz LCCB (2007) Consumption rate of phytonematodes by Pergalumna sp. (Acari: Oribatida: Galumnidae) under laboratory conditions determined by a new method. Experimental and Applied Acarology, 41, 183-189.

Peschel K, Norton RA, Scheu S, Maraun M (2006) Do oribatid mites live in enemy-free space? Evidence from feeding experiments with the predatory mite Pergamasus septentrionalis. Soil Biology and Biochemistry, 38, 2985-2989.

Petersen H, Luxton M (1982) A comparative analysis of soil fauna populations and their role in decomposition processes. Oikos, 39, 288-309.

Pimm SL, Lawton JH, Cohen JE (1991) Food web patterns and their consequences. Nature, 350, 669-674.

Pompanon F, Deagle BE, Symondson WOC, Brown DS, Jarman SN, Taberlet P (2011) Who is eating what: diet assessment using next generation sequencing. Molecular Ecology, 21, 1931-1950.

Pollierer MM, Dyckmans J, Scheu S, Haubert D (2012) Carbon flux through fungi and bacteria into the forest soil animal food web as indicated by compound-specific ${ }^{13} \mathrm{C}$ fatty acid analysis. Functional Ecology, 26, 978-990.

R Development Core Team (2009) R: A Language and Environment for Statistical Computing. R Foundation for Statistical Computing, Vienna, Austria, ISBN 3-900051-07-0. Available from http://www.R-project.org.

Read DS, Sheppard SK, Bruford MW, Glen DM, Symondson WOC (2006). Molecular detection of predation by soil micro-arthropods on nematodes. Molecular Ecology, 15, 1963-1972.

Rocket CL (1980) Nematode predation by oribatid mites (Acari: Oribatida). International Journal of Acarology, 6, 219-224.

Rockett CL, Woodring JP (1966) Oribatid mites as predators of soil nematodes. Annual Entomological Society of America, 59, 669-671.

Ruess $L$ (1995) Studies on the nematode fauna of an acid forest soil: spatial distribution and extraction. Nematologica, 41, 229-239. 
Ruess L, Häggblom MM, Langel R, Scheu S (2004) Nitrogen isotope ratios and fatty acid composition as indicators of animal diets in belowground systems. Oecologia, 139, 336346.

Ruess L, Schütz K, Haubert D, Häggblom MM, Kandeler E, Scheu S (2005) Application of lipid analysis to understand trophic interactions in soil. Ecology, 86, 2075-2082.

Rusek J (1998) Biodiversity of Collembola and their functional role in the ecosystem. Biodiversity and Conservation, 7, 1207-1219.

Schaefer M (1990) The soil fauna of a beech forest on limestone: trophic structure and energy budget. Oecologia, 82, 128-136.

Schatz H (2002) Die Oribatidenliteratur und die beschriebenen Oribatidenarten (1758-2001) - Eine Analyse. Abhandlungen und Berichte des Naturkunde Museums Görlitz, 74, 37-45.

Scheu S, Falca M (2000) The soil food web of two beech forests (Fagus sylvatica) of contrasting humus type: stable isotope analysis of a macro- and a mesofauna-dominated community. Oecologia, 123, 285-286.

Scheu S, Setälä H (2002) Multitrophic interactions in decomposer food webs. In: Multitrophic Level Interactions (eds. Tscharntke T, Hawkins BA), pp. 223-264. Cambridge University Press, Cambridge, UK.

Scheu S, Ruess L, Bonkowski, M (2005) Interactions between microorganisms and soil microand mesofauna. Soil Biology, 3, 253-275.

Schneider K, Migge S, Norton RA, Scheu S, Langel R, Reineking A, Maraun M (2004) Trophic niche differentiation in oribatid mites (Oribatida, Acari): evidence from stable isotope ratios $\left({ }^{15} \mathrm{~N} /{ }^{14} \mathrm{~N}\right)$. Soil Biology and Biochemistry, 36, 1769-1774.

Sheppard SK, Harwood JD (2005) Advances in molecular ecology: tracking trophic links through predator-prey food-webs. Functional Ecology, 19, 751-762.

Sheppard SK, Henneman ML, Memmott J, Symondson WOC (2004) Infiltration by alien predators into invertebrate food webs in Hawaii: a molecular approach. Molecular Ecology, 13, 2077-2088.

Sheppard SK, Bell J, Sunderland KD, Fenlon J, Skervin D, Symondson WOC (2005) Detection of secondary predation by PCR analyses of the gut contents of invertebrate generalist predators. Molecular Ecology, 14, 4461-4468. 
Siepel H (1990) Niche relationships between two panphytophagous soil mites, Nothrus silvestris Nicolet (Acari, Oribatida, Nothridae) and Platynothrus peltifer (Koch) (Acari, Oribatida, Camisiidae). Biology and Fertility of Soils, 9, 139-144.

Sint D, Raso L, Kaufmann R, Traugott M (2011) Optimizing methods for PCR-based analysis of predation. Molecular Ecology Resources, 11, 795-801.

Sokal RR, Rohlf FJ (1995) Biometry. WH Freeman and Co., New York.

Strickland MS, Wickings K, Bradford MA (2012) The fate of glucose, a low molecular weight compound of root exudates, in the belowground foodweb of forests and pastures. Soil Biology and Biochemistry, 49, 23-29.

Sunderland KD (1988) Quantitative methods for detecting invertebrate predation occurring in the field. Annals of Applied Biology, 112, 201-224.

Symondson WOC (2002) Molecular identification of prey in predator diets. Molecular Ecology, $11,627-641$.

Terborgh J, Estes JA (2010) Trophic Cascades and the Changing Dynamics of Nature. Island Press, Washington.

Traugott M, Symondson WOC (2008). Molecular analysis of predation on parasitized hosts. Bulletin of Entomological Research, 98, 223-231.

van Hees PAW, Jones DL, Finlay R, Godbold DL, Lundström US (2005) The carbon we do not see - the impact of low molecular weight compounds on carbon dynamics and respiration in forest soils: a review. Soil Biology and Biochemistry, 37, 1-13.

Visser S, Parkinson D, Hassall M (1987) Fungi associated with Onychiurus subtenuis (Collembola) in an aspen woodland. Canadian Journal of Botany, 65, 635-642.

von Berg K, Traugott M, Symondson WOC, Scheu S (2008a) The effects of temperature on detection of prey DNA in two species of carabid beetle. Bulletin of Entomological Research, 98, 263-269.

von Berg K, Traugott M, Symondson WOC, Scheu S (2008b) Impact of abiotic factors on predator-prey interactions: DNA-based gut content analysis in a microcosm experiment. Bulletin of Entomological Research, 98, 257-261.

Walter DE (1988a) Predation and mycophagy by endostigmatid mites (Acariformes: Prostigmata). Experimental and Applied Acarology, 4, 159-166. 
Walter DE (1988b) Nematophagy by soil arthropods from the Shortgrass Steppe, Chihuahuan Desert and Rocky Mountains of the Central United States. Agriculture, Ecosystems and Environment, 24, 307-316.

Wardle DA Yeates GW (1993) The dual system of competition and predation as regulatory forces in terrestrial ecosystems: evidence from decomposer food-webs. Oecologia, 93, 303306.

Yeates GW, Bongers T, DeGoede RGM, Freckman DW, Georgieva SS (1993) Feeding-habits in soil nematode families and genera - an outline for soil ecologists. Journal of Nematology, 25, 315-331.

Yeates GW, Hawke MF, Rijkse WC (2000) Changes in soil fauna and soil conditions under Pinus radiata agroforestry regimes during a 25-year tree rotation. Biology and Fertility of Soils, 31, 391-406.

Yeates GW (2010) Nematodes in ecological webs. In: Encyclopedia of Life Sciences, pp. 111. Wiley \& Sons, Chichester.

Zaidi RH, Jaal Z, Hawkes NJ, Hemingway J, Symondson WOC (1999) Can multiple-copy sequences of prey DNA be detected amongst the gut contents of invertebrate predators? Molecular Ecology, 8, 2081-2087.

Zunke U, Perry RN (1997) Nematodes: harmful and beneficial organisms. In: Fauna in soil ecosystems (ed. Benckiser G), pp. 85-133. Marcel Dekker, New York. 


\section{Supporting Information}

Table S1: Designed primers, target organism, primer sequence, size of amplified fragments from the 18S rDNA gene and optimized annealing temperature to detect the nematodes Acrobeloides buetschlii, Panagrellus redivivus and Plectus spp. (P. minimus and $P$. velox).

\begin{tabular}{|c|c|c|c|c|}
\hline Target organism & Primer name & Sequence 5'-3' & Size [bp] & Annealing temp. $\left[{ }^{\circ} \mathrm{C}\right]$ \\
\hline Acrobeloides buetschlii & $\begin{array}{l}\text { Acro-F-197 } \\
\text { Acro-R-484 }\end{array}$ & $\begin{array}{l}\text { CGG CTT CGG CTG TTT CTG GTT } \\
\text { GAT GAC CGG CCT CAT AAG AGA ACG GTC } \\
\text { TC }\end{array}$ & $287 \mathrm{bp}$ & $62^{\circ} \mathrm{C}$ \\
\hline Panagrellus redivivus & $\begin{array}{l}\text { Pana-F-278 } \\
\text { Pana-R-494 }\end{array}$ & $\begin{array}{l}\text { CCA ACG GCA GTG TAT TGT CCT GAC G } \\
\text { TAG GAA GGT TGT AAA TTC }\end{array}$ & $217 \mathrm{bp}$ & $63^{\circ} \mathrm{C}$ \\
\hline $\begin{array}{l}\text { Plectus spp. } \\
\text { (P. minimus and } \\
\text { P. velox) }\end{array}$ & Plec-F-644 & TAG ARC CGT GGT CTT ATT CT & $156 \mathrm{bp}$ & $62^{\circ} \mathrm{C}$ \\
\hline
\end{tabular}

Table S2: Cross-reaction test of 108 non-target-species (including the respective target nematode species) with the specific primers for Acrobeloides buetschlii, Panagrellus redivivus and Plectus spp. (P. minimus and P. velox).

- no band occurred; + band occurred on the agarose gel; (+) not all species of the genus were tested positive / no detection in predator's gut.

\begin{tabular}{|c|c|c|c|c|}
\hline Species & Family & $\begin{array}{c}\text { Acrobeloides } \\
\text { buetschlii }\end{array}$ & $\begin{array}{c}\text { Panagrellus } \\
\text { redivivus }\end{array}$ & $\begin{array}{l}\text { Plectus } \\
\text { spp. }\end{array}$ \\
\hline \multicolumn{5}{|l|}{ Acari } \\
\hline Dinychus perforatus Kramer, 1882 & Gamasida & - & - & - \\
\hline Eviphis ostrinus (C.L. Koch, 1838) & Gamasida & - & - & - \\
\hline Geholaspis aeneus Krauss, 1970 & Gamasida & - & - & - \\
\hline Lysigamasus sp. & Gamasida & - & - & - \\
\hline Parasitus lunulatus (J. Müller, 1859) & Gamasida & - & - & - \\
\hline Pergamasus septentrionalis (Oudemans, 1902) & Gamasida & - & - & - \\
\hline Veigaia nemorensis (C.L. Koch, 1836) & Gamasida & - & - & - \\
\hline Zercon sp. & Gamasida & - & - & - \\
\hline Zerconopsis remiger (Kramer, 1876) & Gamasida & - & - & - \\
\hline Achipteria coleoptrata (Linné, 1758) & Oribatida & - & - & - \\
\hline Belbidae & Oribatida & - & - & - \\
\hline Carabodes femoralis (Nicolet, 1855) & Oribatida & - & - & - \\
\hline Chamobates subglobulus (Oudemans, 1900) & Oribatida & - & - & - \\
\hline Eupelops sp. & Oribatida & - & - & $(+)$ \\
\hline Euzetes globulus (Nicolet, 1855) & Oribatida & - & - & - \\
\hline Galumna sp. & Oribatida & - & - & - \\
\hline Hermannia gibba (C.L, Koch, 1836) & Oribatida & - & - & - \\
\hline Hypochthonius rufulus Koch, 1835 & Oribatida & - & - & - \\
\hline Liacarus xylariae (Schrank, 1803) & Oribatida & - & - & + \\
\hline Nothrus palustris (C. L. Koch 1839) & Oribatida & - & - & - \\
\hline Nothrus silvestris Nicolet, 1855 & Oribatida & - & - & - \\
\hline Oribatella calcarata (C. L. Koch, 1836) & Oribatida & - & - & - \\
\hline
\end{tabular}


Oribatella quadricornuta (Michael, 1880)

Oribatida

Platynothrus peltifer (Koch, 1839)

Oribatida

Steganacarus magnus (Nicolet, 1855)

Oribatida

Tritegeus bisulcatus Grandjean, 1953

Oribatida

Oribatida

Uropodida

Trachytes aegrota (C. L. Koch, 1841)

Urodiaspis tecta (Kramer, 1876)

Uropoda cassidea (Hermann, 1804)

Uropodida

Uropodida

Uroseius cylindricus (Berlese, 1916)

Uropodida

Araneae

Coelotes inermis (L. Koch, 1855)

Clubiona terrestris Westring, 1851

Harpactea lepida (C.L. Koch, 1838)

Micrargus herbigradus (Blackwall, 1854)

Microneta viaria (Blackwall, 1841)

Tapinocyba insecta (L. Koch, 1869)

Walckenaeria cucullata (C. L. Koch, 1836)

Walckenaeria obtusa Blackwall, 1836

Robertus lividus (Blackwall, 1836)

Amaurobiidae

Clubionidae

Dysderidae

Linyphiidae

Linyphiidae

Linyphiidae

Linyphiidae

Linyphiidae

Theridiidae

Chilopoda

Strigamia acuminata (Leach, 1815)

Lithobius lapidicola Meinert, 1872

Lithobius mutabilis L. Koch, 1862

Lithobius muticus (C.L. Koch, 1847)

Lithoibius nodupilipes Latzel, 1881

Lithobius crassipes L. Koch, 1862

Geophilomorpha

Lithobiidae

Lithobiidae

Lithobiidae

Lithobiidae

Lithobiidae

\section{Coleoptera}

Abax parallelipipedus (Piller \& Mitterbacher, 1783)

Carabidae

Carabidae

Carabidae

Pterostichus oblongopunctatus (Fabricius, 1787)

Carabidae

Curculionidae

Tropiphorus sp.

Athous haemorrhoidalis (Fabricius, 1801)

Athous subfuscus (Müller, 1764)

Lamprohiza splendidula (Linnaeus, 1767)

Nargus anisotomoides (Spence, 1815)

Domene scabricollis (Erichson, 1840)

Habrocerus capillaricornis (Gravenhorst, 1806)

Philonthus sp.

Stilicus rufipes (Germar, 1836)

Xantholinus laevihatus Jacobsen, 1849

Xantholinus tricolor (Fabricius 1787)

Elateridae

Elateridae

Lampyridae

Leiodidae

Staphylinidae

Staphylinidae

Staphylinidae

Staphylinidae

Staphylinidae

Staphylinidae

Collembola

Entomobrya muscorum (Nicolet, 1841)

Entomobryidae

Entomobryidae

Entomobryidae

Entomobryidae

Entomobryidae

Entomobryidae 
Ceratophysella cf. denticulata (Bagnall, 1941)

Hypogastrura burkilli (Bagnall, 1940)

Folsomia candida Willem, 1902

Isotoma viridis Bourlet, 1839

Proisotoma minuta (Tullberg 1871)

Protaphorura armata (Tullberg, 1869)

Tomocerus minor (Lubbock, 1862)

Dermaptera

Chelidurella sp.

Diplopoda

Haploporatia eremita (Verhoeff, 1909)

Polydesmus complanatus (Linnaeus, 1761)

Glomeris sp.

Diplura

Campodea sp.

Diptera

Drosophila melanogaster Meigen, 1830

Musca domestica Linnaeus, 1758

Isopoda

Ligidium cf. hypnorum (Cuvier, 1792)

Porcellio sp.

Trichoniscus pusillus Brandt, 1833

Trichorhina tomentosa (Budde-Lund, 1893)

Lepidoptera

Galleria sp.

Mollusca

Deroceras sp.

Myriapoda

Symphyla

Nematoda

Acrobeloides buetschlii (de Man, 1884)

Heterorhabditis megidis Poinar, Jackson \& Klein, 1987

Panagrellus redivivus Goodey, 1945

Turbatrix aceti (Müller, 1783)

Plectus minimus Cobb, 1893

Plectus velox Bastian, 1865

Pratylenchus zeae Graham, 1951

Caenorhabditis elegans (Maupas, 1900)

Phasmarhabditis hermaphrodita (Schneider, 1859)

Steinernema feltiae (Filipjev, 1934)

Oligochaeta

Enchytraeidae

Aporrectodea caliginosa (Savigny, 1826)
Hypogastruridae

Hypogastruridae

Isotomidae

Isotomidae

Isotomidae

Onychiuridae

Tomoceridae

Dermaptera

Diplopoda
Diplopoda
Glomeridae

Campodeidae

Drosophilidae

Muscidae

Isopoda
Isopoda
Isopoda
Platyarthridae

Pyralidae

Gastropoda

Myriapoda

Cephalobidae

Heterorhabditidae

Panagrolaimidae

Panagrolaimidae

Plectidae

Plectidae

Pratylenchidae

Rhabditidae

Rhabditidae

Steinernematidae

Enchytraeidae

Lumbricidae 
Dendrobaena octaedra (Savigny, 1826)

Lumbrius terrestris Linnaeus, 1758

Octolasion cyaneum (Savigny 1826)

Opiliones

Lophopilio palpinalis (Herbst, 1799)

Anelasmocephalus cambridgei (Westwood, 1874)

Trogulus nepaeformis (Scopoli, 1763)

\section{Lumbricidae}

Lumbricidae

Lumbricidae

Phalangiidae

Trogulidae

Trogulidae

Pseudoscorpione

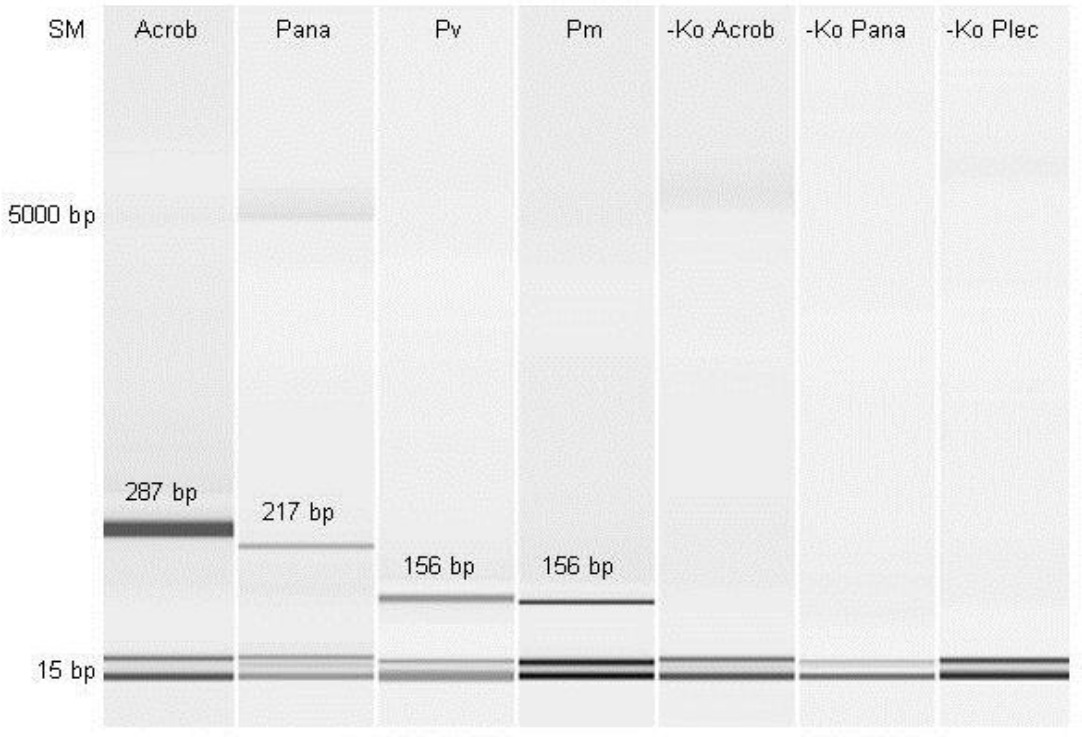

Figure S1: Visualisation of amplified 18S rDNA fragments of Acrobeloides buetschlii, Panagrellus redivivus, Plectus velox and Plectus minimus using specific primer sets in the QIAxcel system (with the QX Alignment Marker 15bp/5kb). Lane 1 Acrob: A. buetschlii (Acrob-F-247 + Acrob-R-554); Lane 2 Pana: P. redivivus (Pana-F-379 + Pana-R-611); Lane 3 Pv and Lane 4 Pm: P. velox and P. minimus (Plec-F-789 + Plec-R-961); Lane 5 - 7: Negative control using $\mathrm{H}_{2} \mathrm{O}$ instead of DNA tested with the respective primer pairs. SM: with QIAxcel, an internal marker (15 and $5000 \mathrm{bp}$ ) is used (QX Alignment Marker 15 bp/ 5kb; Qiagen, Hilden, Germany). 


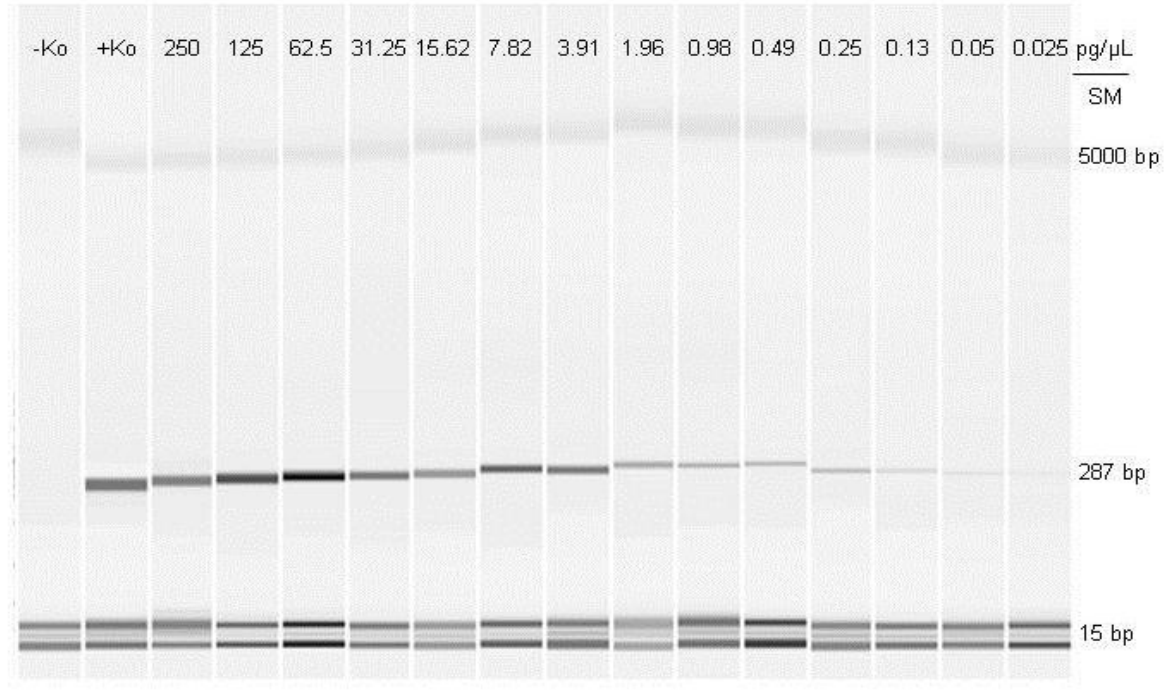

Figure S2: Visualisation of primer sensitivity in the QIAxcel system (with the QX Alignment Marker 15 $\mathrm{bp} / 5 \mathrm{~kb}$ ) using two-fold serial dilution of DNA from Acrobeloides buetschlii as template in a PCR with specific primer sets. Lane $1-\mathrm{Ko}$ : Negative control using $\mathrm{H}_{2} \mathrm{O}$ instead of DNA tested with the primer pair for A. buetschlii (Acrob-F-247 + Acrob-R-554); Lane 2 +Ko: Positive control; Lane 3-16: different concentrations of template DNA $(\mathrm{pg} / \mu \mathrm{l})$ in the PCR reaction in presence of $200 \mathrm{pg} / \mu \mathrm{l}$ DNA of Steganacarus magnus. SM: with QIAxcel, an internal marker (15 and $5000 \mathrm{bp}$ ) is used (QX Alignment Marker 15 bp/ 5kb; Qiagen, Hilden, Germany).

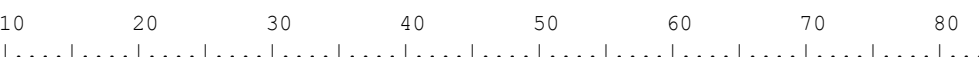
$\ldots|\ldots| \ldots|\ldots| \ldots|\ldots| \ldots|\ldots| \ldots|\ldots| \ldots|\ldots| \ldots|\ldots| \ldots|\ldots| \ldots|\ldots| \ldots \mid$ $\begin{array}{ll}\text { Panagrellus redivivus } & \text { TGGTTGTGACGGGTAACGAGAATTAGGGTTCGACTCCGGAGAAATAGCCTGAGAAACGGCTTTTACATCCAAGGAAGGCAGCAG } \\ \text { Plectus spp. } & \text { TGGTTTCCCTTGATGCTCTTTACTGGGTGTCTTGGGTGGCTAGCGAGTTTACTTTGAAAAAATIAGAGTGCTTAACACAGGCTA }\end{array}$ Plectus spp.

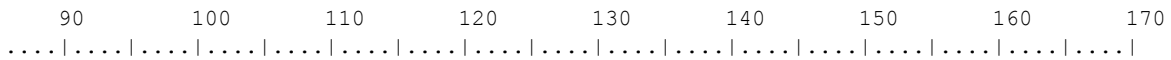

Acrobeloides buetschlii GTATCTGACTACCATGGTGATCACGCGTAACGGAGAATAAGGTTCGGCTCCGGAGAGTTCGCCTGAGAATCGCGACACATCT Panagrellus redivivus GCGCGAAAATTACCCACTCTTAGTACGAGGAGGTAGTGACGAGAAGTGACAAGATCTGTCCCTTCGGGGCGGGTCATTGGAATG Plectus spp. ACGCCTGAATACTTGTGCATGGAATAAT

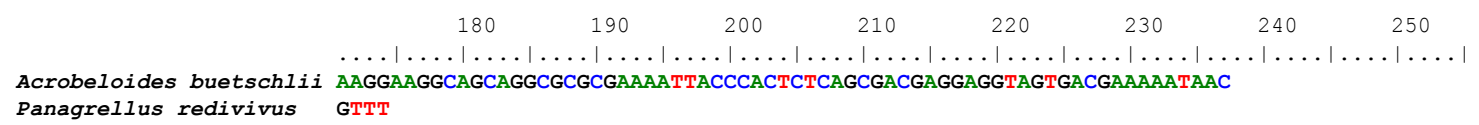

Figure S3: Sequence of the fragments (without primer region) amplified with specific primers for Acrobeloides buetschlii, Panagrellus redivivus and Plectus spp. 


\section{Chapter 4}

Consumption of nematodes by soil microarthropods varies between microhabitats of deciduous forests as indicated by molecular gut content analyses

Kerstin Heidemann, Liliane Ruess, Stefan Scheu, Mark Maraun

Submitted:

Heidemann K, Ruess L, Scheu S, Maraun M. Consumption of nematodes by soil microarthropods varies between microhabitats of deciduous forests as indicated by molecular gut content analyses. 


\section{Abstract}

Soils are complex and heterogeneous habitats including not only litter and soil but also microhabitats such as mosses, fungal mats and grass patches. Soil animal food webs in such microhabitats have been separated in a slow fungal and a fast bacterial energy channel. Bacterial feeding nematodes are an important component of the bacterial energy channel by consuming bacteria and forming prey for higher trophic levels such as soil microarthropods. Investigating the role of nematodes as prey for higher trophic level consumers has been hampered by methodological problems related to their small body size and lack in skeletal structures which can be traced in the gut of consumers. Recent results from molecular gut content analyses suggest that nematodes form major prey of soil microarthropods including those previously thought to live as detritivores. Using molecular markers we traced nematode prey (Plectus spp. and A. buetschlii) in fourteen abundant soil microarthropod species including Mesostigmata and Oribatida (Acari) from three different habitats (litter, grass and moss). We hypothesized that (1) mite species differentially consume different nematode species, (2) mite feeding differs between the three habitats, and (3) feeding on nematodes differs between mite species. Mites indeed differentially consumed the two nematode taxa with consumption of individual species / genera being related to their density. As expected the consumption of nematodes differed between habitats indicating shifts in trophic niches with changing habitat characteristics. Also as expected the different mite species differentially consumed nematodes indicating differences in trophic niches which likely contribute to the high diversity of microarthropods in deciduous forests. Overall, the results suggest that free-living bacterial feeding nematodes form an important prey for soil microarthropods including those previously assumed to live as detritivores. 


\section{Introduction}

The soil system is patchy and comprises different habitats, such as litter, patches of mosses and grass, and fine and coarse woody debris (Mikola \& Sulvaka 2001; Proctor et al. 2002). These habitats significantly affect the density and distribution of species, but also contribute to variations in interactions between soil animal species (Sulkava \& Huhta 1998; Hohberg \& Traunspurger 2005). Microhabitats and associated spatial heterogeneity cause species to be patchily distributed (Nielsen et al. 2012; Caruso et al. 2012a,b). Thereby microhabitats contribute to the turnover of species at small spatial scales and to high diversity of soil animal species (Anderson 1975; Scheu \& Setälä 2002; Maraun et al. 2003a).

Soil food webs form an essential component of terrestrial ecosystems (Scheu \& Setälä 2002; Bardgett \& Wardle 2010). Based on predator-prey interactions they are responsible for the flux of matter and energy through ecological systems (Pimm 1991; Terborgh \& Estes 2010). In soil carbon and nutrients are channelled to higher trophic levels via the bacterial, fungal and plant litter energy channel (Moore \& Hunt 1988; Scheu et al. 2005). Depending on forest type and microhabitat the relative contribution of the different energy channels to carbon and nutrient cycling varies (Ruess 2003). Further, carbon processing is assumed to vary between the different energy channels with the bacterial energy channel being the fastest (van Hees et al. 2005; Strickland et al. 2012). However, the role of different consumer organisms for channelling carbon to higher trophic levels remains little understood, but it is commonly assumed that bacterial feeding nematodes and their microarthropod predators form a major link of the bacterial energy channel (Freckman 1988; Crotty et al. 2011; Ferlian et al. 2012).

Free-living soil nematodes hold a key position in soil food webs (Bongers \& Ferris 1999; Moore et al. 2003). They comprise a large diversity of species differing in feeding nodes thereby consuming a wide range of resources (Yeates et al. 1993). Further, nematodes represent the most abundant metazoan animals of terrestrial ecosystems with densities in soil reaching millions of individuals per square metre (Yeates et al. 2000). Notably, bacterial feeding nematodes typically account for $>50 \%$ of total free-living nematodes but in hot spots of microbial activity they may account for 90-99\% (Zunke \& Perry 1997; Mulder \& Vonk 2011). Together with protists they form the main bacterial consumers in virtually any ecosystem including soils (Griffiths 1990; Zunke \& Perry 1997; Scheu et al. 2005). Due to their high abundance and the fact that they are little defended, nematodes are assumed to form abundant prey of many soil arthropods, in particular predatory soil microarthropods such as gamasid mites (Walter \& Ikonen 1989; Walter \& Proctor 1998). However, due to the scarcity of skeletal elements only the mouthparts can be traced in the gut of nematode predators and therefore nematodes are regarded 'invisible' prey (Walter 1988; Sunderland 1988). Due to the difficulties 
in tracing nematode prey in predators their role in soil food webs likely has been underestimated (Walter 1988; Read et al. 2006; Heidemann et al. 2011).

Mites (Acari) are abundant, diverse and ubiquitous microarthropods in soil (Maraun \& Scheu 2000). Mesostigmatid mites (Mesostigmata: Gamasina and Uropodina) are known to live as predators and many species feed on nematodes (Karg 1993; Koehler 1997; 1999; Klarner et al. 2013). In contrast, most oribatid mite species (Oribatida) are assumed to feed on bacteria, fungi and/or dead organic material. However, recent studies using stable isotopes and molecular markers indicate that many oribatid mite species live as predators or scavengers (Schneider et al. 2004; Heidemann et al. 2011; Maraun et al. 2011). Due to the high density of soil microarthropods feeding on nematodes is likely to contribute substantially to the flux of energy from bacteria via bacterial feeding nematodes through mites and collembolans to top trophic levels (Crotty et al. 2011; Ferlian et al. 2012; Pollierer et al. 2012). Including nematodes as high quality food in their diet is likely to contribute to the high local density of microarthropods and may explain the high trophic position of some detritivore species as indicated by stable isotope analysis (Scheu \& Falca 2000; Pollierer et al. 2009; Maraun et al. 2011).

Studying nematodes as prey for mites is difficult in the field since both are small and difficult to observe in the porous habitat of the soil. Further, mites typically are only ingesting prey liquids preventing detection of prey fragments in their guts (Wardle \& Yeates 1993; Symondson 2002; Scheu et al. 2005). Molecular gut content analysis using molecular markers specific for nematodes i.e., primers that only bind to certain genera or species of nematodes, is a promising tool for investigating predator-prey interactions in soil and is expected to allow fundamental progress in soil food web research, including the opening of hitherto neglected trophic interactions (Read et al. 2006; Heidemann et al. 2011).

The present study aimed at investigating the role of free-living bacterial feeding nematode species as prey for soil mites in deciduous forests and their variation between microhabitats. We used primers for two common and abundant bacterial feeding nematode species/ genera ( $A$. buetschlii and Plectus spp.) developed recently (see Chapter 3 ) and screened 14 soil mite species for feeding on these nematodes. Mites from different forest habitats including litter, and patches of moss and grass were investigated to test whether the food spectrum of these mites varies in space. We hypothesized that (1) mite species differentially consume nematode species, (2) feeding of mites on nematodes varies in space, i.e. differs between forest microhabitats, and (3) mites previously thought to predominantly live as fungivores, i.e. oribatid mites, frequently consume nematodes irrespective of forest microhabitat. 


\section{Material and Methods}

\subsection{The organisms}

Acrobeloides buetschlii (de Man, 1884) and Plectus spp. are free-living bacterial feeding nematodes and were investigated as prey for soil mites. Both have a cosmopolitan distribution and are abundant in the litter layer of forest soils as well as in patches of moss and grass. $A$. buetschlii reaches a length of $0.3-0.5 \mathrm{~mm}$. Species of the genus Plectus are among the most abundant nematodes of the Plectidae, the most widespread nematodes of the world (Wu et al. 2011), and even occur in the Antarctic (Freckman \& Virginia 1993; Powers et al. 1998). Plectus spp. reach a length of $0.35-1.2 \mathrm{~mm}$.

We investigated 14 soil mite species as potential predators of nematodes, including three mesostigmatid mite species, i.e. Dinychus perforatus Kramer, 1882 (Uropodina), Pergamasus septentrionalis (Oudemans, 1902) (Gamasina) and Uropoda cassidea (Hermann, 1804) (Uropodina), and eleven oribatid mite species, i.e. Achipteria coleoptrata (Linné, 1758), Belbidae, Carabodes femoralis (Nicolet, 1855), Eupelops spp., Galumna spp., Hermannia gibba (C.L. Koch, 1836), Nothrus palustris (C.L. Koch 1839), Nothrus silvestris Nicolet, 1855, Oribatella calcarata (C.L. Koch, 1836), Platynothrus peltifer (C.L. Koch, 1839) and Steganacarus magnus (Nicolet, 1855). Specimens from different microhabitats were screened for feeding on $A$. buetschlii and Plectus spp. using specific primers.

\subsection{Study site}

Samples were taken from the litter layer, and patches of moss and grass from an area of $80 \mathrm{~m}^{2}$ of the Hainich forest (near Birkungen, Thüringen, Germany) in May 2010. The Hainich is the largest cohesive deciduous forest of Germany with a mean annual temperature of 6.5-8 ${ }^{\circ} \mathrm{C}$, a mean annual precipitation of $500-800 \mathrm{~mm}$ and an average soil $\mathrm{pH}$ at the study sites of 4.6. It is dominated by beech (Fagus sylvatica) interspersed with ash (Fraxinus excelsior), lime (Tilia europaea), maple (Acer platanoides and A. pseudoplatanus) and wild service trees (Sorbus torminalis). The parent rock is Triassic limestone; the main soil types are Luvisols, Cambisols and Stagnosols (Erdmann et al. 2012).

\subsection{Field sampling}

In May 2010 we collected animals in the litter layer, and in patches of moss and grass of a minimum size of $1 \mathrm{~m}^{2}$. In an area of $80 \mathrm{~m}^{2}$ in the forest three sites were identified and at each 
of these sites samples from each of the three habitats were taken. Mites for molecular gut content analysis were sampled from plots of $\sim 1 \mathrm{~m}^{2}$ by heat for three hours (Kempson et al. 1963) and identified to species level; the species were selected based on their abundance and presence in the three microhabitats. Individuals were checked for attached nematodes; no nematodes were attached. Handling of the specimens followed the recommendations of King et al. (2008) and guidelines given in Heidemann et al. (2011). Three species of mesostigmatid mites and eleven species of oribatid mites were investigated: $D$. perforatus (0-31-0 individuals from litter-moss-grass sites, respectively) [Mesostigmata, Uropodina], P. septentrionalis (128-0) [Mesostigmata, Gamasina], U. cassidea (25-23-10) [Mesostigmata, Uropodina], A. coleoptrata (87-8-17), Belbidae (37-78-25), C. femoralis (0-10-0), Eupelops spp. (37-11-23), Galumna spp. (52-36-15), H. gibba (0-10-0), N. palustris (0-10-21), N. silvestris (0-45-45), O. calcarata (11-0-0), P. peltifer (12-21-0), S. magnus (0-32-0) [all Oribatida]. Individual mites were placed in $180 \mu \mathrm{l}$ buffer ATL of the DNeasy ${ }^{\circledR}$ Blood \& Tissue Kit (Qiagen GmbH, Hilden, Germany) and placed in the freezer at $-80^{\circ} \mathrm{C}$. The time between sampling in the field and freezing of the animals was on average $7 \mathrm{~h}$ with a maximum of $10 \mathrm{~h}$.

For investigating nematode and soil mite communities at the study sites additional samples were taken in close vicinity of the sites the mites for the molecular gut content analysis were taken. Nematodes were extracted from soil cores of a diameter of $2.5 \mathrm{~cm}$ using a modified Baermann method (see Ruess 1995). Mites were extracted from soil cores of a diameter of 20 $\mathrm{cm}$ and extracted by heat (Macfadyen 1961). Nematodes were sorted to trophic groups and within bacterial feeding species the densities of Acrobeloides spp. and Plectus spp. were determined.

\subsection{Molecular gut content analysis}

DNA from whole mite individuals was extracted following the protocol of the DNeasy ${ }^{\circledR}$ Blood \& Tissue Kit (Qiagen GmbH, Hilden, Germany). To verify the success of the DNA extractions and to exclude inhibition of the DNA amplification we performed a PCR with D3 primers amplifying a $320 \mathrm{bp}$ fragment of the $28 \mathrm{~S}$ rDNA for every sample (Maraun et al. 2003b). PCRs with D3 primers and thermal cycle parameters were carried out as described in Heidemann et al. (2011). To avoid false negative amplifications only samples with a PCR product were included in the analyses.

We used specific primers for $A$. buetschlii and Plectus spp. (the latter primer pair was tested positive for $P$. velox and $P$. minimus; we therefore assume it to be specific for the genus 
Plectus) amplifying $287 \mathrm{bp}$ and $156 \mathrm{bp}$ fragments of the 18S rDNA gene, respectively. These primers have been established recently and used successfully for tracing the target nematodes in microarthropod predators (see Chapter 3). Prey DNA was amplified as described in Chapter 3. PCR products were visualised using the capillary electrophoresis system QIAxcel (Qiagen $\mathrm{GmbH}$, Hilden, Germany). About half of the positive samples were sequenced by Macrogen Inc. (Seoul, South Korea) or by the Göttingen Genomics Laboratory at the Institute of Microbiology and Genetics of the Georg August University Göttingen and compared to NCBI (www.ncbi.nlm.nih.gov) to confirm the species identity of amplified fragments.

\subsection{Statistical analysis}

We calculated means and standard derivations of nematode detection rates by using the package 'simpleboot' in R (Simple Bootstrap Routines. R-package version 1.1-3; Roger D. Peng, 2008; R Development Core Team, 2009). Additionally, 95\% confidence limits were calculated by 9999 bootstrap resamples for each predator feeding on a certain prey.

Since $A$. buetschlii was only rarely consumed we excluded data on $A$. buetschlii from the analyses. With the dataset on the detection of Plectus spp. we tested (i) if feeding on Plectus spp. differed between microhabitats, (ii) if the mite species differentially consumed Plectus spp., and (iii) if differential consumption varies between microhabitats (mite species $\times$ microhabitat interaction). The analyses were carried out using logistic regression (Hosmer \& Lemeshow 1989; Sokal \& Rohlf 1995) in SAS 9.13 (SAS Institute Inc., Cary, USA).

\section{Results}

Nematode DNA was detected in the gut from 13 of the 14 studied mite species (in the following termed 'consumption' or 'feeding'). Generally, Plectus spp. was more frequently consumed than $A$. buetschlii $\left(\mathrm{X}^{2}=75.75\right.$, $\left.\mathrm{df}=1, \mathrm{P}<0.0001\right)$. Of the 752 individuals studied in total DNA of $A$. buetschlii was only detected in four mite individuals (in $U$. cassidea from litter and in Belbidae, C. femoralis and H. gibba from moss).

On average Plectus spp. was detected in $23.6 \%$ of the total mite individuals studied. Plectus spp. was detected more frequently in mites from litter (16.9\%) than in those from grass $(9.0 \%)$ and from moss patches $(8.1 \%)$ with the effect of microhabitat being significant $\left(X^{2}=11.71\right.$, df $=2, P=0.0029$ ). Detection of nematode DNA differed significantly between the studied mite species $\left(X^{2}=80.47, d f=13, P<0.0001\right)$, with the differences between mite species varying 
among microhabitats (mite species $\times$ microhabitat interaction; $X^{2}=29.71$, df $=12, P=0.0031$; Fig. 1).

Among the three mesostigmatid mite species studied feeding on Plectus spp. was most pronounced in P. septentrionalis (Fig. 1). Most individuals of this species from litter (83.3\%) were tested positive for Plectus spp., whereas none of the eight individuals studied from moss were tested positive; in grass patches no $P$. septentrionalis were found. The gamasid mite $D$. perforates was only found in moss patches were it fed on Plectus spp., however, detection frequency was low $(9.7 \%)$. In contrast, in the uropodid mite $U$. cassidea about half of the individuals from litter were tested positive for Plectus spp., $17.4 \%$ from moss and $30 \%$ from grass. In oribatid mites feeding on Plectus spp. was most pronounced in Belbidae with on average $14-24 \%$ of the individuals tested positive and the frequency of detection differing little between microhabitats. Three oribatid mite species were tested positive for Plectus spp. in two of the three studied microhabitats with the detection frequency being generally $<20 \%$ (Eupelops spp., N. palustris and $N$. silvestris.). Four oribatid mite species ( $A$. coleoptrata, Galumna spp., O. calcarata and P. peltifer) were tested positive for Plectus spp. in one of the three microhabitats with the detection frequency again being generally $<20 \%$ and a maximum in P. peltifer in moss (19.1\%) Only three of the eleven oribatid mite species studied were not detected to feed on Plectus spp. (C. femoralis, H. gibba and S. magnus).

Half of the samples positive for nematode DNA were sequenced and the sequences blasted for matches in the NCBI database (www.ncbi.nlm.nih.gov). The hits indicated that virtually all (99\%) of the bands indeed originated from Plectus or Acrobeloides indicating high specificity of the primers used and confirming that cross-reactions of non-target species are negligible.

Average nematode densities in the litter, grass and moss microhabitats were $2,277,366 \pm 423,016,898,317 \pm 207,557$ and $1,027,599 \pm 515,451 \mathrm{ind} . / \mathrm{m}^{2}$, respectively. Thereof Plectus spp. contributed 7.4, 9.3 and $11.9 \%$ in litter, grass and moss microhabitats, respectively. Respective values for Acrobeloides spp. were 5.4, 2.4 and $0.8 \%$. 


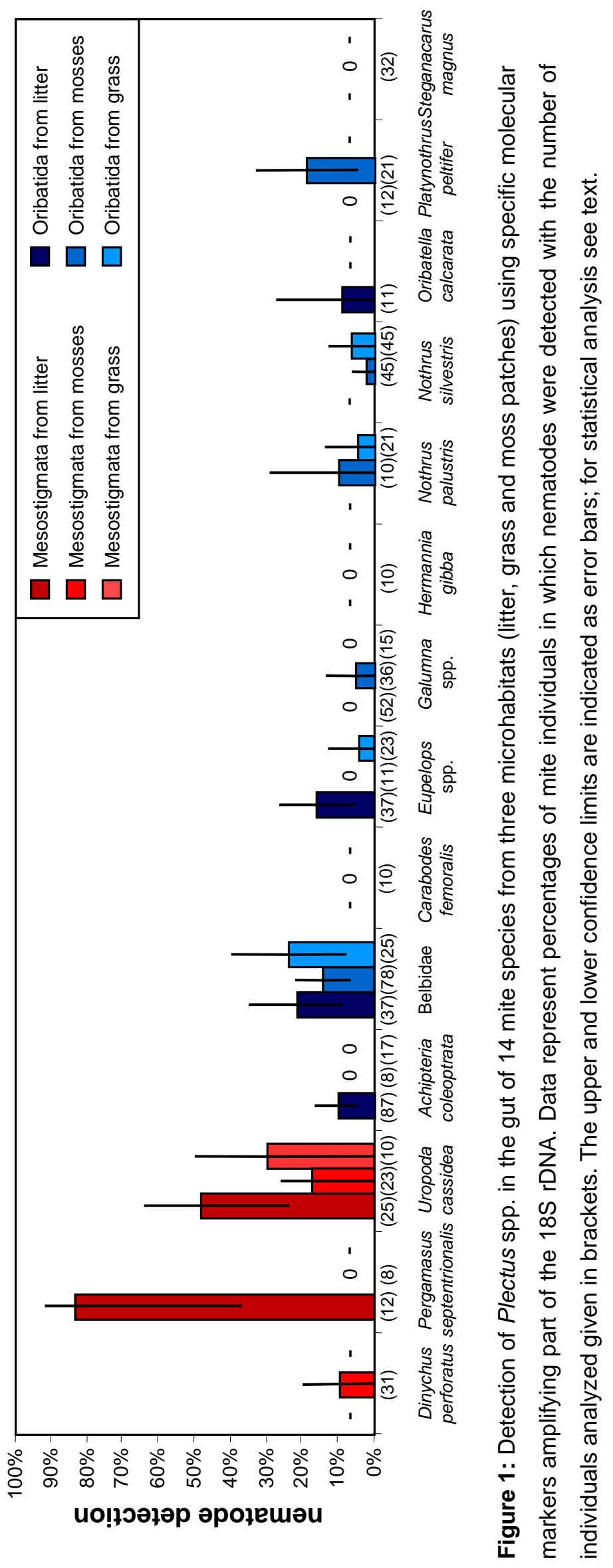




\section{Discussion}

Overall, 13 of the 14 mite species studied were detected to feed on nematodes with feeding on Plectus spp. being more important than feeding on $A$. buetschlii. This suggests that freeliving bacterial-feeding nematodes form an important component of the diet of soil mites including species that previously have been assumed to live as detritivores or fungal feeders, i.e. oribatid mites.

More frequent detection of Plectus spp. than A. buetschlii indicates that either $A$. buetschlii is avoided as prey, e.g. due to defense mechanism, or that it was less consumed because it was less abundant than Plectus spp. Additionally, A. buetschlii may also have been detected less frequently than Plectus spp. since the primers for $A$. buetschlii were species-specific whereas the primers for Plectus spp. presumably detect all species from the genus. Notably, the body size of both $A$. buetschlii and Plectus spp. overlapped suggesting that differential detection of the two target species/genera was not due to differences in body size.

Detection frequency of Plectus spp. as prey of mites in litter exceeded that in moss and grass patches indicating that feeding on nematodes varies between microhabitats of the forest floor. This suggests that trophic niches of soil microarthropods vary in space and indicates that mites adjust their prey spectrum if environmental conditions and prey availability change. Notably, differences in detection frequency of Plectus spp. in litter as compared to grass and moss corresponded to differences in density of Plectus spp. in these habitats. This suggests that nematodes were fed according to their availability as prey and indicates that mites opportunistically feed on nematodes.

The mite species studied differentially consumed Plectus spp. As expected feeding on nematodes in the two mesostigmatid mites $P$. septentrionalis and $U$. cassidea generally exceeded that in the studied oribatid mite species. Notably, feeding on Plectus spp. in the studied microhabitats by $U$. cassidea was more balanced than by $P$. septentrionalis. $P$. septentrionalis has been assumed to predominantly feed on collembolans and other little sklerotized mites (Karg 1993; Peschel et al. 2006). High detection frequency of Plectus spp. in $P$. septentrionalis in litter $(>80 \%)$ identifies this mite species as ferocious predator of nematodes and supports results of recent studies based on variations in stable isotope ratios suggesting this species to predominantly feed on nematodes (Scheu \& Falca 2000; Klarner et al. 2013). High detection frequency is remarkable considering that Plectus spp. contributed only $7.4 \%$ to total nematode density in litter. Failure to detect $P$. septentrionalis to feed on Plectus spp. in moss suggests that nematodes are less important prey for $P$. septentrionalis in moss as compared to litter, however, it may also be related to the low number of individuals 
studied (eight).

Uropodid mites have been assumed to predominantly feed on fungi but natural variations in stable isotope ratios suggested them to predominantly feed on nematodes. Assuming that they not only feed on Plectus spp. but on a range of nematode species results of the present study support this conclusion. Notably, uropodid mites reach high densities at sites rich in organic matter which typically are also colonized heavily by nematodes (Koehler 1999). D. perforatus (Mesostigmata) was only found in mosses where it occasionally fed on Plectus spp. This species is known to frequently occur in mosses (Karg 1989) where it has been assumed to predominantly feed on nematodes (Karg 1993). Considering that Plectus spp. contributed only $11.9 \%$ to total nematode density in moss and $D$. perforatus was tested positive for Plectus spp. in $9.7 \%$ of the studied individuals this may well be the case.

Oribatid mites have been assumed to mainly feed on litter, dead organic material, lichens or fungi (Behan-Pelletier 1999; Maraun \& Scheu 2000; Schneider et al. 2004), but some studies suggested them to also feed on nematodes (Rockett \& Woodring 1966; Muraoka \& Ishibashi 1976; Rockett 1980; Oliveira et al. 2007). Recent molecular studies highlighted that feeding on nematodes is common in oribatid mites (Heidemann et al. 2011). Results of the present study suggest that irrespective of forest floor microhabitat feeding on nematodes is common in Belbidae and this has been suggested earlier using parasitic nematodes as model nematode prey (Heidemann et al. 2011). Since Belbidae also feed on fungi as indicated by laboratory observations and stable isotopes (Maraun et al. 1998; 2011) they likely function as trophic level omnivores. Eupelops spp., N. palustris, N. silvestris, A. coleoptrata, O. calcarata, P. peltifer and Galumna spp. occasionally consumed Plectus spp. indicating that nematodes form part of their diet. The typical pincette-like 'peloptoid' mouthparts of Eupelops spp. have been assumed to serve for parenchyma feeding although nematode consumption is also conceivable. Eupelops spp. has been assumed to predominantly feed on fungi; however, Erdmann et al. (2007) suggested this species to feed on a mixture of litter, fungi and nematodes. $N$. palustris and $N$. silvestris were both tested positive for nematode prey in grass and moss patches, confirming earlier observations that both feed on nematodes (Heidemann et al. 2011). Stable isotope analysis suggested $N$. palustris to predominantly feed on litter but $N$. silvestris to feed on animal diet (Schneider et al. 2004). Similar detection frequency for Plectus spp. in $N$. palustris and $N$. silvestris in the present study does not support niche differentiation in respect to nematode prey in these two species. A. coleoptrata, $O$. calcarata and $P$. peltifer in litter occasionally consumed Plectus spp. indicating that these species regularly feed on nematodes but predominantly feed on other food sources. In fact, natural variations in stable isotope ratios suggest them to mainly feed on litter (Schneider et al. 2004). 
Galumna spp. consumed Plectus spp. only in moss not in litter and grass patches which was unexpected. Nematode feeding of Galumnidae (especially species of the genus Pergalumna) has been observed before (Rockett \& Woodring 1966; Muraoka \& Ishibashi 1976; Oliveira et al. 2007; Norton \& Behan-Pelletier 2009) and stable isotope signatures also indicate them to live as predators or scavengers (Schneider et al. 2004). Possibly, Galumna spp. mainly feed on other nematode species than the ones tested in our study. S. magnus, $C$. femoralis and $H$. gibba were not detected to feed on Plectus spp. indicating that they live on other diets than nematodes; indeed, based on natural variations in stable isotope ratios these species have been assumed to predominantly feed on litter and fungi (Schneider et al. 2004). However, in previous studies using molecular gut content analysis $S$. magnus has also been found to feed on nematodes in the litter layer of deciduous forests (Heidemann et al. 2011). As S. magnus was only found in moss patches in the present study the diet of this species may vary between microhabitats.

\section{Conclusions}

Overall, results of the study suggest that feeding of mites on nematodes is more common than previously assumed. By consuming bacterial feeding nematodes mites form an important link channelling carbon from bacteria to higher trophic levels. As many bacteria live on easily available carbon resources, such as root exudates and dissolved organic carbon leaching from litter, mites integrate rhizosphere and litter resources thereby contributing to the channelling of both above- and belowground resources to higher trophic levels of soil food webs. Differential feeding on nematodes by mite species suggests niche differentiation of mite species thereby contributing to the coexistence of the many mite species in the seemingly homogeneous soil habitat. Differences in the fraction of nematodes in the diet of mites of different microhabitats suggest generalistic feeding and high plasticity in prey capture. Notably, these conclusions not only apply to mites previously viewed as predators, such as mesostigmatid mites, but also to mites assumed to predominantly live as detritivores, such as oribatid mites. This highlights that mite-nematode interactions are more widespread than previously assumed and form a hitherto understudied link in soil food webs.

\section{Acknowledgements}

This work was funded by the German Research Foundation (DFG; MA 2461/8) and performed at the Georg August University Göttingen. We thank Garvin Schulz and Diana 
Consumption of nematodes by soil microarthropods varies between microhabitats of deciduous forests as indicated by molecular gut content analyses

Grubert for help with the field work and we thank Christel Fischer and Simone Cesarz for the identification of mesofauna- and nematode-species from the Macfayden samples. 


\section{References}

Anderson JM (1975) The enigma of soil animal species diversity. In: Vanek J (Ed.), Progress in Soil Ecology. Proceedings of the Fifth International Colloquium of Soil Zoology, 1973, Academica, Prague, pp. 51-58.

Bardgett RD, Wardle DA (2010) Above-Belowground Linkages: Biotic Interactions, Ecosystem Processes, and Global Change (Oxford Series in Ecology and Evolution). Oxford University Press, New York.

Bongers T, Ferris H (1999) Nematode community structure as a bioindicator in environmental monitoring. Trends in Ecology and Evolution, 14, 224-228.

Caruso T, Taormina M, Migliorini M (2012a) Relative role of deterministic and stochastic determinants of soil animal community: a spatially explicit analysis of oribatid mites. Journal of Animal Ecology, 81, 214-221.

Caruso T, Trokhymets V, Bargagli R, Convey P (2012b) Biotic interactions as a structuring force in soil communities: evidence from the micro-arthropods of an Antarctic moss model system. Oecologia, in press, doi: 10.1007/s00442-012-503-9.

Crotty FV, Blackshaw RP, Murray PJ (2011) Tracking the flow of bacterially derived ${ }^{13} \mathrm{C}$ and ${ }^{15} \mathrm{~N}$ through soil fauna feeding channels. Rapid Communication of Mass Spectromony, 25, 1503-1513.

Erdmann G, Otte V, Langel R, Scheu S, Maraun M (2007) The trophic structure of bark-living oribatid mite communities analysed with stable isotopes $\left({ }^{15} \mathrm{~N} ;{ }^{13} \mathrm{C}\right)$ indicates strong niche differentiation. Experimental and Applied Acarology, 41, 1-10.

Erdmann G, Scheu S, Maraun M (2012) Regional factors rather than forest type drive the community structure of soil living oribatid mites (Acari, Oribatida). Experimental \& Applied Acarology, 57, 157-169.

Ferlian O, Scheu S, Pollierer MM (2012) Trophic interactions in centipedes (Chilopoda, Myriapoda) as indicated by fatty acid patterns: Variations with life stage, forest age and season. Soil Biology and Biochemistry, 52, 33-42.

Freckman DW (1988) Bacterivorous nematodes and organic-matter decomposition. Agriculture, Ecosystems and Environment, 24, 195-217. 
Freckman DW, Virginia RA (1993) Extraction of nematodes from Dry Valley Antarctic soils. Polar Biology, 13, 483-487.

Griffiths BS (1990) A comparison of microbial-feeding nematodes and protozoa in the rhizosphere of different plants. Biology and Fertility of Soils, 9, 83-88.

Heidemann K, Scheu S, Ruess L, Maraun M (2011) Molecular detection of nematode predation and scavenging in oribatid mites: Laboratory and field experiments. Soil Biology \& Biochemistry, 43, 2229-2236.

Hohberg K, Traunspurger W (2005) Predator-prey interaction in soil food web: functional response, size-dependent foraging efficiency, and the influence of soil texture. Biology and Fertility of Soils, 41, 419-427.

Hosmer DW, Lemeshow S (1989) Applied Logistic Regression. Wiley, New York.

Karg W (1989) Acari (Acarina), Milben. Unterordnung Parasitiformes (Anactinochaeta). Cohors Uropodina Kramer. Schildkrötenmilben. Die Tierwelt Deutschlands 67. Teil; 2. überarbeitete Auflage. Gustav Fischer, Jena, Germany.

Karg W (1993) Acari (Acarina), Milben. Unterordnung Parasitiformes (Anactinochaeta). Cohors Gamasina Leach. Raubmilben. Die Tierwelt Deutschlands 59. Teil; 2. überarbeitete Auflage. Gustav Fischer, Jena, Germany.

Kempson D, Lloyd M, Ghelardi R (1963) A new extractor for woodland litter. Pedobiologia, 3, $1-21$.

Klarner B, Maraun M, Scheu S (2013) Trophic diversity and niche partitioning in a species rich predator guild - natural variations in stable isotope ratios $\left({ }^{13} \mathrm{C} /{ }^{12} \mathrm{C},{ }^{15} \mathrm{~N} /{ }^{14} \mathrm{~N}\right)$ of mesostigmatid mites (Acari, Mesostigmata) from Central European beech forest. Soil Biology and Biochemistry, 57, 323-333.

Koehler HH (1997) Mesostigmata (Gamasina, Uropodina), efficient predators in agroecosystems. Agriculture, Ecosystems \& Environment, 62, 105-117.

Koehler HH (1999) Predatory mites (Gamasina, Mesostigmata). Agriculture, Ecosystem and Environment, 74, 395-410.

Macfadyen A (1961) Improved funnel-type extractors for soil arthropods. Journal of Animal Ecology, 30, 171-184. 
Maraun M, Scheu S (2000) The structure of oribatid mite communities (Acari, Oribatida): patterns, mechanisms and implications for future research. Ecography, 23, 374-383.

Maraun M, Martens H, Migge S, Theenhaus A, Scheu S (2003a) Adding to "the enigma of soil animal diversity": fungal feeders and saprophagous soil invertebrates prefer similar food substrates. European Journal of Soil Biology, 39, 85-95.

Maraun M, Heethoff M, Scheu S, Weigmann G, Norton RA, Thomas RH (2003b) Radiation in sexual and parthenogenetic oribatid mites (Oribatida, Acari) as indicated by genetic divergence of closely related species. Experimental \& Applied Acarology, 29, 265-277.

Maraun M, Erdmann G, Fischer BM, Pollierer MM, Norton RA, Schneider K, Scheu S (2011) Stable isotopes revisited: Their use and limits for oribatid mite trophic ecology. Soil Biology and Biochemistry, 43, 877-882.

Mikola J, Sulkava P (2001) Responses of microbial-feeding nematodes to organic matter distribution and predation in experimental soil habitat. Soil Biology and Biochemistry, 33, 811-817.

Moore JC, Hunt HW (1988) Resource compartmentation and the stability of real ecosystems. Nature, 333, 261-263.

Moore JC, McCann K, Setälä H, De Ruiter PC (2003) Top-down is bottom-up: does predation in the rhizosphere regulate aboveground dynamics? Ecology, 84, 846-857.

Mulder C, Vonk JA (2011) Nematode traits and environmental constraints in 200 soil systems: scaling within the 60-6000 $\mu \mathrm{m}$ body size range. Ecology, 92, 2004.

Muraoka M, Ishibashi N (1976) Nematode-feeding mites and their feeding behaviour. Applied Entomology and Zoology, 11, 1-7.

Nielsen UN, Osler GHR, Campbell CD, Burslem DFRP, van der Wal R (2012) Predictors of fine-scale spatial variation in soil mite and microbe community composition differ between biotic groups and habitats. Pedobiologia, 55, 83-91.

Norton RA, Behan-Pelletier VM (2009) Suborder Oribatida. In: Krantz GW, Walter DE (Editors), A manual of Acarology, third ed. Texas Tech University Press.

Oliveira AR, de Moraes GJ, Ferraz LCCB (2007) Consumption rate of phytonematodes by Pergalumna sp. (Acari: Oribatida: Galumnidae) under laboratory conditions determined by a new method. Experimental and Applied Acarology, 41, 183-189. 
Pimm SL, Lawton JH, Cohen JE (1991) Food web patterns and their consequences. Nature, 350, 669-674.

Pollierer MM, Langel R, Scheu S, Maraun M (2009) Compartmentalization of the soil animal food web as indicated by dual analysis of stable isotope ratios $\left({ }^{15} \mathrm{~N} /{ }^{14} \mathrm{~N}\right.$ and $\left.{ }^{13} \mathrm{C} /{ }^{12} \mathrm{C}\right)$. Soil Biology and Biochemistry, 41, 1221-1226.

Pollierer MM, Dyckmans J, Scheu S, Haubert D (2012) Carbon flux through fungi and bacteria into the forest soil animal food web as indicated by compound-specific ${ }^{13} \mathrm{C}$ fatty acid analysis. Functional Ecology, 26, 978-990.

Powers LE, Ho M, Freckman DW, Virginia RA (1998) Distribution, community structure and microhabitats of soil invertebrates along an elevational gradient in Taylor Valley, Antarctica. Arctic and Alpine Research, 30, 133-141.

Proctor HC, Montgomery KM, Rosen KE, Kitching RL (2002) Are tree trunks habitats or highways? A comparison of oribatid mite assemblages from hoop-pine bark and litter. Australian Journal of Entomology, 41, 294-299.

Read DS, Sheppard SK, Bruford MW, Glen DM, Symondson WOC (2006) Molecular detection of predation by soil micro-arthropods on nematodes. Molecular Ecology, 15, 1963-1972.

Rocket CL (1980) Nematode predation by oribatid mites (Acari: Oribatida). International Journal of Acarology, 6, 219-224.

Rockett CL, Woodring JP (1966) Oribatid mites as predators of soil nematodes. Annual Entomological Society of America, 59, 669-671.

Ruess $L$ (1995) Studies on the nematode fauna of an acid forest soil: spatial distribution and extraction. Nematologica, 41, 229-239.

Ruess L (2003) Nematode soil faunal analysis of decomposition pathways in different ecosystems. Nematology, 5, 179-181.

Scheu S, Falca M (2000) The soil food web of two beech forests (Fagus sylvatica) of contrasting humus type: stable isotope analysis of a macro- and a mesofauna-dominated community. Oecologia, 123, 285-296.

Scheu S, Setälä H (2002) Multitrophic interactions in decomposer food webs. In: Multitrophic Level Interactions (eds. Tscharntke T, Hawkins BA), Cambridge University Press, Cambridge, pp. 223-264. 
Scheu S, Ruess L, Bonkowski M (2005) Interactions between microorganisms and soil microand mesofauna. Soil Biology, 3, 253-275.

Schneider K, Migge S, Norton RA, Scheu S, Langel R, Reineking A, Maraun M (2004) Trophic niche differentiation in oribatid mites (Oribatida, Acari): evidence from stable isotope ratios $\left({ }^{15} \mathrm{~N} /{ }^{14} \mathrm{~N}\right)$. Soil Biology and Biochemistry, 36, 1769-1774.

Sheppard SK, Bell J, Sunderland KD, Fenlon J, Skervin D, Symondson WOC (2005) Detection of secondary predation by PCR analyses of the gut contents of invertebrate generalist predators. Molecular Ecology, 14, 4461-4468.

Sokal RR, Rohlf FJ (1995) Biometry. W.H. Freeman and Co., New York.

Strickland MS, Wickings K, Bradford MA (2012) The fate of glucose, a low molecular weight compound of root exudates, in the belowground foodweb of forests and pastures. Soil Biology and Biochemistry, 49, 23-29.

Sulkava P, Huhta V (1998) Habitat patchiness affects decomposition and faunal diversity: a microcosm experiment on forest floor. Oecologia, 116, 390-396.

Sunderland KD (1988) Quantitative methods for detecting invertebrate predation occurring in the field. Annals of Applied Biology, 112, 201-224.

Symondson WOC (2002) Molecular identification of prey in predator diets. Molecular Ecology, 11, 627-641.

Terborgh J, Estes JA (2010) Trophic Cascades and the Changing Dynamics of Nature. Island Press, Washington.

van Hees PAW, Jones DL, Finlay R, Godbold DL, Lundström US (2005) The carbon we do not see - the impact of low molecular weight compounds on carbon dynamics and respiration in forest soils: a review. Soil Biology and Biochemistry, 37, 1-13.

Walter DE (1988) Predation and mycophagy by endostigmatid mites (Acariformes: Prostigmata). Experimental and Applied Acarology, 4, 159-166.

Walter DE, Ikonen EK (1989) Species, guilds, and functional groups: taxonomy and behavior in nematophagous arthropods. Journal of Nematology, 21, 315-327.

Walter DE, Proctor HC (1998) Feeding behaviour and phylogeny: observations on early derivative Acari. Experimental \& Applied Acarology, 22, 39-50. 
Wardle DA, Yeates GW (1993) The dual system of competition and predation as regulatory forces in terrestrial ecosystems: evidence from decomposer food-webs. Oecologia, 93, 303306.

Wu T, Ayres E, Bardgett RD, Wall DH, Garey JR (2011) Molecular study of worldwide distribution and diversity of soil animals. Proceedings of the National Academy of Sciences of the United States of America, 108, 17720-17725.

Yeates GW, Bongers T, DeGoede RGM, Freckman DW, Georgieva SS (1993) Feeding-habits in soil nematode families and genera - an outline for soil ecologists. Journal of Nematology, 25, 315-331.

Yeates GW, Hawke MF, Rijkse WC (2000) Changes in soil fauna and soil conditions under Pinus radiata agroforestry regimes during a 25 -year tree rotation. Biology and Fertility of Soils, 31, 391-406.

Zunke U, Perry RN (1997) Nematodes: harmful and beneficial organisms. In: Fauna in soil ecosystems (ed. Benckiser G), Marcel Dekker, New York. pp. 85-133. 
Chapter 5

General Discussion 
Results of this thesis represent major advances in the understanding of the soil animal food web which is more complex and trophically diverse than previously assumed. It provides promising tools to investigate soil animal food webs pointing to the role of bacterial-feeding nematodes as prey for microarthropods thereby channelling carbon from the rhizosphere to higher trophic levels.

The first part of this thesis, which used specific molecular markers for two entomopathogenic nematode species (Phasmarhabditis hermaphrodita and Steinernema feltiae; Read et al. 2006), showed that soil mites indeed consume nematodes and include dead and living prey in their diet (Chapter 2). Mite species, which previously were assumed to be decomposers, preyed on nematodes, although both feeding modes (predation and scavenging) seem to be common in microarthropods.

In the second part of this thesis newly designed molecular markers were used to investigate the role of free-living bacterial-feeding nematodes ( $A$. buetschlii, Panagrellus redivivus, Plectus minimus and Plectus velox) as prey for microarthropods (Chapter 3). Nematode DNA was detectable in the gut of a predator up to $128 \mathrm{~h}$; however, the detection time varied in each of the studied nematode-mite combination indicating that detection times vary individually for every predator-prey interaction. Although only few nematode taxa were analyzed, they were frequently detected as prey in a range of microarthropod species. This indicates that in the field nematodes form an important part of the diet of collembola and mite species including those previously thought to live as detritivores or fungivores.

The third part of this thesis showed that soil mites consume the investigated free- living soil nematodes to a different degree depending on their microhabitat indicating that the trophic niche of mites varies in space (Chapter 4). Overall, I conclude that trophic niche differentiation contributes to the coexistence of the large number of mite species in the seemingly homogeneous soil habitat.

Results of this thesis clearly show that several collembolan, mesostigmatid and oribatid mite species frequently consume nematodes in the field. Mesostigmatid mites have been assumed to feed on nematodes before (Karg 1993; Klarner et al. 2013) which was confirmed by results of this thesis indicating that especially Uropoda cassidea consumes nematodes frequently. Most microarthropods such as collembolans and oribatid mites were assumed to be 'classical decomposers' feeding mainly on litter, dead organic material or fungi (Behan-Pelletier 1999; Maraun \& Scheu 2000). However, results of this thesis support earlier studies suggesting nematode consumption for e.g., Folsomia candida, Hypochthonius rufulus and Nothrus silvestris (Read et al. 2006; Schneider et al. 2004; Pollierer et al. 2009), whereas for some species, such as Entomobrya muscorum, Nothrus palustris, Platynothrus peltifer and 
Steganacarus magnus, nematode consumption has never been observed or proposed before (Siepel 1990; Schneider et al. 2004; Chahartaghi et al. 2005;).

Whether feeding on nematodes is based on scavenging or predation remains unclear, although scavenging has been proposed to be frequent in microarthropods (Schneider et al. 2004; Chahartaghi et al. 2005). Predators have to attack, subdue and kill their prey whereas scavengers live on an easily available energy-rich resource that does not defend itself (Foltan et al. 2005). In contrast to scavenging, predation has a top-down effect since it contributes to population regulation of the species consumed. Therefore, from a food web perspective differentiating between predation and scavenging is essential. Results of this thesis showed that in the field dead and living prey is available as food for microarthropods, and frequent consumption of dead and living nematodes by mite species suggests that both feeding modes, predation and scavenging, are common in microarthropods. Therefore, soil microarthropods not only benefit from the high nutritional values of nematodes but likely also exert top-down forces on nematode populations. Unfortunately, molecular gut content analysis determines only the presence or absence of nematode DNA and can not discriminate between dead and living prey. However, the approach of adding model nematodes to the field uncovered that scavenging occurs in the field and needs more attention in the future.

Not only the feeding mode differs between microarthropod species, also nematode species were consumed differentially by the mites pointing to differences in the predator-prey interactions at the species level. This may be due to body size ratios, life stages, defense mechanisms, behavioural or physical resistance of the prey (Mulder et al. 2011). Results of this thesis indicate that the small $P$. minimus was avoided whereas the large $P$. velox was preferred by $P$. septentrionalis suggesting that body size ratios are likely to determine the prey choice of this mesostigmatid mite (Karg 1993). P. minimus was particularly important for deutonymphs of $U$. cassidea supporting the view that the size spectrum of prey differs between developmental stages in predators (Klarner et al. 2013). Results of this thesis also showed differences between the rate of consumption of $A$. buetschlii and Plectus spp. in the field. However, the body sizes of these nematodes overlapped suggesting that differential detection of the two target taxa in microarthropods was not due to differences in body size but rather due to differences in density of these nematode taxa at the study site indicating that mites opportunistically feed on nematodes.

Moreover, the model nematode $P$. hermaphrodita was more frequently consumed than $S$. feltiae and the latter was preferred as carrion over living individuals. This may be due to behavioural differences which are likely to affect encounter rates between prey and predators and the outcome of predator-prey interactions, e.g. S. feltiae follows a sit and wait strategy (Susurluk 2009) and P. hermaphrodita moves actively in search for hosts (MacMillan et al. 
2009). Furthermore, S. feltiae contains the specific symbiotic bacterium Xenorhabdus bovienii (Kaya and Gaugler 1993) which is necessary to kill insect hosts and has been observed to be toxic to Acari (Bussaman et al. 2006). This defence against consumption likely continues to function in dead specimens - at least temporarily.

Results of this thesis indicate that the detection frequency of Plectus spp. as prey of mites in litter exceeds that in moss and grass patches indicating that microarthropods consume nematodes to a different degree depending on the respective microhabitat. For instance, Galumna spp. and $P$. septentrionalis are known to feed on nematodes (Rockett \& Woodring 1966; Muraoka \& Ishibashi 1976; Scheu \& Falca 2000; Schneider et al. 2004; Oliveira et al. 2007; Norton \& Behan-Pelletier 2009; Klarner et al. 2013). However, in litter detection frequency of Plectus spp. in $P$. septentrionalis was high, but the nematode was not detected in mite individuals from patches of moss. In contrast, Galumna spp. consumed Plectus spp. in moss but not in litter and grass patches. This indicates that nematodes are less important prey for $P$. septentrionalis in the respective habitats. $P$. septentrionalis possibly relies on other nematode species as prey suggesting that they can switch their trophic niche and adjust their prey spectrum to changes of environmental conditions and prey availability. Differential feeding on nematodes by putative decomposer mite species of different microhabitats suggests generalist feeding mode and high plasticity in their prey capture ability thereby contributing to the coexistence of the many mite species in the soil habitat. Microarthropods may have a major influence on nematode populations as they typically reach high densities, have wide diet range and since only few free-living nematode species were investigated but frequently detected as prey.

Overall, nematode-microarthropod interactions in soil need more consideration. Molecular gut content analyses using specific nematode markers are a promising method to study neglected predator-prey interactions at the species or genus level (Symondson 2002; Read et al. 2006; King et al. 2008) and has been used earlier to study a wide range of trophic interactions in the soil system, mainly that of macrofauna (Agusti et al. 2003; Admassu et al. 2006; Juen \& Traugott 2007; Eitzinger \& Traugott 2011). Although it is eligible to calibrate feeding events in the field, the results of this thesis indicate strong variation of detection rate and time of nematode DNA in mite predators. Together with earlier findings results of my thesis indicate that the prey detection frequency varies in every predator-prey combination (Zaidi et al. 1999; Hoogendorn \& Heimpel 2001; Harwood et al. 2004; Sheppard et al. 2005; Hosseini et al. 2008; Traugott \& Symondson 2008; von Berg et al. 2008a,b; Gagnon et al. 2011; Sint et al. 2011). In the case of microarthropods as predators of nematodes the feeding is difficult to prove. Therefore, the detection frequency additionally depends on the duration predators fed 
on prey. Therefore, data on detection frequencies of prey in predators to evaluate feeding events in the field remain a goal for future studies (Greenstone et al. 2007).

Nevertheless, as demonstrated in this thesis nematode DNA is detectable up to $128 \mathrm{~h}$ in the gut of microarthropods. This long detection time is advantageous for prey screening in predators in the field (Sheppard \& Harwood 2005). Therefore, the presented method in this thesis will contribute to identifying nematode predators, tracing the role of nematodes as prey and the better understanding of mechanisms influencing predator-prey interactions in soil.

A number of methodological challenges remain, e.g. the establishment of a multiplex PCR approach would be beneficial to save costs and time in screening experiments in future studies. As a further goal to evaluate feeding events of nematodes by microarthropods in the field more work is necessary to optimize prey exposure time for a wider range of predator-prey combinations and real-time quantitative PCR assay (qPCR) needs to be developed for quantifying the consumed prey DNA and track its decline during digestion. Further, more experimental work is needed for uncovering factors influencing predator-prey interactions in the field, such as body size of prey and predator, prey density, forest type, season, humidity and other biotic and abiotic factors. Therefore, the new designed molecular markers and the methodology adopted in this thesis opens promising perspectives to better understand the structure and functioning of the nematode-based food chain as major component of belowground food webs. 


\section{References}

Admassu B, Juen A, Traugott M (2006) Earthworm primers for DNA-based gut content analysis and their cross-reactivity in a multi-species system. Soil Biology and Biochemistry, 38, 1308-1315.

Agusti N, Shayler SP, Harwood JD, Vaughan IP, Sunderland KD, Symondson WOC (2003) Collembola as alternative prey sustaining spiders in arable ecosystems: prey detection within predators using molecular markers. Molecular Ecology, 12, 3467-3475.

Behan-Pelletier VM (1999) Oribatid mite biodiversity in agroecosystems: role for bioindication. Agriculture, Ecosystems and Environment, 74, 411-423.

Bussaman P, Sermswan RW, Grewal PS (2006) Toxicity of the entomopathogenic bacteria Photorhabdus and Xenorhabdus to the mushroom mite (Luciaphorus sp., Acari: Pygmephoridae). Biocontrol Science and Technology, 16, 245-256.

Chahartaghi M, Langel R, Scheu S, Ruess L (2005) Feeding guilds in Collembola based on nitrogen stable isotope ratios. Soil Biology and Biochemistry, 37, 1718-1725.

Eitzinger B, Traugott M (2011) Which prey sustains cold-adapted invertebrate generalist predators in arable land? Examining prey choices by molecular gut-content analysis. Journal of Applied Ecology, 48, 591-599.

Foltan P, Sheppard SK, Konvicka M, Symondson WOC (2005) The significance of facultative scavenging in generalist predator nutrition: detecting decayed prey in the guts of predators using PCR. Molecular Ecology, 14, 4147-4158.

Gagnon A-Ė, Doyon J, Heimpel GE, Brodeur J (2011) Prey DNA detection success following digestion by intraguild predators: influence of prey and predator species. Molecular Ecology Resources, 11, 1022-1032.

Greenstone MH, Rowley DL, Weber DC, Payton ME, Hawthorne DJ (2007) Feeding mode and prey detectability half-lives in molecular gut-content analysis: an example with two predators of the Colorado potato beetle. Bulletin of Entomological Research, 97, 201-209.

Harwood JD, Sunderland K, Symondson WOC (2004) Prey selection by linyphiid spiders: molecular tracking of the effects of alternative prey on rates of aphid consumption in the field. Molecular Ecology, 13, 3549-3560.

Hosseini R, Schmidt O, Keller MA (2008) Factors affecting detectability of prey DNA in the gut contents of invertebrate predators: a polymerase chain reaction-based method. Entomologia Experimentalis et Applicata, 126, 194-202. 
Hoogendorn M, Heimpel GE (2001) PCR-based gut content analysis of insect predators: using ribosomal ITS-1 fragments from prey to estimate predation frequency. Molecular Ecology, 10, 2059-2067.

Juen A, Traugott M (2007) Revealing species-specific trophic links in soil food webs: molecular identification of scarab predators. Molecular Ecology, 16, 1545-1557.

Karg W (1993) Acari (Acarina), Milben. Unterordnung Parasitiformes (Anactinochaeta). Cohors Gamasina Leach. Raubmilben. Die Tierwelt Deutschlands 59. Teil; 2. überarbeitete Auflage. Gustav Fischer, Jena, Germany.

Kaya HK, Gaugler R (1993) Entomopathogenic nematodes. Annual Review of Entomology, 38, 181-206.

King RA, Read DS, Traugott M, Symondson WOC (2008) Molecular analysis of predation: a review of best practice for DNA-based approaches. Molecular Ecology, 17, 947-963.

Klarner B, Maraun M, Scheu S (2013) Trophic diversity and niche partitioning in a species rich predator guild - natural variations in stable isotope ratios $\left({ }^{13} \mathrm{C} /{ }^{12} \mathrm{C},{ }^{15} \mathrm{~N} /{ }^{14} \mathrm{~N}\right)$ of mesostigmatid mites (Acari, Mesostigmata) from Central European beech forest. Soil Biology and Biochemistry, 57, 323-333.

MacMillan K, Haukeland S, Rae R, Young I, Crawford J, Hapca S, Wilson M (2009) Dispersal patterns and behaviour of the nematode Phasmarhabditis hermaphrodita in mineral soils and organic media. Soil Biology and Biochemistry, 41, 1483-1490.

Maraun M, Scheu S (2000) The structure of oribatid mite communities (Acari, Oribatida): patterns, mechanisms and implications for future research. Ecography, 23, 374-382.

Mulder C, Helder J, Vervoort MTW, Vonk JA (2011) Trait-mediated diversification in nematode predator-prey systems. Ecology and evolution, 1, 386-391.

Muraoka M, Ishibashi N (1976) Nematode-feeding mites and their feeding behaviour. Applied Entomology and Zoology, 11, 1-7.

Norton RA, Behan-Pelletier VM (2009) Suborder Oribatida. In: Krantz GW, Walter DE (Editors), A manual of Acarology, third ed. Texas Tech University Press.

Oliveira AR, de Moraes GJ, Ferraz LCCB (2007) Consumption rate of phytonematodes by Pergalumna sp. (Acari: Oribatida: Galumnidae) under laboratory conditions determined by a new method. Experimental and Applied Acarology, 41, 183-189. 
Pollierer MM, Langel R, Scheu S, Maraun M (2009) Compartmentalization of the soil animal food web as indicated by dual analysis of stable isotope ratios $\left({ }^{15} \mathrm{~N} /{ }^{14} \mathrm{~N}\right.$ and $\left.{ }^{13} \mathrm{C} /{ }^{12} \mathrm{C}\right)$. Soil Biology and Biochemistry, 41, 1221-1226.

Read DS, Sheppard SK, Bruford MW, Glen DM, Symondson WOC (2006). Molecular detection of predation by soil micro-arthropods on nematodes. Molecular Ecology, 15, 1963-1972.

Rockett CL, Woodring JP (1966) Oribatid mites as predators of soil nematodes. Annual Entomological Society of America, 59, 669-671.

Scheu S, Falca M (2000) The soil food web of two beech forests (Fagus sylvatica) of contrasting humus type: stable isotope analysis of a macro- and a mesofauna-dominated community. Oecologia, 123, 285-286.

Schneider K, Migge S, Norton RA, Scheu S, Langel R, Reineking A, Maraun M (2004) Trophic niche differentiation in oribatid mites (Oribatida, Acari): evidence from stable isotope ratios $\left({ }^{15} \mathrm{~N} /{ }^{14} \mathrm{~N}\right)$. Soil Biology and Biochemistry, 36, 1769-1774.

Sheppard SK, Bell J, Sunderland KD, Fenlon J, Skervin D, Symondson WOC (2005) Detection of secondary predation by PCR analyses of the gut contents of invertebrate generalist predators. Molecular Ecology, 14, 4461-4468.

Sheppard SK, Harwood JD (2005) Advances in molecular ecology: tracking trophic links through predator-prey food-webs. Functional Ecology, 19, 751-762.

Siepel H (1990) Niche relationships between two panphytophagous soil mites, Nothrus silvestris Nicolet (Acari, Oribatida, Nothridae) and Platynothrus peltifer (Koch) (Acari, Oribatida, Camisiidae). Biology and Fertility of Soils, 9, 139-144.

Sint D, Raso L, Kaufmann R, Traugott M (2011) Optimizing methods for PCR-based analysis of predation. Molecular Ecology Resources, 11, 795-801.

Susurluk Al (2009) Seasonal and vertical distribution of the entomopathogenic nematodes Heterorhabditis bacteriophora (TUR-H2) and Steinernema feltiae (TUR-S3) in turf and fallow areas. Nematology, 11, 321-327.

Symondson WOC (2002) Molecular identification of prey in predator diets. Molecular Ecology, 11, 627-641.

Traugott M, Symondson WOC (2008). Molecular analysis of predation on parasitized hosts. Bulletin of Entomological Research, 98, 223-231. 
von Berg K, Traugott M, Symondson WOC, Scheu S (2008a) The effects of temperature on detection of prey DNA in two species of carabid beetle. Bulletin of Entomological Research, 98, 263-269.

von Berg K, Traugott M, Symondson WOC, Scheu S (2008b) Impact of abiotic factors on predator-prey interactions: DNA-based gut content analysis in a microcosm experiment. Bulletin of Entomological Research, 98, 257-261.

Zaidi RH, Jaal Z, Hawkes NJ, Hemingway J, Symondson WOC (1999) Can multiple-copy sequences of prey DNA be detected amongst the gut contents of invertebrate predators? Molecular Ecology, 8, 2081-2087. 


\section{Acknowledgements}

I want to thank Mark Maraun and Stefan Scheu for their great support throughout all the years. I was always sure that the best solutions for all problems were found.

Mark, I thank you for sharing your enthusiasm for science with me and motivation in troubled times; you are a supervisor, mentor and friend to me. Thank you for a good time, always an open door, mites and the faith in me.

Stefan, I thank you for the long time I could be a member of your group and the possibility for doing this dissertation. Thank you for all your encouragement, especially during the paper reviewing and publishing processes, for wonderful excursions and for always offering me a pleasant and caring atmosphere.

I am also deeply grateful to Liliane Ruess for her helpful input, encouragement, nematode knowledge and for being my supervisor and part of my thesis committee.

I thank Ulrich Brose, Marko Rohlfs and Holger Kreft for being part of my examination commission.

A big "Thank you" goes to the whole 'Molli-group' for providing a nice atmosphere in the lab and for fruitful discussions.

For help at any time and for technical support I thank Guido Humpert, Christel Fischer, Susanne Boning-Klein, Ingrid Kleinhans, Andrea Lambertz and Dieter Nünchert.

I thank all the members of the working group AG Scheu for providing such an excellent working atmosphere and also for the barbeque events.

Many thanks for friendship to: my room mates Diana Grubert and Valentyna Krashevska, my flat mates Patrick Pachl and Martin Rosenberger, Nicole Scheunemann, Britta Merkel, Verena Eißfeller, Kai Schneider, Bernhard Eitzinger, Bernhard Klarner, Andreas Klein, Helge von Saltzwedel and Garvin Schulz.

Many thanks also to Michael Ackermann and Rene Seimel-Buchinger for helping me with nematodes and for nice company during my Berlin trips.

Christiane, Peter, Fynn and Liam Gref, Guido Ocker, Gunnar Ganz, Nicolas Meinders and Sven, Jessica and Finn Burgey: I thank you for being my friends; this means much to me.

I am thankful to my family for always loving, supporting and believing in me.

Finally, I thank my husband Marcus Heidemann for support and love in all situations. 


\section{List of Publications}

Heidemann K, Scheu S, Ruess L, Maraun M (2011) Molecular detection of nematode predation and scavenging in oribatid mites: Laboratory and field experiments. Soil Biology \& Biochemistry 43, 2229-2236.

(Please note that for this publication I have used my maiden name Peschel)

Peschel K, Norton RA, Scheu S, Maraun M (2006) Do oribatid mites live in enemy-free space? Evidence from feeding experiments with the predatory mite Pergamasus septentrionalis. Soil Biology \& Biochemistry, 38, 2985-2989.

\section{Submitted}

Kerstin Heidemann, Annika Hennies, Johanna Schakowske, Lars Blumenberg, Liliane Ruess, Stefan Scheu, Mark Maraun. The role of free-living nematodes as prey for higher trophic levels of forest soil food webs. Submitted

Kerstin Heidemann, Liliane Ruess, Stefan Scheu, Mark Maraun. Consumption of nematodes by soil microarthropods varies between microhabitats of deciduous forests as indicated by molecular gut content analyses. Submitted 


\section{Thesis declarations}

\section{Declaration of the author's own contribution to manuscripts with multiple authors}

Chapter 2 comprises a manuscript that have been published in a peer-reviewed journal; Chapter 3 and 4 comprise manuscripts that are currently submitted to peer reviewed journals. In all manuscripts I am the first author and I have collected and analyzed the data, written the manuscripts, developed the main ideas, created tables, figures and appendices and contributed significantly to the study design. Annika Hennies, Johanna Schakowske and Lars Blumenberg performed their Bachelor thesis as part of this project. They contributed to Chapter 2 by collecting and analyzing the data, creating tables and figures, and contributed significantly to the no-choice experiment with collembolans (Annika Hennies) and the evaluation of the detection time of $P$. minimus (Johanna Schakowske) and P. velox (Lars Blumenberg) after 48 $\mathrm{h}$ of nematode exposure. All persons contributing to the manuscripts have been named so. All co-authors contributed to finalising the manuscripts.

\section{Plagiarism declaration}

I declare that I have written this doctoral thesis independently. All persons contributing to the manuscripts have been named so. All sentences or passages quoted from other people's work have been specifically acknowledged by clear cross-referencing. I have not submitted this thesis in any form for another degree at any university or institution.

Kerstin Heidemann

Göttingen, February 2013 